\title{
An intelligent portfolio management approach to gas storage field deliverability maintenance and enhancement
}

\author{
Kazim A. Malik \\ West Virginia University
}

Follow this and additional works at: https://researchrepository.wvu.edu/etd

\section{Recommended Citation}

Malik, Kazim A., "An intelligent portfolio management approach to gas storage field deliverability maintenance and enhancement" (2006). Graduate Theses, Dissertations, and Problem Reports. 3262. https://researchrepository.wvu.edu/etd/3262

This Thesis is protected by copyright and/or related rights. It has been brought to you by the The Research Repository @ WVU with permission from the rights-holder(s). You are free to use this Thesis in any way that is permitted by the copyright and related rights legislation that applies to your use. For other uses you must obtain permission from the rights-holder(s) directly, unless additional rights are indicated by a Creative Commons license in the record and/ or on the work itself. This Thesis has been accepted for inclusion in WVU Graduate Theses, Dissertations, and Problem Reports collection by an authorized administrator of The Research Repository @ WVU. For more information, please contact researchrepository@mail.wvu.edu. 


\title{
An Intelligent Portfolio Management Approach to Gas Storage Field Deliverability Maintenance and Enhancement
}

\author{
Kazim A. Malik \\ Thesis Submitted to the \\ College of Engineering and Mineral Resources \\ at West Virginia University \\ in partial fulfillment of the requirements \\ For the degree of \\ Master of Science \\ in \\ Petroleum and Natural Gas Engineering \\ Shahab Mohaghegh, PhD., Chair \\ Kashy Aminian, Ph.D. \\ Razi Gaskari, Ph.D.
}

Department of Petroleum and Natural Gas Engineering

Morgantown, West Virginia

2006

Keywords: Petroleum and Natural Gas Engineering, Candidate Well Selection, Intelligent Systems, Gas Storage 


\title{
ABSTRACT \\ An Intelligent Portfolio Management Approach to Gas Storage Field Deliverability Maintenance and Enhancement
}

\begin{abstract}
Kazim A. Malik
The main goal of this thesis is to modify and apply the state-of-the-art intelligent, optimum portfolio management to the gas storage field in order to optimize the return on investment associated with well remedial operations. It continues the development of a methodology for candidate selection and stimulation design and optimization using Artificial Intelligence techniques.

The project used the data of an actual gas storage field to test the results. The project data include Well-bore, Completion, Perforation, Stimulation, Well-test and Reservoir Data. The software developed in parallel with this selection methodology includes an easy to use interface that allows the user to edit the data for a gas storage field, perform well-test analysis and use neural networks in association with Genetic optimization tool. The software ranks the well according to maximum change in skin value for a well and thus a decision to re-stimulate the well or not is made accordingly.
\end{abstract}




\section{ACKNOWLEDGEMENTS}

First of all I will like to express my gratitude towards my graduate advisor Dr. Shahab Mohaghegh who supported me throughout my stay in West Virginia University. His constant guidance and encouragement during my graduate program proved very helpful in completion of my thesis study.

I am deeply indebted to Dr Razi, who constantly provided solutions to my problems during my project and who acted as a mentor for me. He was always there when I required his assistance. I am very grateful for the time he took to make visits to the office where he would advise me on how to improve the software.

Many thanks to Dr Kashy Aminian for guidance and support during my graduate studies at West Virginia University. I learned a lot about reservoir and well-test analysis from him.

Special thanks to Department Chair Samuel Ameri and my professors in the Department of West Virginia University for the knowledge they imparted to me so that I can write this thesis.

I would like to acknowledge people from the industry like Richard Silber and Jason Martin from Columbia Gas Transmission Corp., and Len Fry from Halliburton, who provided valuable assistance and information about this project.

I owe great appreciation to my colleagues and friends Jalal Jalali, Emre Artun, Nikola Maricic, Miguel Tovar, Delal Gunayden, Daniel, Domingo Mata, Sunil and Irfan for their help and encouragement.

Last but not the least; I would like to thank all of my family, especially my parents and wife Menaal, for their constant support and care, without which my studies would not have been possible. 


\section{TABLE OF CONTENTS}

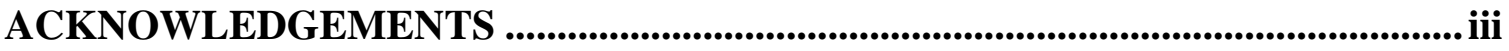

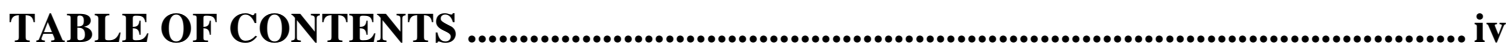

LIST OF FIGURES ............................................................................................. vi

LIST OF TABLES $\quad$ T.............................................................vii

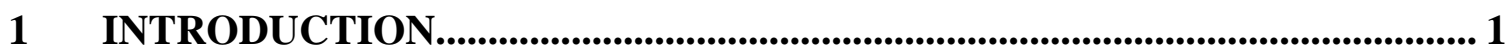

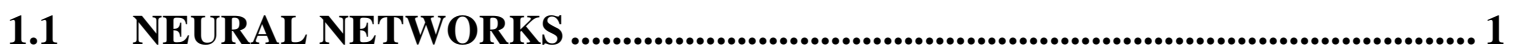

1.1.1 Background and characteristics .......................................................................... 1

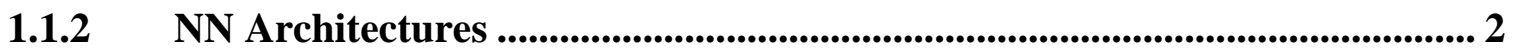

1.1.3 Setting the Weights / Learning paradigms .................................................. 3

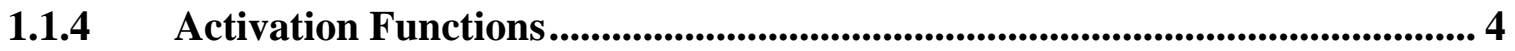

1.1.5 General Regression Neural Network (GRNN) .......................................... 4

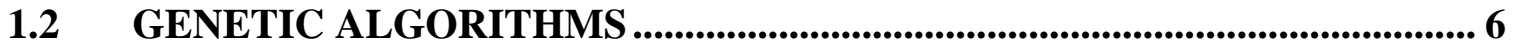

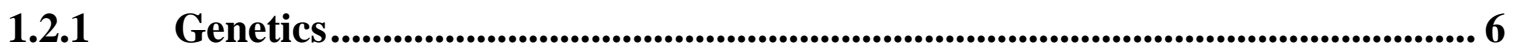

1.2.2 Algorithm........................................................................................................ 6

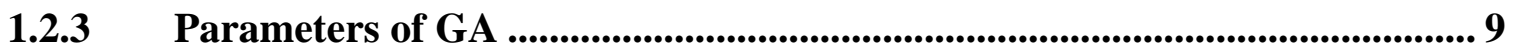

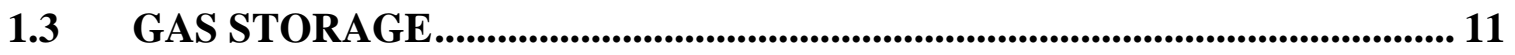

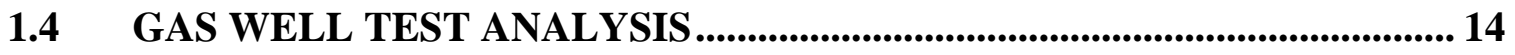

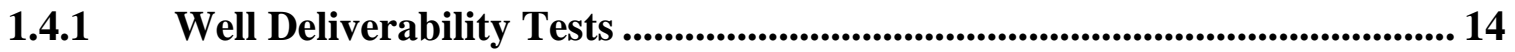

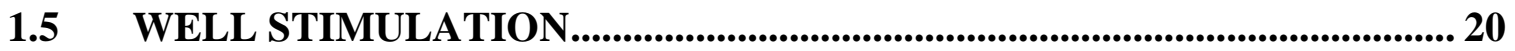


2.1 WELL-TEST ANALYSIS FOR GAS WELLS........................................... 22

2.2 GAS STORAGE FIELDS AND STIMULATIONS ...................................... 24

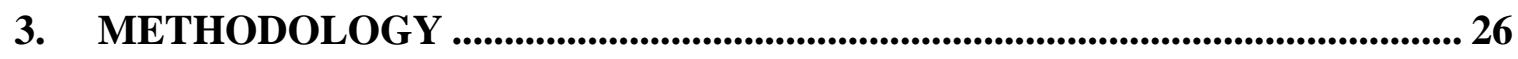

3.1 PROBLEM STATEMENT AND OUR APPROACH...................................... 26

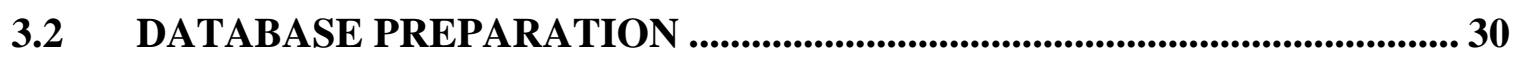

3.2.1 Well-bore data.............................................................................................................. 31

3.2.2 Completion Data ..................................................................................................... 33

3.2.3 Perforation Data......................................................................................................... 36

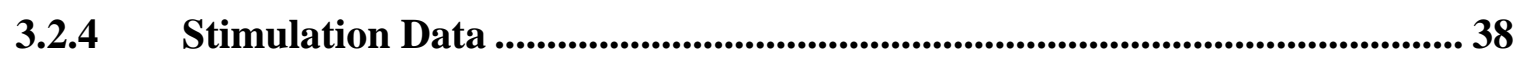

3.2.5 Well Test Data .......................................................................................................... 42

3.3 SOFTWARE IMPLEMENTATION .................................................................. 44

3.3.1 Well-Test Analysis module...................................................................................... 45

3.3.2 Neural Network as Skin Predictor ...................................................................... 47

3.3.3 Optimization of Stimulations ............................................................................. 50

4. RESULTS AND DISCUSSION ........................................................................... 53

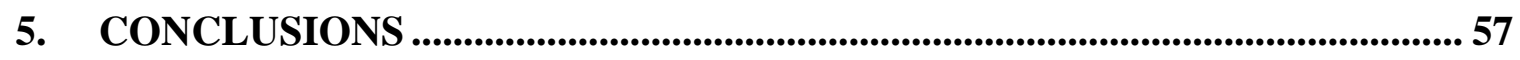

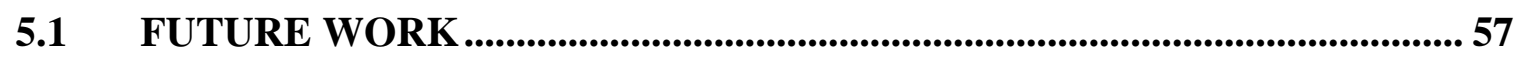

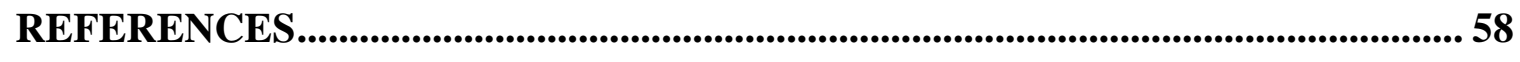

APPENDIX (USER MANUAL)........................................................................................60 


\section{LIST OF FIGURES}

Figure 1.1 A Motor Neuron [7] ......................................................................... 2

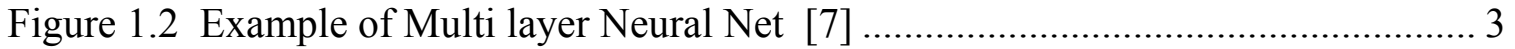

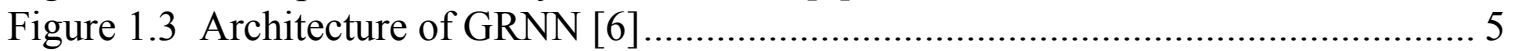

Figure 1.4 . Types of Underground Natural Gas Storage Facilities............................... 11

Figure 1.5 . Underground Natural Gas Storage Facilities in Lower 48 States................. 13

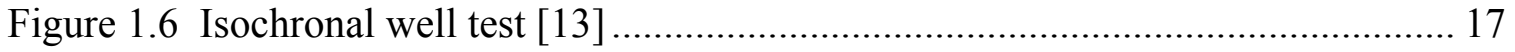

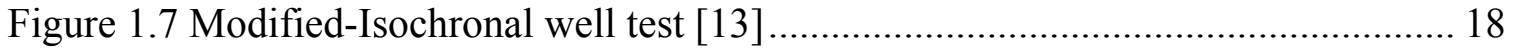

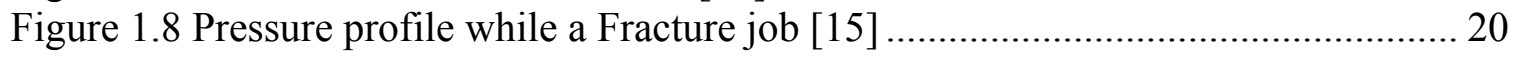

Figure 3.1 Permeability Analysis done on the storage wells ..................................... 26

Figure 3.2 Flow chart of our problem solving approach .......................................... 27

Figure 3.3 Flow Diagram of Well Test Analysis procedure ....................................... 28

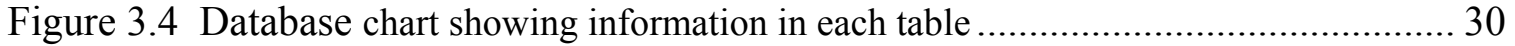

Figure 3.5 Data addition and refinement for Well-bore Data ...................................... 32

Figure 3.6 Multiple Data Entries in Completion Table ................................................. 34

Figure 3.7 Data addition and refinement for Completion Data .................................... 35

Figure 3.8 Data addition and refinement for Perforation Data .................................... 37

Figure 3.9 All the steps taken for retrieving data from microfishe............................... 39

Figure 3.10 Data addition and refinement for Stimulation Data .................................. 41

Figure 3.11 Data addition and refinement for Well-Test Data .................................... 43

Figure 3.12 Main Screen of software....................................................................... 44

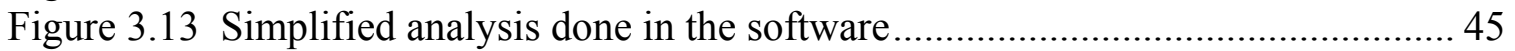

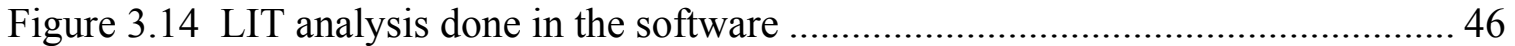

Figure 3.15 Accuracy of training data for the Neural net ......................................... 48

Figure 3.16 Accuracy of calibration data for the Neural net .................................... 49

Figure 3.17 Accuracy of verification data for the Neural net ..................................... 49

Figure 3.18 Different options in the software that make it versatile ............................ 51

Figure 4.1 Comparison of Average skin after the stimulations ..................................... 54

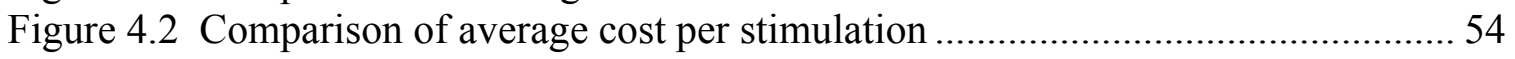

Figure 4.3 Comparison of Total cost of Stimulations ................................................ 55 


\section{LIST OF TABLES}

Table 3.1 Storage Reservoir Characteristics ........................................................... 29

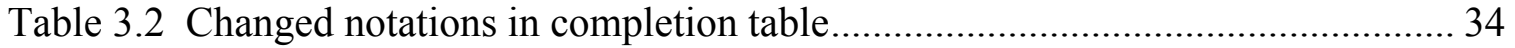

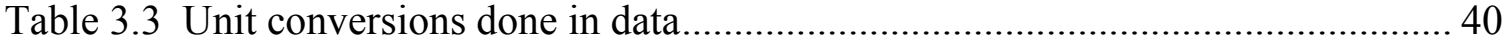

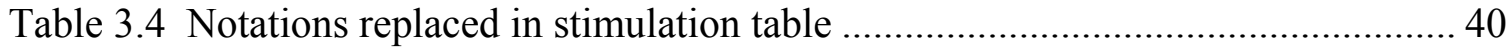

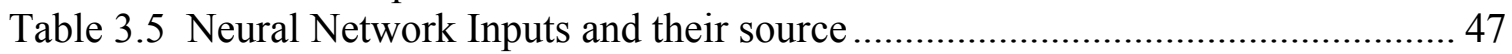

Table 3.6 Calculations to determine the length of chromosome ................................. 50

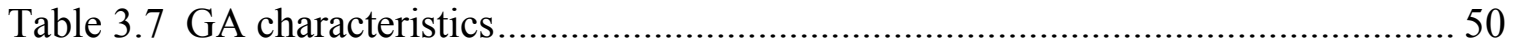

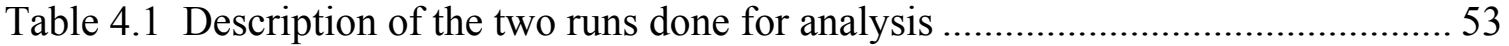

Table 4.2 Comparison of actual \& predicted skin for Well \# 61 .................................. 55

Table 4.3 Results of Optimized Skin and cost.......................................................... 56 


\section{INTRODUCTION}

\subsection{Neural Networks}

\subsubsection{Background and characteristics}

In 1943, Warren McCulloch and Walter Pitts designed what are generally regarded as the first neural networks [9]. Neural Networks are very refined modeling techniques capable of modeling extremely complex functions. An artificial neural network (ANN) is also commonly reffered as neural network (NN) and is an interconnected group of artificial neurons that uses a mathematical or computational model for information processing based on a connectionist approach to computation [7]. Sometimes an ANN is adaptive like a system that changes its structure in reply to an external or internal information that flows in the network. More practical term that can be used for neural networks are nonlinear statistical data modeling tools. They have the ability to find complex relationship between inputs and outputs .

They bear a resemblance to brain in following ways:

- They use learning process to acquire Knowledge as our brain keeps the record of our past

- Similar to brain they store knowledge by changing the inter-neuron connection strengths known as synaptic weights

Neural systems may be found in many diverse forms, but there are certain features that are common to all:

- They have parameters called weights, which are attuned to generate learning and have many interrelated units called nodes

- They use a learning rule like supervised or un-supervised learning rule to describe the flow of information in the network

- They aim to minimize or maximize a cost function or a combination of functions thus can be regarded as optimization tools 


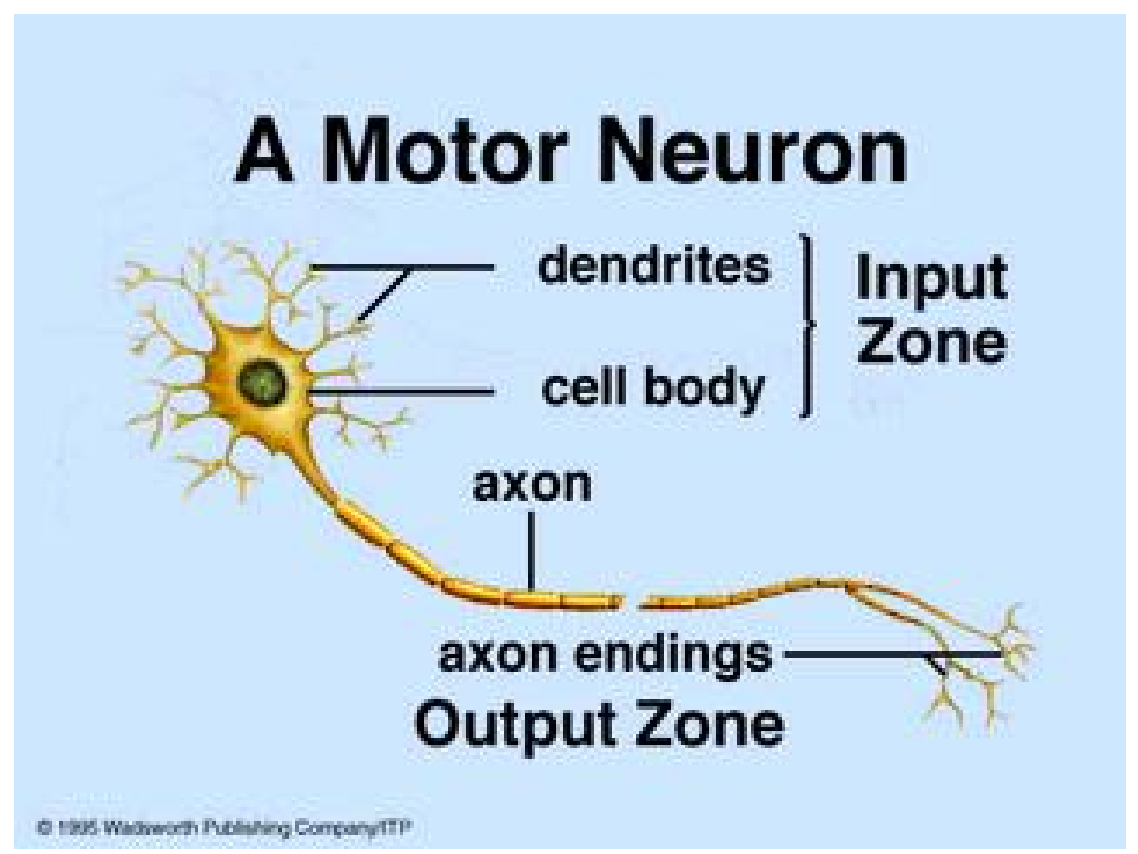

Figure 1.1 A Motor Neuron [7]

While designing a Neural Network a designer takes into account many considerations, which can be categorized as following:

1- NN Architecture

2- $\quad$ Setting the Weights / Learning paradigms

3- Activation Functions

\subsubsection{NN Architectures}

The arrangement of neurons into layers and the connection patterns within and between layers is called the net architecture [8]. Neural nets are frequently classified as

1. Single layer or

2. Multi-layer 


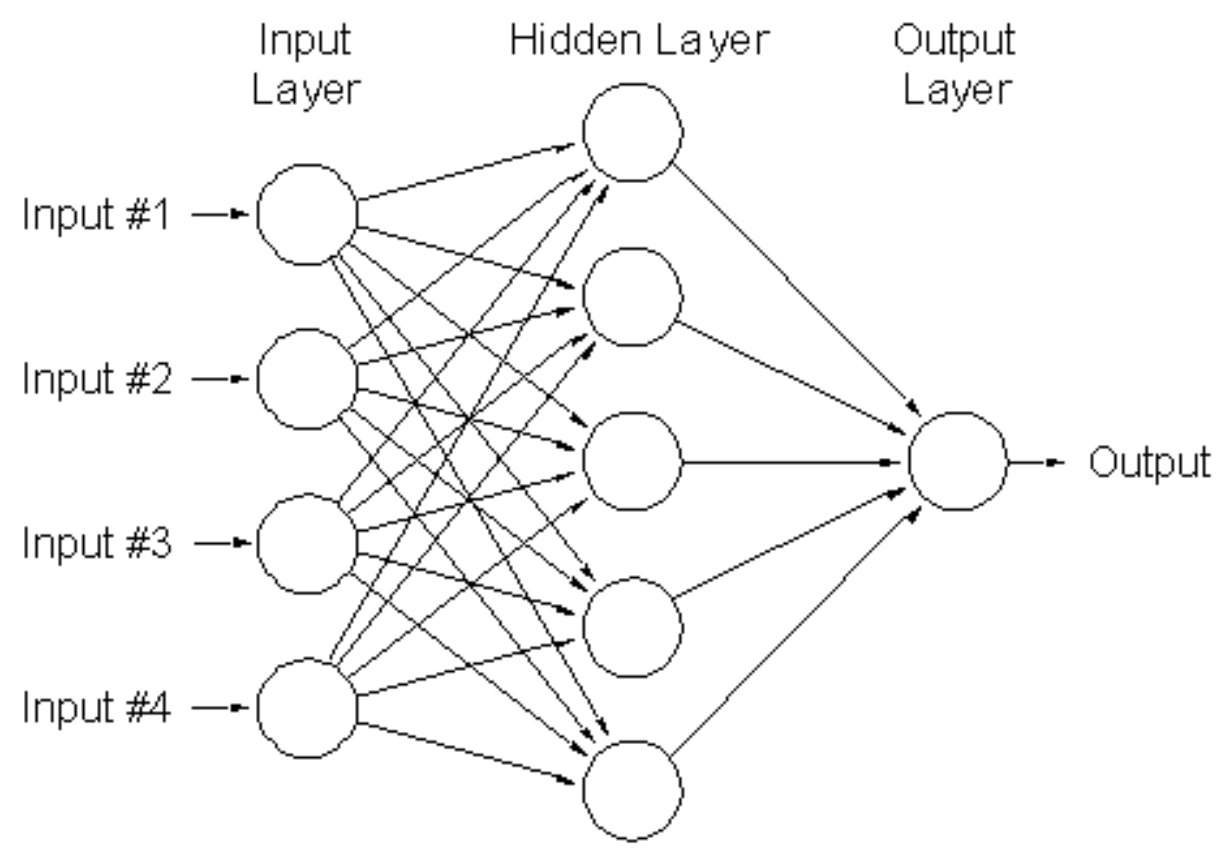

Figure 1.2 Example of Multi layer Neural Net [7]

In formatting the number of layers, the input units are not counted as a layer, because they perform no calculation or function evaluation

\subsubsection{Setting the Weights / Learning paradigms}

However interesting the neural nets may be in designing, the thing that has attracted the most attention is their possibility of learning [7]. They learn by changing the values of their weights betweens two layers. The main categories of training supervised and unsupervised are discussed below: [7]

Supervised learning: In supervised training a sequence of training vectors or patterns is presented with an associated target output vector. The weights are then adjusted according to a learning algorithm [8]. Supervised learning algorithm is used mostly for pattern recognition or classification, regression, speech and gesture recognition [7].

Unsupervised learning: Unsupervised learning self-organizing neural nets groups similar input vector together without the training data and without specifying to which 
each group each vector belongs [8]. Thus the input vector is provided with no specified target vector. Unsupervised learning algorithm is used mostly for estimation problems, clustering and filtering. [7].

\subsubsection{Activation Functions}

Artifical neuron sum the weighted input signal and applying an output, or activation function. In the design of most Neural nets mostly linear activation function is used. The examples of some of the activation functions is below:

i) Identity function :

$$
f(x)=x \text { for all } x .
$$

ii) Binary step function (with threshold $\theta$ ):

$$
f(x)= \begin{cases}1 & \text { if } x \geq \theta \\ 0 & \text { if } x \prec \theta\end{cases}
$$

iii) Binary Sigmoid:

$$
f(x)=\frac{1}{1+\exp (-\sigma x)}
$$

iv) Bipolar sigmoid:

$$
g(x)=\frac{1-\exp (-\sigma x)}{1+\exp (-\sigma x)}
$$

\subsubsection{General Regression Neural Network (GRNN)}

Generalized Regression Neural Networks (GRNN) is modification of the Radial Basis Function (RBF) network [6]. Weights of theses networks can be calculated analytically. In regression problems, characteristically only a single output is predicted.

GRNN is used universally for smooth functions, so it can solve any smooth functionestimation problem given enough data. 


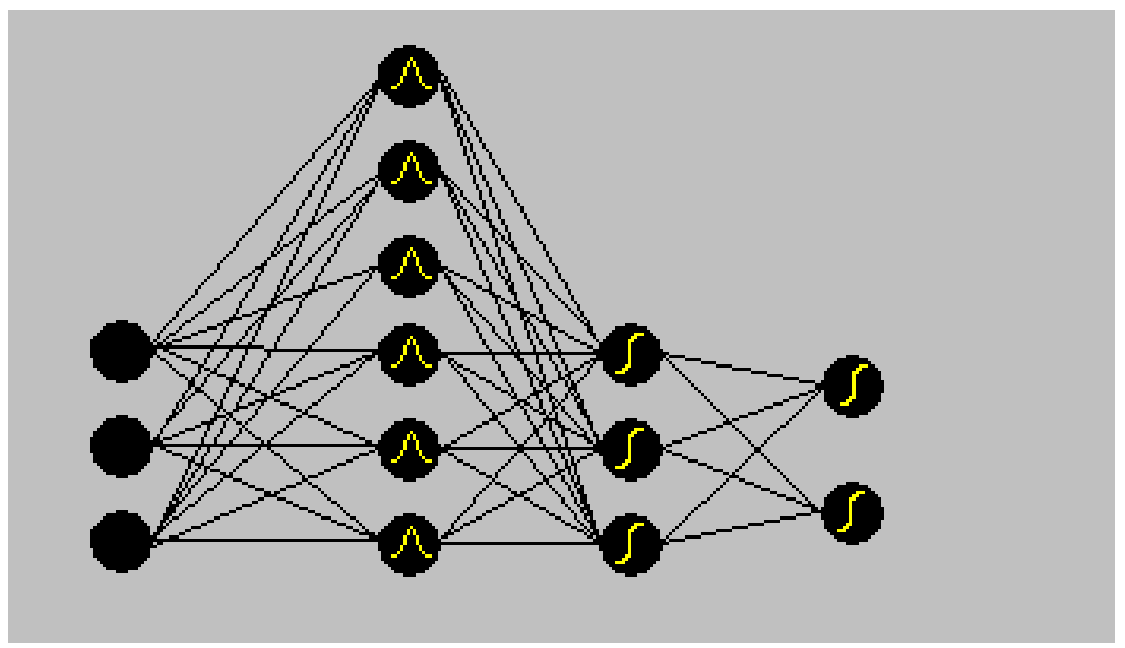

Figure 1.3 Architecture of GRNN [6] 


\subsection{Genetic Algorithms}

\subsubsection{Genetics}

C. Darwin has put the fundamental principle of natural selection together long before the finding of genetic mechanisms. He was ignorant of the basic inheritance principles but intelligent enough to propose that blending of offspring's from parents is due to a mix of fluids in the offspring organism. Near 1900 Genetics was fully developed by T.Morgan and his collaborators, who proved experimentally that chromosomes are the main carries of hereditary information [2].

During the last three decades there has been an increased interest in algorithms, which rely on analogies to natural processes like Artificial Intelligence Neural Nets, and Genetic Algorithms. The emergence of massively parallel and fast computers made these algorithms of practical interest which otherwise would have been very difficult to perform.

\subsubsection{Algorithm}

The Genetic Algorithm is a model of machine learning, which derives its behavior from the processes of evolution in nature [4]. The beginnings of genetic algorithms can be traced back to the early 1950s when several biologists used computers for simulations of biological systems [1]. However, the work done in late 1960s and early 1970s at the University of Michigan under the direction of John Holland led to genetic algorithms, as they are known today.

There are many problems for which no reasonably fast algorithm has been developed yet. Many of them relate to the optimization of a function. To find such an efficient algorithm that provides approximately optimal solution is very difficult but not impossible. In general, any conceptual task to be performed can be thought of as solving a predicament, 
which, in turn, can be perceived as a investigation through a space of prospective solutions. Zbigniew Michalewicz [2] (pg 15) said, "Genetic algorithms are a class of general purpose (domain dependent) search methods which strike a remarkable balance between exploration and exploitation of the search space".

A genetic algorithm for a particular problem must at least have the subsequent components [2]:

1- A genetic representation for potential solutions to the problems

2- A way to create an initial population of potential solutions

3- An evaluation function that plays the role of the environment, rating solutions in terms of their "fitness"

4- Genetic operators that alter the composition of children during reproduction

5- Values for various parameters that the genetic algorithm uses (population size, probabilities of applying genetic operators, etc.)

In [3] the authors discuss different categories of selection procedures for new generation. They divide selection procedure into dynamic and static methods - a static selection requires that selection probabilities remain constant between generations (for example ranking selection), whereas a dynamic selection doesn't have such requirement (e.g., proportional selection). Furthermore, some selection procedures are pure in the sense that parents are allowed to reproduce in one generation only. Some selections are generational in the sense that the pair of parents is fixed until all the offsprings replaces their parent right away.

The Algorithm starts by initializing the set of solutions represented by chromosomes called population. The population is evaluated to a fitness function and a new population is created by mutation and crossover. Better the fitness value more is the chance to have an offspring. The new population is thought to have better solution than the old or at least equal in fitness value. 
The intuition behind the applicability of the crossover operator is information exchange between different potential solutions. Mutation operator on the other hand introduces some extra variability into the population.

Chromosome: A binary string represents chromosome. A chromosome should in one way or another contain information about solution that it represents [5]. One can also encode directly integer or real numbers instead of binary numbers depending on the dimensionality of the problem. Each bit in the string can represent some qualities of the solution. A chromosome with binary coding will look like this:

\begin{tabular}{|l|l|}
\hline Chromosome 1 & 1101100100110110 \\
\hline Chromosome 2 & 1101111000011110 \\
\hline
\end{tabular}

Crossover: Crossover as evident from the name operates on parent chromosomes and creates new offspring. The crossover point is randomly chosen and everything before this point is copied from the first parent similarly then everything after this point is copied from other parent. Crossover operation can be exemplified as follows: ( $\mid$ is the crossover point):

\begin{tabular}{|c|c|}
\hline Chromosome 1 & $11011 \mid 00100110100$ \\
\hline Chromosome 2 & $11010 \mid 11000011110$ \\
\hline Offspring 1 & $11011 \mid 11000011110$ \\
\hline Offspring 2 & $11010 \mid 00100110100$ \\
\hline
\end{tabular}

Mutation: The technique of mutation is intended to prevent all solutions in the populations from converging to local optima instead of universal optima. Mutation takes place after crossover and randomly changes the resulting offspring. In crossover a 
randomly chosen bit is flipped from 1 to 0 or from 0 to 1 . Mutation can be shown as follows:

\begin{tabular}{|l|l|}
\hline Original offspring 1 & 1101011000011100 \\
\hline Original offspring 2 & 1101100100110110 \\
\hline Mutated offspring 1 & 1101111000011110 \\
\hline Mutated offspring 2 & 1101101100110100 \\
\hline
\end{tabular}

\subsubsection{Parameters of GA}

There are four basic parameters of GA

1- Crossover probability

2- Mutation probability

3- Population size

4- No of Generations

Crossover probability: It determines how often crossover will be performed. If there is no crossover, offspring will be exact copies of parents. If crossover probability is $100 \%$, then all offspring are made by crossover from parent population. Crossover is done in hope that new chromosomes will contain superior element of old chromosomes thus the new chromosomes will improve. Nevertheless, it is good ideas to leave some old population survive to next generation so that a mix of old and new population is kept for the new generation.

Mutation probability: It defines how often parts of chromosome will be mutated. If there is no mutation, offspring are generated directly after crossover without any modification. If mutation is performed, one or more parts of a chromosome are changed. If mutation probability is $100 \%$, entire chromosome is changed, if it is $0 \%$, nothing is 
changed. Mutation prevents the GA from falling into local maxim but too much mutation changes the chromosomes so much that the GA converts into random search.

Population size: This characteristic determines as to how many chromosomes are in population. If there are too few chromosomes, GA has few possibilities to perform crossover and mutation and only a small part of search space is explored. On the other side too many chromosomes will slow down the GA.

No of Generations: This identifies the number of times the new populations are created. If No of generations are low and so is the population size then the GA might not find the universal optimum. On the other hand increase in Population size slows down the GA. So an optimum value for population size and GA has to be balanced out. 


\subsection{Gas Storage}

Natural gas is a very important commodity, which can be stored for indefinite period of time. Usually the producing regions and the consumption area are not the same so when the gas reaches its destination it might not be readily used. Instead it can be stored. The gas storage facility if made for the Liquefied Natural Gas (LNG) can cost nearly \$ 10 per MMscf but using natural way of storage i.e. in underground reservoirs might cost nearly 50 cents per MMscf.

Natural gas can be stored underground in three major ways:

1- Depleted reservoirs in oil or gas fields

2- Aquifers

\section{3- Salt Cavern}

Some research is still going on to determine suitability of gas storage in abandoned mines and hard rock caverns.

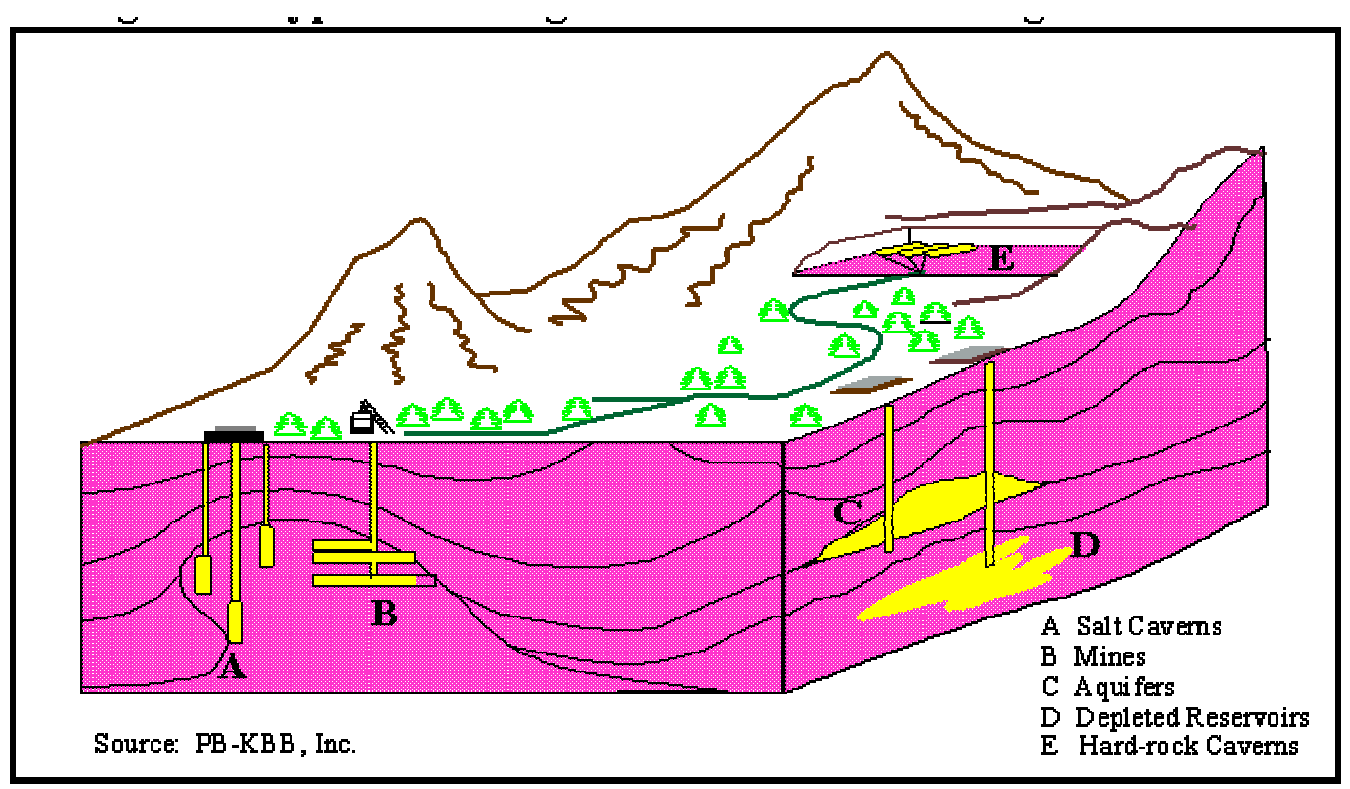

Figure 1.4 . Types of Underground Natural Gas Storage Facilities 
The first time natural gas was successfully stored underground occurred in Weland County, Ontario, Canada in 1915 [12]. It was a depleted natural gas well that had been converted to a storage field. By 1930, the United States had six storage fields, all in depleted reservoirs.

Depleted Reservoirs: Formation that has already been tapped of all their recoverable natural gas or oil [12]. As the formation already has a geological formation capable of sealing the reservoir and tested to hold up to at least the discovery pressure and surface and distribution facilities are already established thus this form of storage is the most cheapest and economical to maintain. The factors that determine if a depleted reservoir will make a suitable gas storage field dependent on geology as well as geography. Geologically it should have both porosity and permeability. Porosity for gas storage capacity and permeability for gas deliverability (injection and production rate) Geographically it should be located near the gas pipelines and consuming areas. One advantage of the depleted gas field is that they already have the cushion gas stored in them so no extra gas has to be injected for this purpose.

Aquifers: Aquifers are underground permeable rock formations that act as natural water reservoirs [12]. They have some advantages like high natural gas withdrawal rate for peak consumption seasons but generally are not desirable due to following reasons:

1- Geological features may not be meticulously known

2- Capacity of formation is not known and can be verified only when the aquifer has been developed into a storage field

3- Surface facilities and drilling of well has to be done

4- Sufficient high pressure to push down the water is required

5- Retention capability of aquifer is less than a depleted reservoir

6- Dehydration of gas may be required

7- More cushion gas has to be injected as the original reservoir had no gas bearing formation 
8- More restrictions by Environmental protection Agency (EPA) to protect fresh water contamination

Salt caverns: Salt caverns are another type of underground formations that can store lesser amount of natural gas as compared to depleted fields but offer very high deliverability. Thus they are more suited for peak load requirements. Once a salt formation is identified it is leached to make a cavity for gas storage. The cost for developing salt cavern storage field is high but one can achieve good returns per injection and withdrawal cycle. Figure 1.5 shows the location of the three types of storage facilities discussed.

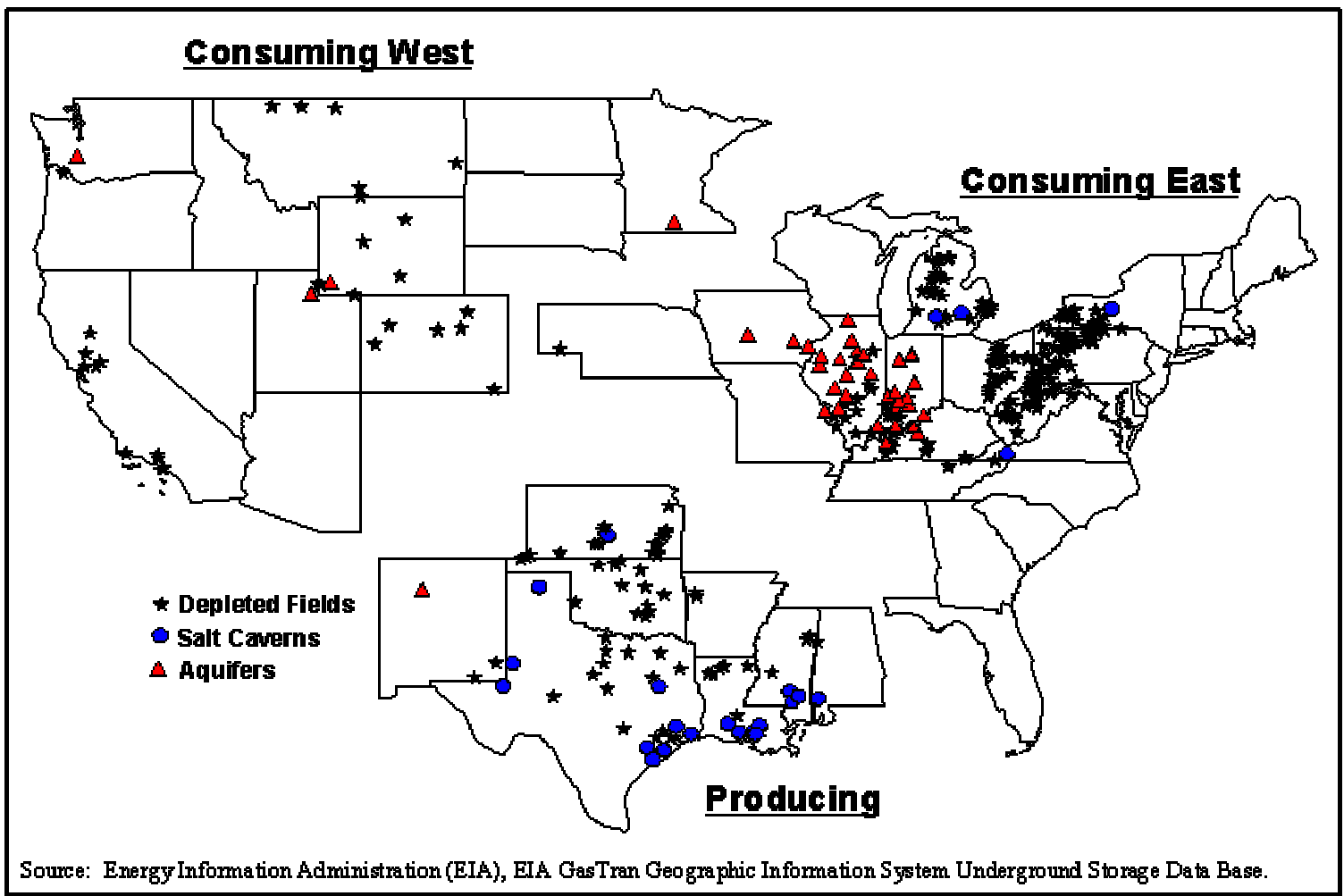

Figure 1.5 . Underground Natural Gas Storage Facilities in Lower 48 States 


\subsection{Gas Well Test Analysis}

Gas well test analysis can be considered as a branch of reservoir engineering. Pressures and flow-rates are the most valuable data in reservoir engineering. Commonly, gas well test analysis is conducted for following intention [13]:

- To obtain reservoir parameters

- To determine the producing zone

- To estimate Skin or damage to a gas well so that based on its magnitude a decision regarding well stimulation can be made

Generally speaking, there are two types of gas well testing. The first kind, deliverability testing and other includes draw-down or buildup testing.

The main aim of deliverability testing is to find the well performance parameters and of build-up test is to find reservoir parameters like Skin factor (S) and formation thickness (kh). In this report we will concentrate on deliverability testing as it is very closely related to gas storage field maintenance. Permeability is usually known for such wells and deliverability well tests can be used to determine an estimate of well-bore skin using LIT Analysis.

\subsubsection{Well Deliverability Tests}

Back Pressure test/Simplified test analysis: Rawlins and Schellhardt observed that a plot

of $\left(\bar{p}^{2}-p_{w f}{ }^{2}\right)$ versus $q_{g}$ would yield a straight line on a logarithmic plot with slope $1 / \mathrm{n}$ for a stabilized flow. The backpressure equation known as simplified analysis equation is written as [13,pg 154]:

$$
q_{g}=C\left(\bar{p}^{2}-p_{w f}^{2}\right)^{n}
$$


Where;

$q_{g}=$ Flow-rate, $\mathrm{McfD}$

$\bar{p}=$ Closed average formation pressure, $\mathrm{psi}$

$p_{w f}=$ Stabilized flowing sand face pressure, $\mathrm{psi}$

$\mathrm{n}=$ Turbulence exponent

$\mathrm{C}=$ Flow co-efficient

Once the value of $\mathrm{n}$ has been determined from the plot, the value $\mathrm{C}$ can be calculated by using data from one of the test that falls on the straight line by following formula:

$$
C=\frac{q_{g}}{\left(\bar{p}^{2}-p_{w f}^{2}\right)^{n}}
$$

For wells in which flow is affected by turbulence the value of slope is greater than 1 $(1 / n>1)$ or in other words $n$ approaches 0.5 , whereas for wells in which turbulence is negligible the value of $\mathrm{n}$ approaches 1 . So generally $\mathrm{n}$ obtained from the well-test will fall between 0.5 and 1 . Also exponents of $\mathrm{n}<0.5$ may be caused by liquid accumulation in the well-bore.

A parameter usually used to compare wells is the flow rate that would occur if $p_{w f}$ could be brought to zero. This is called Absolute Open Flow (AOF) and given by following equation:

$$
A O F=C\left(\bar{p}^{2}-0^{2}\right)^{n}
$$

Another parameter used to compare wells is the flow rate at a peak pressure difference $\Delta^{2} p=\left(\bar{p}^{2}-p_{w f}{ }^{2}\right)$. This pressure is different for every field and for the gas storage field from which the data was used for analysis it is $250,000 \mathrm{psi}^{2}$. Thus in equation form 


$$
\text { PDRate }=(C \times 250,000)^{n}
$$

If in a back-pressure test the $p_{w f}$ is zero then that test is called Open-Flow Test and if it is kept at a back-pressure like separator pressure or distribution line pressure then its called Single Point Test.

Isochronal Test: In 1955, Cullender [14] proposed a series of flow tests at different rates for the same length of time. The resulting plot of $\Delta^{2} \mathrm{P}$ versus Qsc, would have the same slope as the stabilized back pressure performance curve. Then, extending the last flowrate to reach stabilized pressure $\mathrm{P}$ and imposing the slope onto the stabilized point $\left(\bar{p}^{2}-P^{2}\right)$, one could obtain an approximate performance curve without stabilizing the pressures except for the last flow-rate. Figure 1.6 shows a typical isochronal well test. Formula for the slope is :

$$
\frac{1}{n}=\frac{\log \left(\bar{p}^{2}-p_{w f}{ }^{2}\right)_{2}-\log \left(\bar{p}^{2}-p_{w f}^{2}\right)_{1}}{\log q_{2}-\log q_{1}}
$$




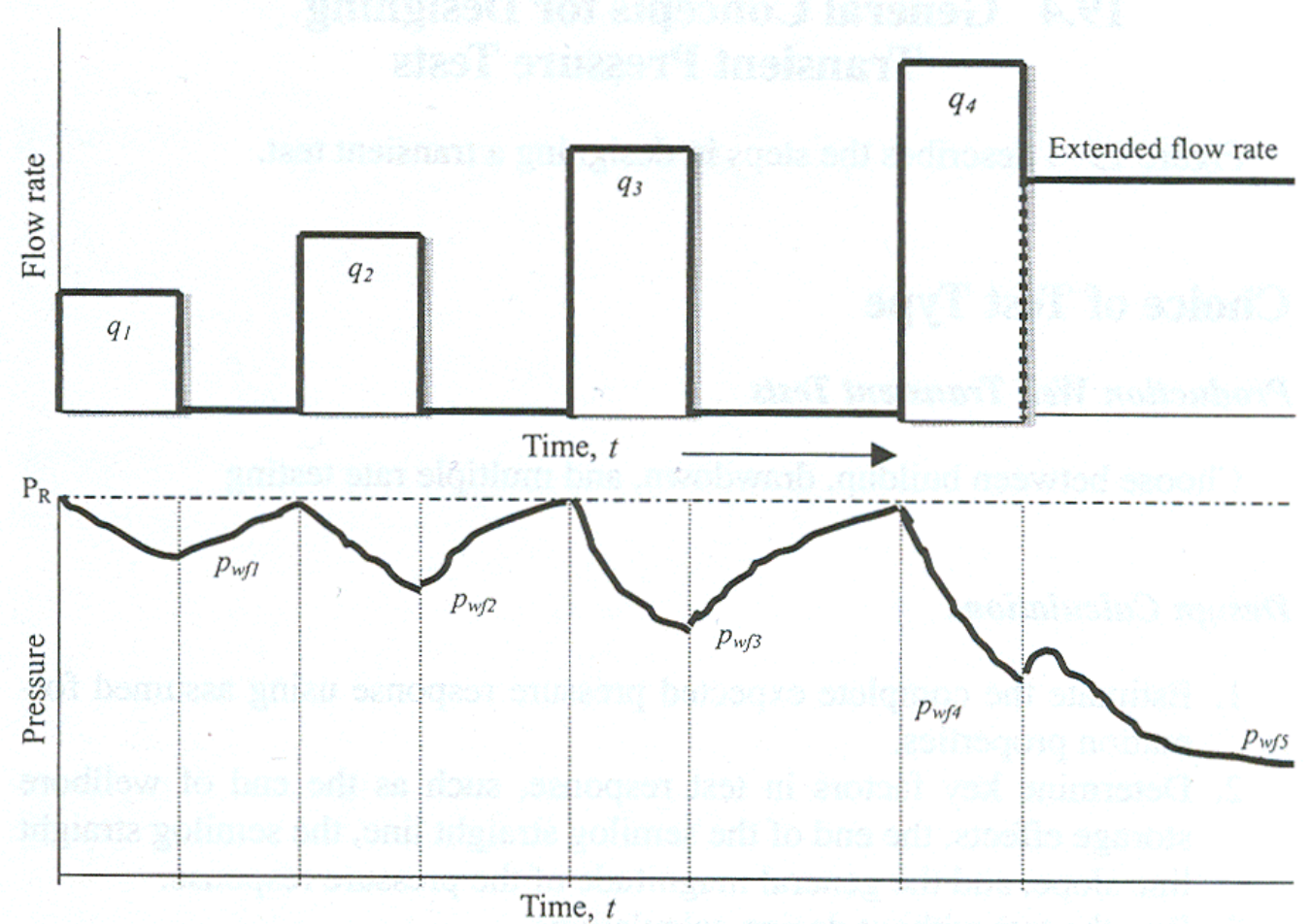

Figure 1.6 Isochronal well test [13]

Modified Isochronal Test: This type of testing is the same as isochronal well testing except that instead of $(\bar{p})$ the preceding shut-in pressure is used to obtain $\Delta p$. The shut in pressure to be used for stabilized point is $(\bar{p})$, the true stabilized shut-in pressure. The pressure and flow-rate characteristics of the modified isochronal test are shown in Figure 1.7. More information and greater accuracy can result from proper conducting and analysis of tests. 

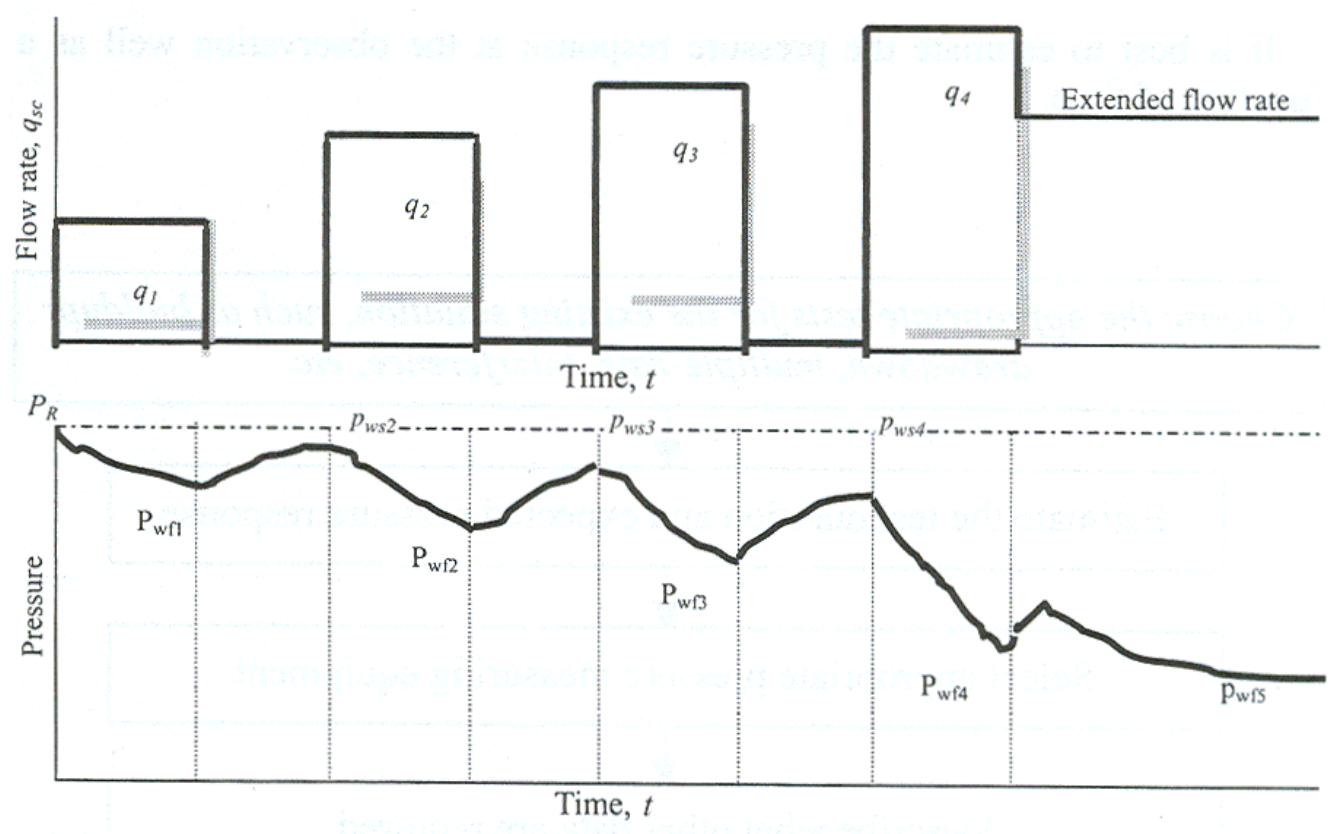

Figure 1.7 Modified-Isochronal well test [13]

Laminar Inertial Turbulent (LIT): Analysis of data from isochronal type test using Laminar Inertial Turbulent (LIT) flow equation will yield considerable data. This method can also be used to find skin of a well from single-point test when the value of permeability of reservoir is known from prior multi-point test. The LIT equation is written as $[13,164]$

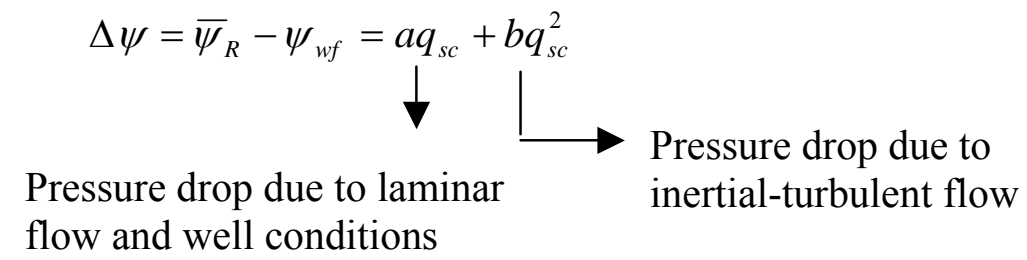

Procedure for calculating Skin from LIT analysis for known permeability $(\mathrm{k})$ value is below: 
1. Calculate $a_{t}$ and $b$ from equations below:

$$
\begin{gathered}
a_{t}=\frac{\sum \frac{\Delta \Psi}{q_{s c}} \sum q_{s c}^{2}-\sum q_{s c} \sum \Delta \Psi}{N \sum q_{s c}^{2}-\sum g_{s c} \sum g_{s c}} \\
b=\frac{N \sum \Delta \Psi-\sum q_{s c} \sum \frac{\Delta \Psi}{q_{s c}}}{N \sum q_{s c}^{2}-\sum g_{s c} \sum g_{s c}}
\end{gathered}
$$

2. Plot $\left(\Delta \Psi-b q_{s c}^{2}\right) v s . q_{s c}$ on a logarithmic scale. The transient data points should form a straight line. If they don't form a straight line, calculate $a_{t}$ and $b$ again with the data which forms the straight line

3. Calculate Skin (S) with the formula [16]

$$
S=\frac{1}{0.869}\left[a_{t} \times 10^{6} \frac{k h}{1.632 \times 10^{6} T}-\log \left(\frac{k t}{\phi \mu_{i} c_{i} r_{w}{ }^{2}}\right)+3.23\right]
$$

Where:

$\mathrm{k}$ : effective permeability to gas, md

h: net pay thickness, $\mathrm{ft}$

$\mathrm{T}$ : Temperature of the reservoir, ${ }^{\circ} \mathrm{R}$

$\mathrm{r}_{\mathrm{w}}$ : well-bore radius, $\mathrm{ft}$

S: skin factor, dimensionless 


\subsection{Well Stimulation}

After years and years of operation from storage well the flow-rates become too low to permit required high demand of natural gas in the market. Actually after many injection and withdrawal cycle the reservoir conditions near the well bore deteriorate. If the storage formation is sandstone then many small sand particles might obstruct the pore space in the formation thus requiring more pressure differential to flow. Sometimes hydrates might be formed in case the storage field was developed from a depleted oil field.

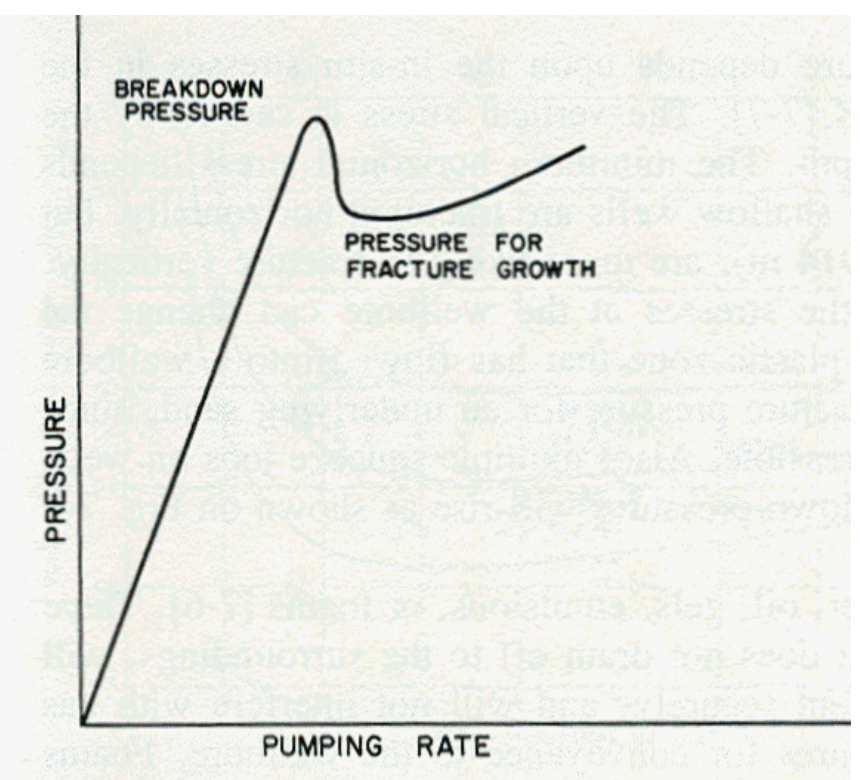

Figure 1.8 Pressure profile while a Fracture job [15]

Fracturing is a way to stimulate gas flow rates. Figure 1.8 shows the pressure profile during a normal stimulation job. Well bores connected to gas storage field are pressurized with fluid to the extent that rock fractures, admitting large volumes of fluids. Sand or other synthetic solids may be mixed with fluid so that the fractures remain open and gas can flow through them. The pressure required to cause fracturing is normally in the range of 0.8 to 1.1 psi per foot of depth [14, pg, 303] 
Fracturing in the earlier times used to be done with thickened gasoline, diesel fuel, kerosene and other such type of fluids. The first chemical used to thicken the fracturing fluid used in the late 1940s, was the war surplus napalm, which contains large amounts of aluminum. In the late 1960s cross-linked gel and guar gum was a common fracture fluid. Nowadays Nitrogen and Carbon dioxide are also used in the fracture job due to their low specific gravity and high expansion energy, which helps to remove the debris left after the fracture job. 


\section{LITERATURE REVIEW AND BACKGROUND}

\subsection{Well-Test Analysis for Gas Wells}

The first known Well Test analysis method was developed by Schellherdt and Rawlins [13] published in their well known Monograph 7: Back-pressure Data on Natural Gas Wells and Their Application to Production Practices (1936). It was based on empirical method applicable to very porous and permeable reservoirs. They showed that plot of $\left(\bar{p}^{2}-p_{w f}{ }^{2}\right)$ versus $q_{g}$ would yield a straight line on a logarithmic plot with slope $1 / \mathrm{n}$. After that there has been numerous work done to analysis well-test of fractured wells. Fractured wells are significantly different from un-fractured wells. Their pressure transient analysis depends on end of well-bore storage and linear flow regime. This analysis requires a very meticulous conductance of well-test and data recording.

Steady state Analytical model was first published by Muskat to describe behavior of naturally fractured wells. The hydraulically fractured well behave comparable to natural fractured well in their pressure and flow rate response. After that Prat et al gave a concept of effective well-bore radius, which is a function of fracture length and dimensionless conductivity.

Unsteady state behavior of infinite conductive vertical fractures was studied by Russell and Truitt. They showed the usefulness of semi-log analysis for fractured reservoirs if the fracture length is much smaller than the drainage radius.

Linear flow technique was first used by Clark, Millheim and Cichowicz. They discovered that a Cartesian graph of pressure versus square root of time yields a linear relationship. Cinco and Samaniego's work on finite conductivity fractures revealed that log-log graph of delta pressure versus time would have a quarter slope. Agarwal et al. extended the work of Cinco et al. to produce type curves to find solution of finite conductivity fracture flow. In 1955, Cullender [14] proposed a series of flow tests at different rates for the 
same length of time, which came to be known as isochronal well-test. A slightly modified version of this called modified-isochronal well-test is widely used in petroleum industry.

\section{2. Candidate Wells Selection}

Operator companies spend millions of dollars each year around the world to increase the performance of gas storage wells. There are many tools available for candidate selection. Usually the companies have to rely on change in AOF's and Peak day rates coupled with the storage potential of (kh) to make theses decisions.

Almost all of methods for hydraulic fracture optimization use of fracture simulators that require extensive reservoir data. Due to the inherent geology and behavior of Clinton sandstone this data is very difficult to get. Usually the companies make the candidate selection in four steps.

In first step they use reservoir simulators to predict the expected flow-rate at wells. From this they can identify the under performing wells. Secondly, to keep every thing in perspective they look at the history of its flow-rate. If it coincides with their results they go to third step and use hydraulic fracture simulators to determine required fracture length and conductivity to achieve that well performance. Once the stimulation slurry is designed their fourth step is to use cost optimization tools to select the wells for stimulations. It's a step-by-step tedious process and has many chances of error.

Candidate well selections using intelligent tools have been previous used to predict the production rates and hydraulic fracture optimization but never has it been used for storage wells using skin as the optimization parameter. Skin is fundamentally the most important parameter in storage candidate well selection. 


\subsection{Gas Storage Fields And Stimulations}

Gas storage fields maybe selected with some criteria. The first and foremost criterion is the existence of a suitable geo-structure [14]. It should have a sealing mechanism. Second is the depth of storage field. For gas storage $1000 \mathrm{ft}$, which represents a pressure of 433 psi, is considered to be a minimum depth. High permeability and porosity in a reservoir are strongly desirable. The Clinton sandstone represents one such good example but the heterogeneity of this parameter makes Clinton sand storage reservoir very unpredictable.

Nearly all fracture stimulation treatments, both historically and today in the Appalachian basin, have several standard components. Some of them are discussed below:

Pad or Cushion: A pad, or cushion is used to initiate and create the fracture. It is usually a viscosified liquid or foam

Viscosified fluid: Viscosified fluid (liquid or foam) to carry proppant (sand)

Proppant: Sand or beads as a proppant to hold the fracture open

Flush: Flush (liquid or foam) to displace the sand-laden fluid down the well bore and into the fracture.

In addition, the majority of the fracs have some sort of acid spearhead (HCL, mud acid, etc.) that is pumped ahead of the pad. And some fracs, and not very many, have had some sort of alcohol, usually methanol, pumped prior to the job as a miscible surfacetension reducing agent. The vast majority of the fracs in the storage field are water-based fracs. There are several types of water-based fracs that have been used:

1. Linear gel ("water-N2", "water-gel", "Hydra", "water")

2. Crosslinked gel ("borate crosslink", "Delta", "Viking x-link", "Lightning", "WideFrac")

3. Foam ("Foam" and others) 
A linear gel is a mixture of water and a gelling agent, typically guar gel. The fluid itself would look like cloudy, thick water. It has a viscosity of around 7 to 11 Centipoise (cp) depending upon how much gel is added to the water in pounds per $1000 \#$ (lb/Mgal). Many linear gel fracs, but not all, have nitrogen added in during frac to provide additional energy for cleanup. A typical job may have up to $20 \%$ nitrogen in the fluid. Historically, some have nitrogen in them and some don't.

A cross-linked gel frac is simply linear gel that has had a cross linking agent added to the mixture. The cross linker has the effect of joining the ends of the guar molecules which creates substantially more viscosity. A typical cross-linked gel has viscosities ranging from several hundred to several thousand centipoise. These cross-linked fluids also have a chemical breaker added to later break the bonds between the guar molecules, which reduces the viscosity down below the base gel. These chemicals have time-dependent mechanism that allow them to be pumped and then flow the excess fluid back out of the well while leaving the sand in place after the frac closes. Typical breakers are usually organic enzymes that "digest" the gel or are oxidizers that chemically alter the fluid. Most, but not all, cross-linked gel fracs have nitrogen added to the mixture to provide additional energy for cleanup. A typical job may have $20 \%$ nitrogen in the mixture.

A foam frac is defined as a frac where the majority of the fluid pumped is a gas. Foam is formed when the gaseous phase is between $55 \%$ and roughly $95 \%$ of the total mixture by volume. The other part of the mixture is usually a linear gel or sometimes a cross-linked gel along with a foaming agent/surfactant (soap). Foam is usually used for the pad, as a carrier for the sand, and to flush the sand to the formation.

In the old days, typically the late-1950's and early-1960's, there were some fracs pumped that were hydrocarbon-based. These include the old "Petro-gel" and "Viso-frac". The oilbased fluid is typically kerosene 


\section{METHODOLOGY}

\subsection{Problem statement and our approach}

To make an intelligent decision about the candidate well selection we need to have a judgment whether the stimulation was good or bad. To make that decision we collected all the relevant data and put it in a database so that we can manipulate it the way we like to look at it. To make candidate selection either of three parameters can predict the effectiveness of the stimulation. One in Peak Day rate second is Absolute open flow and third is change in skin provided permeability values don't vary much. Permeability analysis was done for all the wells in the storage field and frequency graph was plotted to check the variability of permeability values in the field which is shown in Figure 3.1.

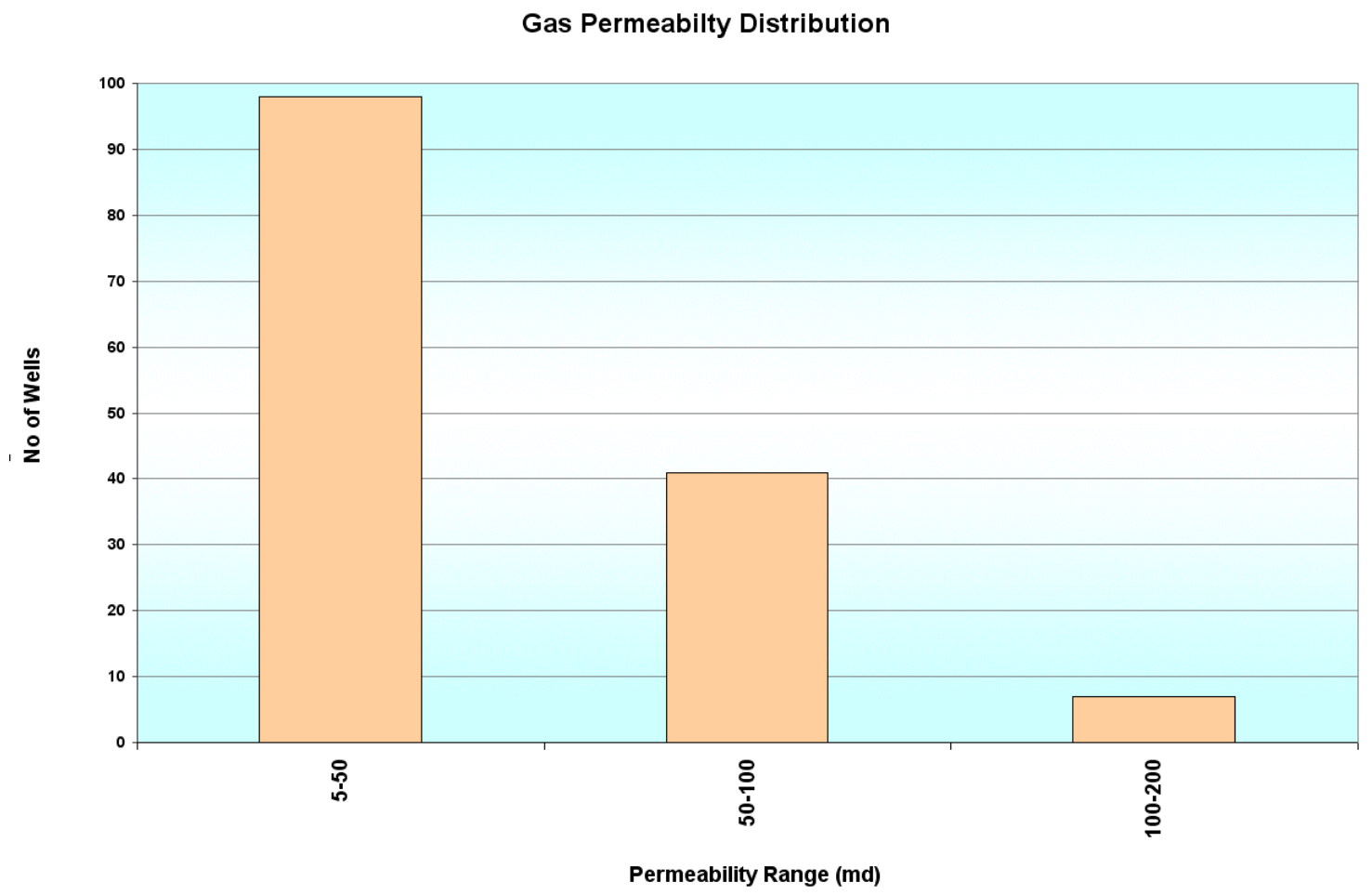

Figure 3.1 Permeability Analysis done on the storage wells

Almost more than 140 (more than 94\%) wells that had permeability values, the range of permeability was from 5md to $100 \mathrm{md}$. The Peak Day rate and Absolute Open Flow 
parameters for this field didn't give us desired results to make an intelligent decision so change in skin was used to make candidate selection.

The well-test data found was very less so a software containing tools to analyze the welltests by simplified and LIT analysis was developed. Another tool to find permeability from an extended build-up test was added later. With this data a neural network was trained to predict the non-linear relationship of skin after the stimulation. Now when we can predict skin from any stimulation we made a Genetic Optimization tool that uses genetic algorithm to find the optimum stimulation parameters. As we have got the best stimulation parameters for each well and its corresponding predicted skin we can now rank the wells and select candidate wells.

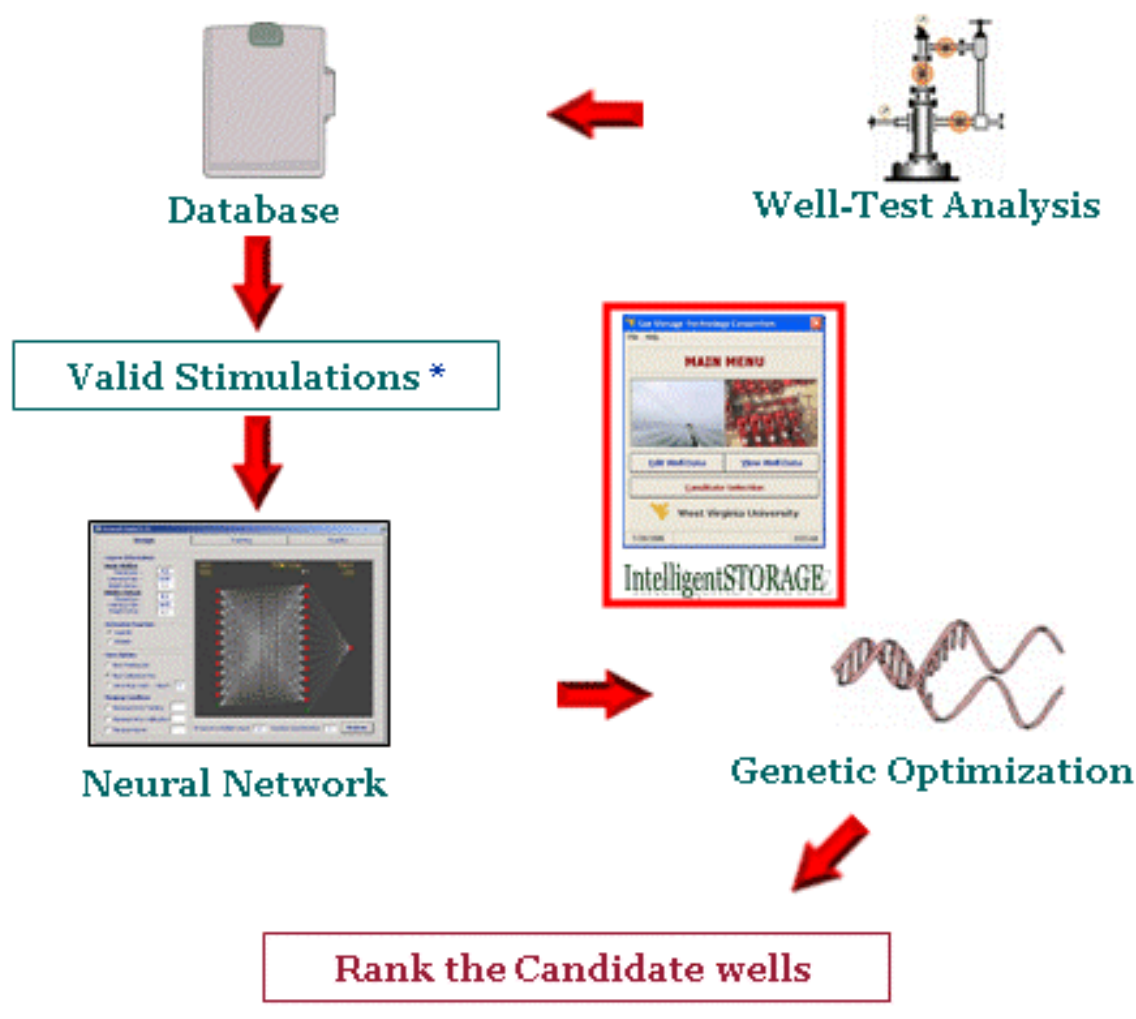

* Skin value is known prior and after the stimulation

Figure 3.2 Flow chart of our problem solving approach 
Following is the flow diagram of the well test analysis procedure and the type of values that we get from the data.

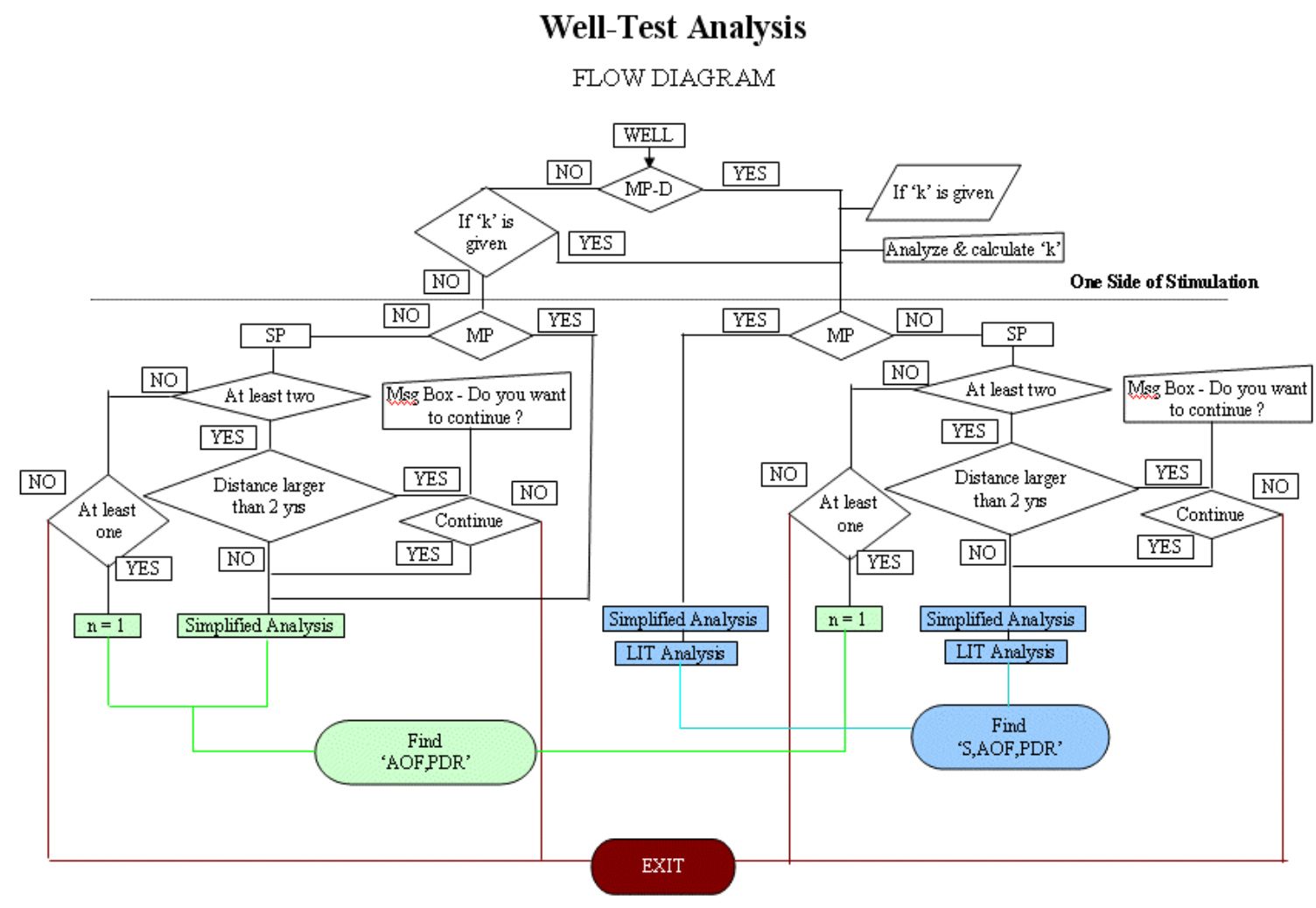

Figure 3.3 Flow Diagram of Well Test Analysis procedure 
Characteristics of the reservoir: The data used in this study was taken from a gas storage field in Ohio. The gas storage formation was Clinton sandstone and it properties are shown in Table 3.1.

\begin{tabular}{|ll|}
\hline STORAGE RESERVOIR CHARACTERISTICS & VALUE \\
Specific gravity of gas & 0.585 \\
Porosity & $14 \%$ \\
Average formation depth & $2000 \mathrm{ft}$ \\
Max Allowable Pressure & $1150 \mathrm{psi}$ \\
Del pressure squared for Peak Day rate calculation & 250,000 \\
Average thickness of storage formation & $10 \mathrm{ft}$ \\
\hline
\end{tabular}

Table 3.1 Storage Reservoir Characteristics

Valid Stimulations: For intelligent candidate selection of wells it is very important that only valid data is given to the Neural Network (NN) for training. Valid data is one, which if given to $\mathrm{NN}$ for training and contains no empty or null value otherwise it will degrade the neural network. Following is the criteria for a valid stimulation:

Valid Stimulation - It should have skin value before $\&$ after stimulation Valid perforation - perforation just before the stimulation Valid Completion - the smallest size completion run before stimulation Valid Well-test - $\quad$ well-test having skin value just before or after the well-test 


\subsection{Database preparation}

Visual Basic v 6.0 was used to code the software and interact with the accompanying database. This software uses MS Access to store large amounts of data required for this software. MS access was chosen due to its versatility to make queries, edit data and due to the fact that it is available to almost everyone. The data could be segregated into five main tables, each relating to specific characteristic features of the gas storage wells and one table for the cost of materials and other of reservoir characteristics. Following are the main tables:
1- Well-bore data
2- $\quad$ Completion Data
3- $\quad$ Perforation Data
4- $\quad$ Stimulation Data
5- Well-Test Data

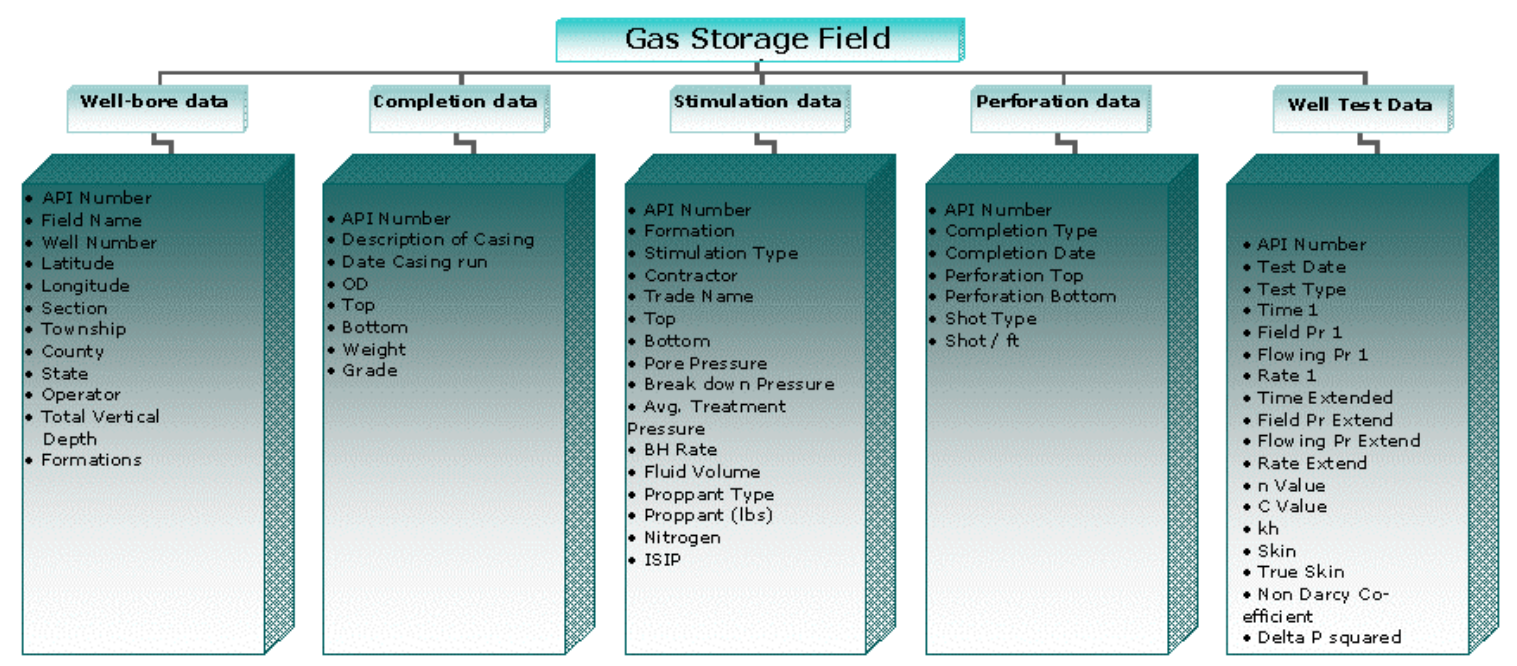

Figure 3.4 Database chart showing information in each table 


\subsubsection{Well-bore data}

It includes basic features of the well like location, depth, well name ... etc. Data about well bore was retrieved mostly from well schematics and well summary reports. The data already provided by Columbia Transmission Corporation was also verified. The complete list of the data type retrieved is below
1. API Number
2. Field Name
3. Well
4. Lease Name
5. Classification
6. Latitude (Lat)
7. Longitude (Long)
8. Section
9. Township
10. County
11. State
12. Operator
13. Total Vertical Depth
14. Formation

The tables contained many minor mistakes like wrong Well API number length and many spelling mistakes: 
Graphical Analysis of Raw Data vs. Refined Data

\begin{tabular}{|c|c|c|c|c|c|c|c|c|c|c|c|c|c|c|}
\hline \multicolumn{15}{|c|}{ WELLB ORE DATA } \\
\hline $\begin{array}{l}\text { DATA } \\
\text { FIELDS }\end{array}$ & $\begin{array}{l}\bar{d} \\
\frac{\bar{E}}{\mathbf{E}} \\
\frac{\bar{\Sigma}}{\bar{\alpha}} \\
\frac{\alpha}{\alpha}\end{array}$ & 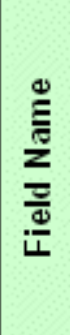 & $\sum_{3}^{\overline{0}}$ & 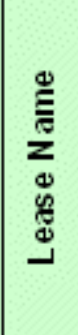 & 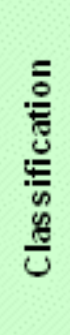 & $\Xi$ & $\stackrel{\square}{5}$ & 高 & 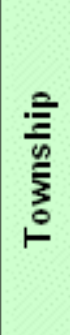 & $\stackrel{\vec{E}}{\grave{\Xi}}$ & है & 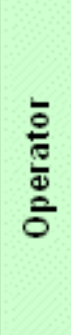 & 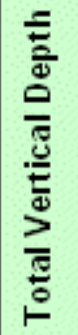 & 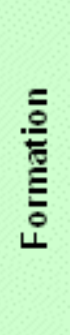 \\
\hline $\begin{array}{c}\text { INITIIAL } \\
\text { DATA } \\
\text { AVAILABLE }\end{array}$ & 430 & 427 & 430 & 430 & 427 & 429 & 430 & 430 & 430 & 430 & 430 & 430 & 425 & 430 \\
\hline $\begin{array}{c}\text { FINAL } \\
\text { DATA } \\
\text { AVAILABLE }\end{array}$ & 430 & 430 & 430 & 430 & 430 & 430 & 430 & 430 & 430 & 430 & 430 & 430 & 430 & 430 \\
\hline
\end{tabular}

WELLBORE DATA

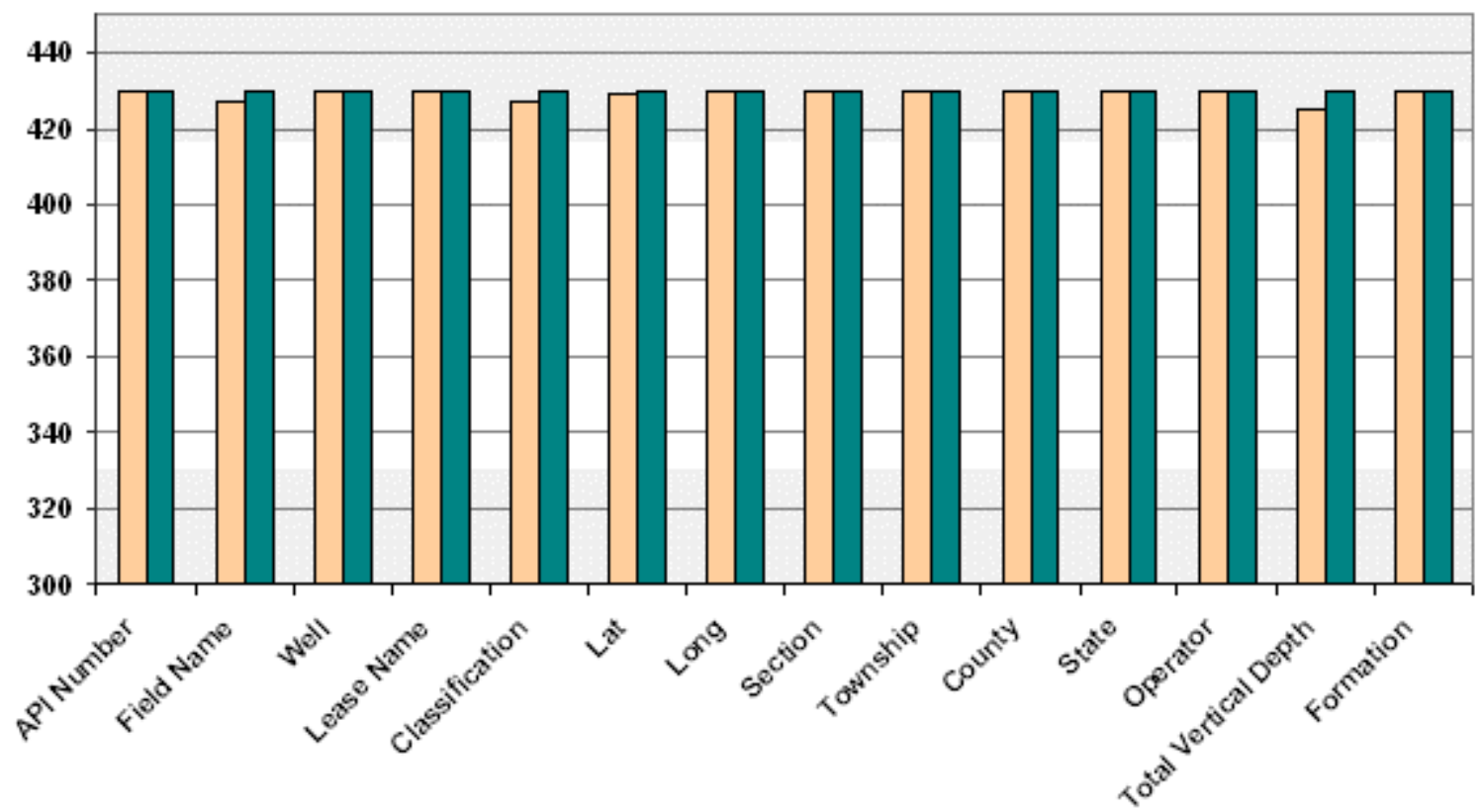

Number of DataEntries

口INITIAL DATA AVAILABLE

FINAL DATA

Figure 3.5 Data addition and refinement for Well-bore Data 


\subsubsection{Completion Data}

Completion data mostly relates to the type and depth of casing/liner/tubing run in the gas storage wells. The data type retained for the database includes following

1. API Number

2. Field Name

3. Well Name (Well)

4. Completion Description (Des)

5. Date Tubing Run (Dt Tm Rn)

6. Outer Diameter (OD)

7. Top of Casing

8. Bottom of Casing (Bot)

9. Casing Weight (Weight)

10. Casing Grade (Grade)

Unfortunately the data was mostly in an excel file and had to be verified with well schematic drawings. This led to the most unusual step in this project as it lead to reduction of valuable data available to us. This was due to the erroneous and multiple data entry originally in the completion table. Identification of the multiple entries and their removal from table was the most focused act of cleaning the data, as omission of desirable records was unacceptable. Following pictures show one of such flawed multiple data entries, which were removed. 


\begin{tabular}{|c|c|c|c|c|c|c|c|c|c|c|c|c|}
\hline & $A$ & B & $\mathrm{C}$ & $D$ & $E$ & $F$ & G & $\mathrm{H}$ & 1 & $\mathrm{~J}$ & $\mathrm{~K}$ & L \\
\hline 1 & Field Name & Well & $\mathrm{API}$ & Des & DtTmRun & $O D$ & Top & Bot & Weight & Grade & & \\
\hline 71 & 4 & & & Casing & $03.0 \mathrm{ct}-17$ & 7.00 & 0 & 2043 & 20.00 & & & \\
\hline 72 & 1 & & & Casing & $02-$ Mar-64 & 5.50 & 0 & 2908 & 17,00 & Seamless & & \\
\hline 73 & 4 & & & Drive Pipe & 01-Now-24 & 10.75 & 0 & 33 & 40.00 & & & \\
\hline 74 & t & & & Surface Pipe & C2-Now 24 & 8.63 & 0 & 299 & 24.00 & & & \\
\hline 75 & t. & & & Casing & $03 \cdot N o r-24$ & 7.00 & 1893 & 1931 & 20.00 & & & \\
\hline 76 & t. & & & Casing & 04-Nor-24 & 5.50 & 0 & 2681 & 17.00 & & & \\
\hline 77 & ! & & & Casing & C2-Now63 & 3.50 & 0 & 2684 & 9.20 & Used & & \\
\hline 78 & l & & & Packer & $\mathrm{OB} \cdot \mathrm{Nov}-\mathrm{GZ}$ & $5 \mathrm{sn}$ & $268 n$ & 2581 & & Straight Anchor & & \\
\hline 79 & ! & & & Packer & $03 \cdot N o n$ & \multirow{2}{*}{\multicolumn{3}{|c|}{ Multiple Data }} & & & & \\
\hline 80 & & & & & $03-\mathrm{Now}$ & & & & & Straight Anchor & & \\
\hline 81 & & & & Drive Pipe & 01-vut & \multicolumn{3}{|l|}{ Entry } & $\overline{00}$ & & & \\
\hline 82 & & & & Surface Pipe & $02 \sqrt{y})^{-}$ & $v^{\prime}$ & & & -100 & & & \\
\hline 83 & & & & Packer & Co. Jut-25 & 8.63 & 1829 & 1639 & & Larkin Lead B.H. & & \\
\hline 84 & & & & Packer & 6o. Jut25 & 8.63 & 1829 & $16 C 9$ & & & & \\
\hline 65 & & & & Casing & Co. Jut25 & 7.00 & 1793 & $18 C 9$ & 20.00 & & & \\
\hline 86 & & & & Packer & 04-Jul-25 & 7.00 & 2500 & 2510 & & & & \\
\hline 87 & & & & Packer & 04-Jut-25 & 7.00 & 2500 & 2510 & & O VS Midget & & \\
\hline 86 & & & & Casing & 04 JuF 25 & 5.50 & 0 & 2510 & 1700 & & & \\
\hline 89 & & & & Casing & $02-0 \mathrm{ct}-63$ & 5.50 & 0 & 2654 & & & & \\
\hline 90 & & & & Packer & $02.0 \mathrm{ct}-53$ & 5.50 & 2551 & 2561 & & & & \\
\hline 91 & & & & Anchor & 02.0ct-63 & 5.50 & 2561 & 2571 & & & & \\
\hline 92 & & & & Packer & $02.0 \mathrm{ct}-63$ & 5.50 & 2551 & 2561 & & & & \\
\hline 93 & & & & Anchior & Docotas & 5.50 & 2561 & 2571 & & & & \\
\hline 94 & LUCAS & $\overline{00050}$ & 3400592060 & Casing & $01-0 \mathrm{ct}-25$ & 10.75 & 0 & 64 & 40.00 & & & \\
\hline
\end{tabular}

Figure 3.6 Multiple Data Entries in Completion Table

In the completion table the following notations used as casing description were discarded to have a standard definition

\begin{tabular}{|l|l|}
\hline NOTATION KEPT IN DATABASE & Surface casing \\
\hline NOTATIONS DISCARDED & Drive pipe \\
\cline { 2 - 2 } & Driver Pipe \\
\cline { 2 - 2 } & Swedge \\
& Two stage \\
\hline
\end{tabular}

Table 3.2 Changed notations in completion table 


\section{Analysis of Raw Data vs. Refined Data}

Please note that multiple data entry was the major reason for the reduction in the refined data from the initial

\begin{tabular}{|c|c|c|c|c|c|c|c|c|c|c|c|}
\hline \multicolumn{12}{|c|}{ COMPLETION DATA } \\
\hline $\begin{array}{c}\text { DATA } \\
\text { FIELDS }\end{array}$ & 递訔产 & $\frac{\bar{d}}{\frac{\bar{d}}{\bar{z}}}$ & 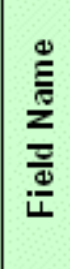 & के & 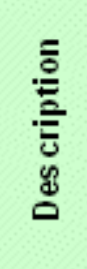 & 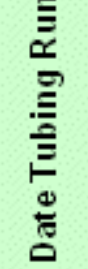 & ๑ิ & 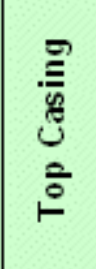 & ๑े & $\frac{\frac{5}{5}}{3}$ & $\frac{\frac{\omega}{\pi}}{\frac{\pi}{\sigma}}$ \\
\hline $\begin{array}{c}\text { INITIIAL } \\
\text { DATA } \\
\text { AVAILABLE }\end{array}$ & 2910 & 431 & 431 & 431 & 2909 & 2909 & 2909 & 2909 & 2909 & 1781 & 1607 \\
\hline $\begin{array}{c}\text { FINAL } \\
\text { DATA } \\
\text { AVAILABLE }\end{array}$ & 2413 & 430 & 431 & 431 & 2413 & 2413 & 2413 & 2413 & 2413 & 1723 & 1607 \\
\hline
\end{tabular}

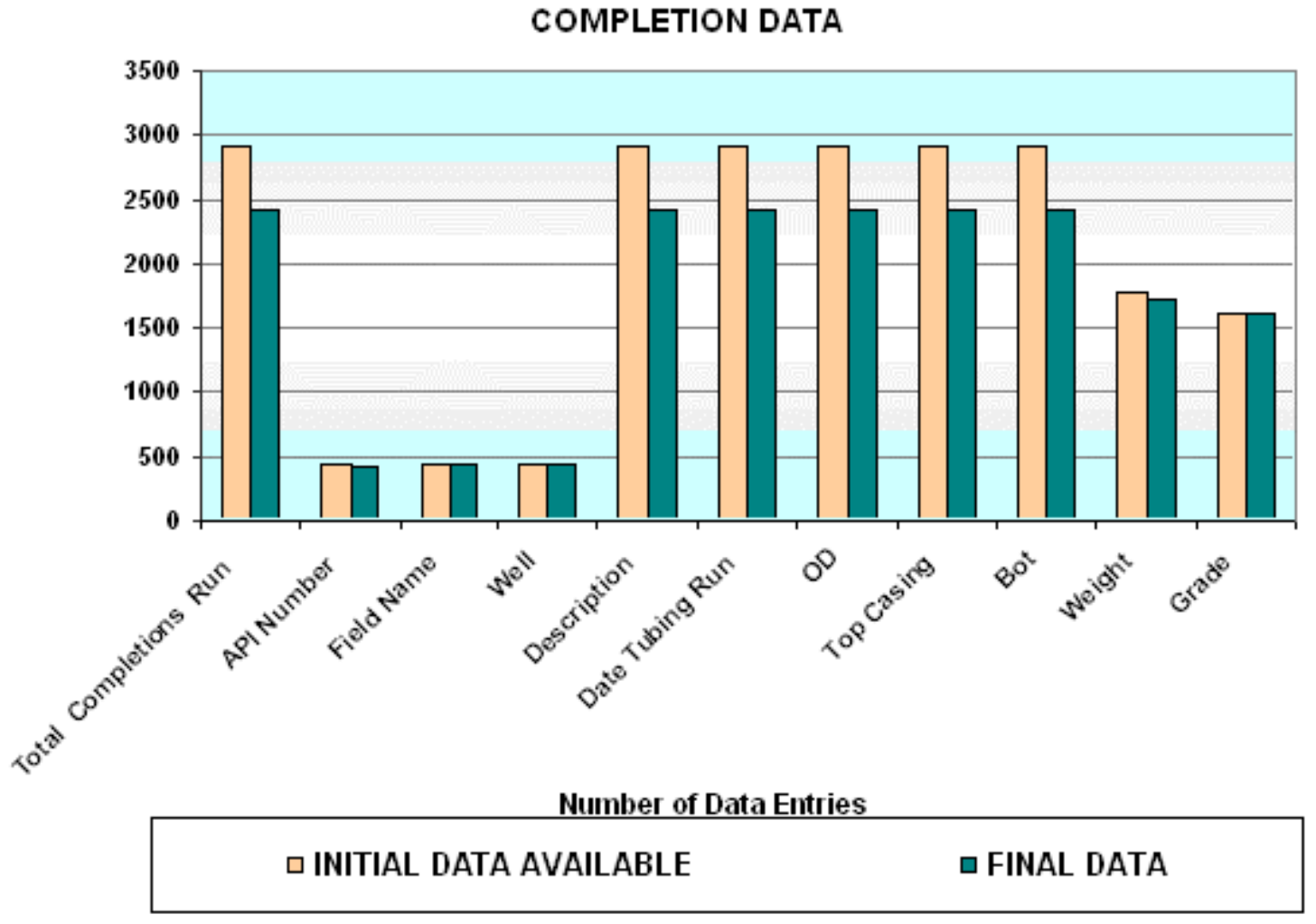

Figure 3.7 Data addition and refinement for Completion Data 


\subsubsection{Perforation Data}

This data set contains mostly all the information relating to the perforations done on the gas storage well like perforation top \& bottom depth and shots per feet. Following are the data types included in this type of data set are below.

Following are the data types included in this type of data set:

1. Well API Number

2. Field Name

3. Well Name

4. Completion Type

5. Perforation Date (Perf Date)

6. Perforation Top (Perf Top)

7. Perforation Bottom (Perf Btm)

8. Shot Type

9. Shot Per feet (Shot Per ft) 


\section{Analysis of Raw Data vs. Refined Data}

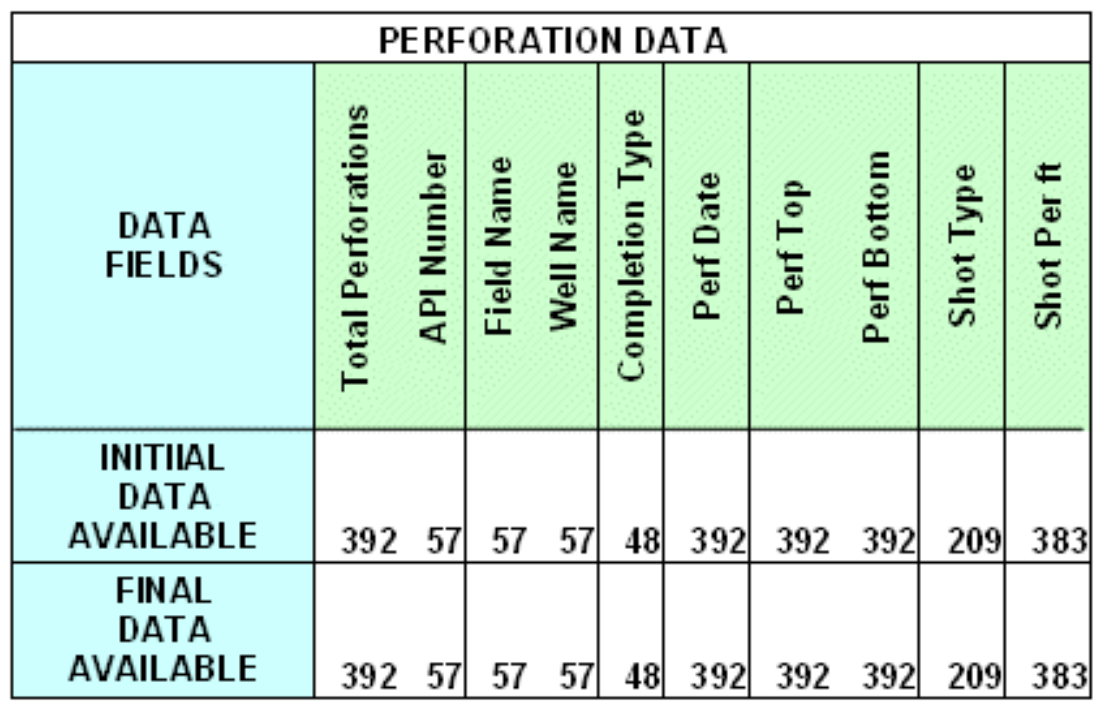

PERFORATION DATA

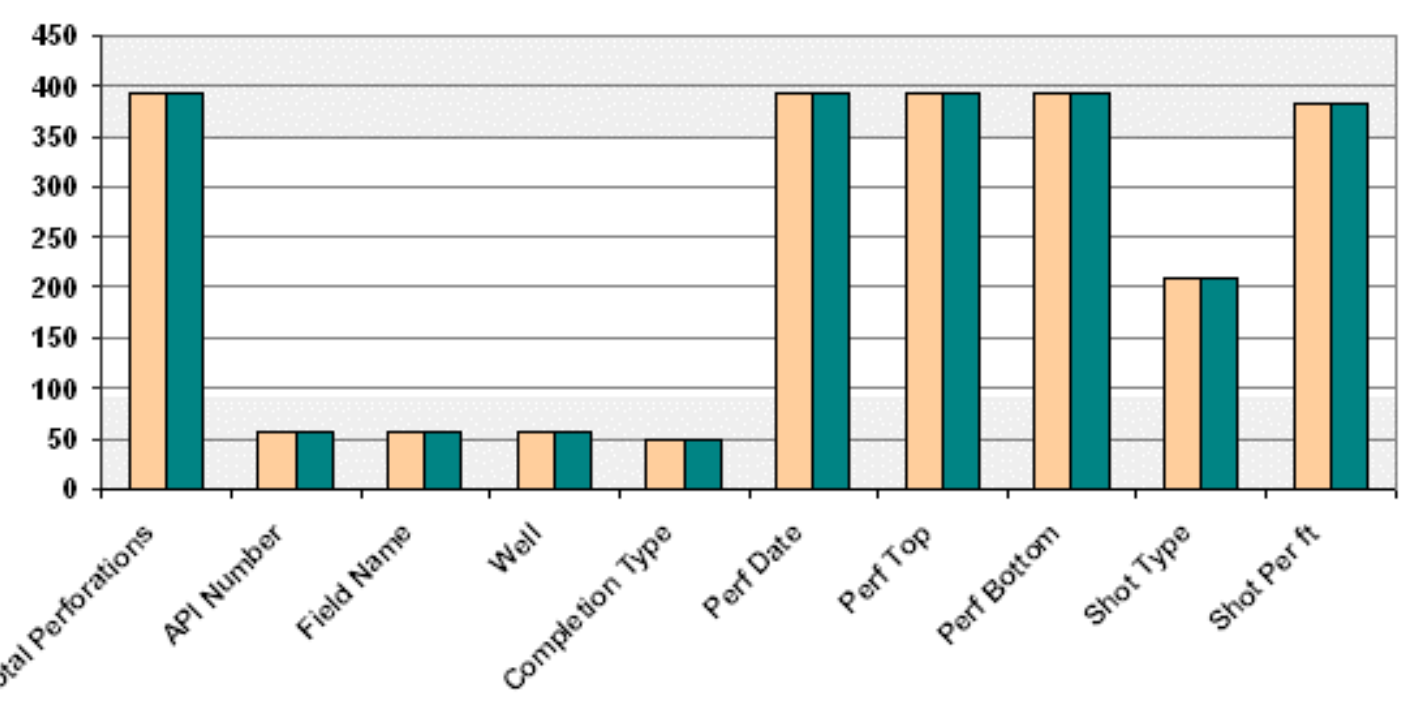

Number of Data Entries

口INITIAL DATA AVAILABLE

IFINAL DATA

Figure 3.8 Data addition and refinement for Perforation Data 


\subsubsection{Stimulation Data}

Stimulation data is the one of the most significant dataset about the storage wells. Because of this it was very important that we have maximum records of stimulations. Following data type is used to represent stimulation

$\begin{array}{llll}\text { 1. } & \text { API Well Number } & 13 . & \text { Foam } \\ \text { 2. } & \text { Well Name } & 14 . & \text { Nitrogen } \\ \text { 3. } & \text { Size of String } & 15 . & \text { Alcohol } \\ \text { 4. } & \text { Stimulation From } & 16 . & \text { Cushion } \\ \text { 5. } & \text { Stimulation To } & 17 . & \text { Flush } \\ \text { 6. } & \text { No Of Shots } & 18 . & \text { Sand Quantity } \\ \text { 7. } & \text { Fractured by } & 19 . & \text { Sand Type } \\ \text { 8. } & \text { Stimulation Type } & 20 . & \text { Injection Rate } \\ \text { 9. } & \text { Stimulation Date } & 21 . & \text { Total Fluid } \\ \text { 10. } & \text { Water } & 22 . & \text { Breakdown Pressure } \\ \text { 11. } & \text { Acid } & 23 . & \text { ISIP } \\ \text { 12. } & \text { Gel } & & \end{array}$

Unfortunately initially we didn't have much data about the stimulations being done in this Storage field. With this in mind every record with the company was carefully examined. The largest source of stimulation data came from the thousands of microfiche with some data being found in well summary reports. Following is a picture of data in well summary reports.

All the steps taken to retrieve data from microfiche are explained in a flow in Figure 3.9. 


\section{MICROFICHE TO DATABASE}

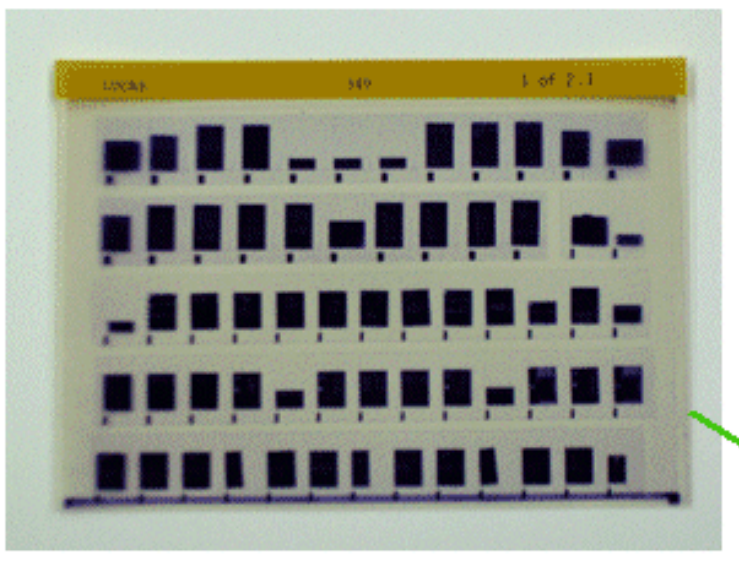

Microfiche were read by digital Microfilm scanners

Each Microfiche contained dozens of documents from invoices to valuable stimulation and well-test data

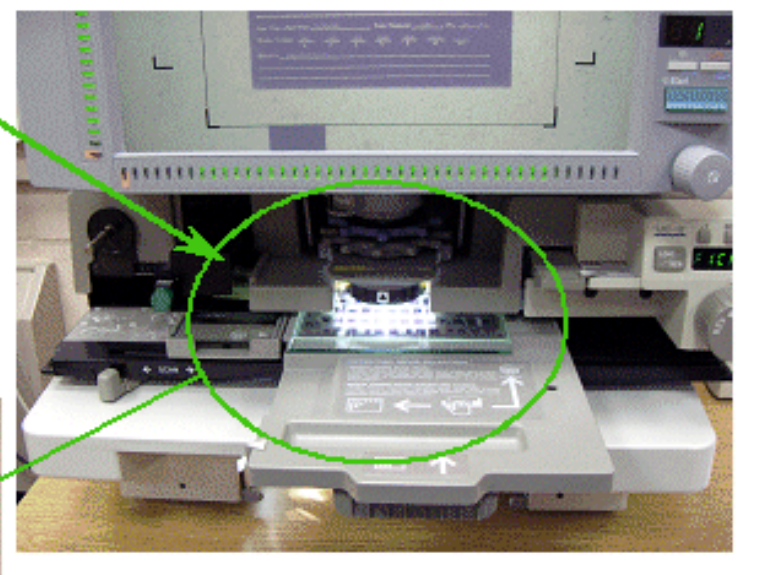

Each scanned image of the microfiche was searched and read for valuable data

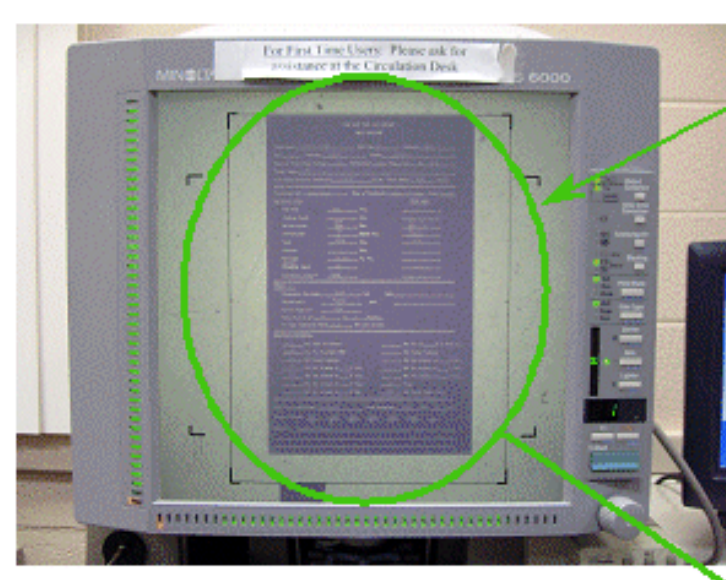

Prints were taken of the documents containing data

\begin{tabular}{|c|c|c|c|c|c|c|}
\hline \multicolumn{7}{|c|}{ E Slimilatios Dete: Table } \\
\hline AF, Nimber & Sitorsting & Stmemm & StimTa NoOf hots & Factuandy & Type & St \\
\hline $34005-01272$ & 45 & 2062 & 29068 & $0 \log 1 \mathrm{he}$. & Witen-Ged & 111 \\
\hline $34.005-02430$ & 45 & 2799 & $2 \pi e s 11$ & $0 x \rightarrow 1 \mathrm{ht}$. & Waterow & 120 \\
\hline 34.005 .02887 & 4.5 & 2804 & 281013 & Desal we. & Water-10 & \\
\hline $34,005-02009$ & 4.5 & 2000 & 204512 & Dosal he. & Watering & \\
\hline $34-005-02889$ & 45 & 2000 & 282810 & Oonal he. & Wistertio & 60 \\
\hline $34.005-02897$ & 45 & 2053 & 205012 & Halisutón Co & Whateroed & 7개 \\
\hline $34.005-02501$ & 4.5 & 2723 & 274812 & Haliauton Co & Water.Gel & 테 \\
\hline $34 \cos -0250 ?$ & 35 & 2023 & 204513 & Halisution Co & Water.Ge & \\
\hline $34 \cdot 005-002009$ & 15 & 2766 & 28145 & Halisurton Co & Wasterged & 7d \\
\hline $34.005-02509$ & 4.5 & 2809 & 29146 & Haliauton Co & Water.0el & 개 \\
\hline $34,005-02911$ & 4.5 & 2705 & 200513 & Heliauton Co & Water.Gol & si \\
\hline $34-005-00290$ & 4.5 & 2911 & 292119 & Ocoul he. & Witen:GN & 100 \\
\hline $34.005-10516$ & 55 & 2568 & 2808 & Halibution $\mathrm{Co}$ & Woso-Fac & 12 \\
\hline $34.005-10517$ & 5.5 & 2559 & 2950 & Desal he. & Wattr-12 & sin \\
\hline $34005-10518$ & 5.5 & 2500 & 2522 & Dosel he. & Putrogel & 12] \\
\hline $34 \cdot 005-10519$ & 5.5 & 2874 & 20802 & Halibuton Ca & Witem 10 & के \\
\hline $34.005-105000$ & 50 & 2905 & 2901 & $D \in$ he. & Wister.0ed & (1) \\
\hline $34.005-10527$ & 55 & 2886 & 2801 & Desal he. & Water-10 & \\
\hline 34005 - 10533 & 6.5 & 2027 & 2053 & Docel hs. & PetroGel & 14 \\
\hline $34 \cdot 005-10538$ & 55 & 2004 & 2804 & 0 ond he. & PetroGed & 12 \\
\hline $34-005-105: 20$ & 55 & 2860 & 2906 & Dewl he. & water.t2 & 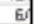 \\
\hline
\end{tabular}

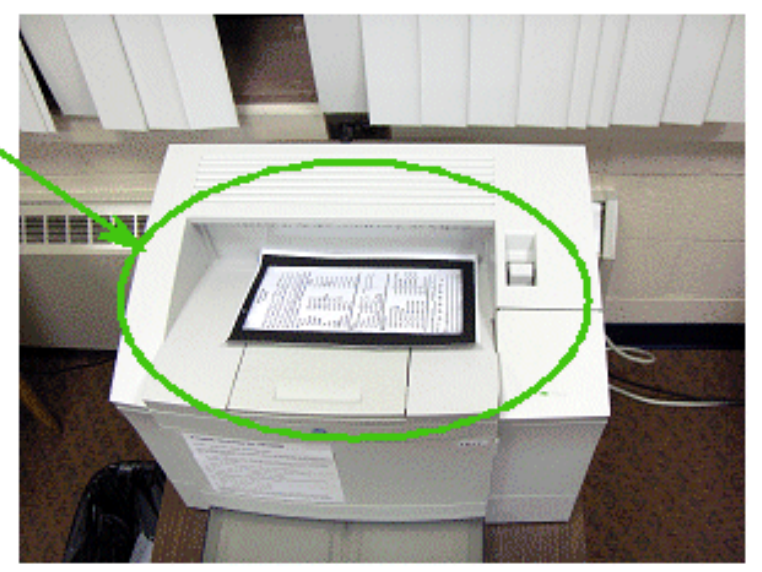

Data was entered in the database

Figure 3.9 All the steps taken for retrieving data from microfishe 
During the data entry different sign conventions and unit conversions were carried out as follows

\begin{tabular}{|cc|c|}
\hline MEASURED & UNITS IN & UNITS USED IN \\
QUANTITY & RECORDS & DATABASE \\
\hline SAND & 1 sack & $100 \mathrm{lbs}$ \\
& $1 \mathrm{sks}$ & \\
\hline NITROGEN & $52 \mathrm{M}$ & $52,000 \mathrm{SCF}$ \\
\hline LIQUID & $1 \mathrm{bbl}$ & $42 \mathrm{gal}$ \\
PERFORATIONS & $2000-2005 \mathrm{ft}, 10$ shots & 2 shots $/ \mathrm{ft}$ \\
& $10 / 5$ & \\
\hline
\end{tabular}

Table 3.3 Unit conversions done in data

The following notations were used in place of different notations being used in the tables

\begin{tabular}{|c|c|c|c|c|c|c|c|}
\hline $\begin{array}{l}\text { NOTATIONS } \\
\text { USED IN } \\
\text { DATABASE }\end{array}$ & $\begin{array}{l}\text { WATER } \\
\text { GEL } \\
\text { FRAC }\end{array}$ & $\begin{array}{l}\text { PETRO } \\
\text { GEL } \\
\text { FRAC }\end{array}$ & $\begin{array}{l}\text { FOAM } \\
\text { FRAC }\end{array}$ & $\begin{array}{l}\text { NITRO } \\
\text { SHOT }\end{array}$ & $\begin{array}{l}\text { WATER/N2 } \\
\text { FRAC }\end{array}$ & $\begin{array}{l}\text { WATER } \\
\text { FRAC }\end{array}$ & $\begin{array}{l}10 / 20 \\
\text { SAND }\end{array}$ \\
\hline \multirow{3}{*}{$\begin{array}{l}\text { NOTATIONS } \\
\text { THAT } \\
\text { WERE } \\
\text { REPLACED }\end{array}$} & $\begin{array}{l}\text { Gelled } \\
\text { water } \\
\text { frac }\end{array}$ & Petrl gel & Foam & Shot & Water / N2 & water & $10 / 20$ \\
\hline & $\begin{array}{c}\text { Water } \\
\text { Gel }\end{array}$ & $\begin{array}{l}\text { Petro Gel } \\
\text { Petro gel } \\
\text { fracture }\end{array}$ & $\begin{array}{c}\text { foam } \\
\text { Frac } \\
\text { foam } \\
\text { fracture }\end{array}$ & & $\begin{array}{c}\text { Water N2 } \\
\text { Fracture } \\
\text { Water nitrogen }\end{array}$ & & $\begin{array}{l}\text { Sand } \\
10 / 20\end{array}$ \\
\hline & & & & & $\begin{array}{c}\text { Water/N2 assist } \\
\text { Water Fracture } \\
\text { W/N2 assist }\end{array}$ & & \\
\hline
\end{tabular}

Table 3.4 Notations replaced in stimulation table

All records of Nitro-shots were discarded for this database as they have no stimulation parameters on record and are part of history now plus they also damage the well. Above all they will tend to degrade the Neural Network. 
Graphical Analysis of Raw Data vs. Refined Data

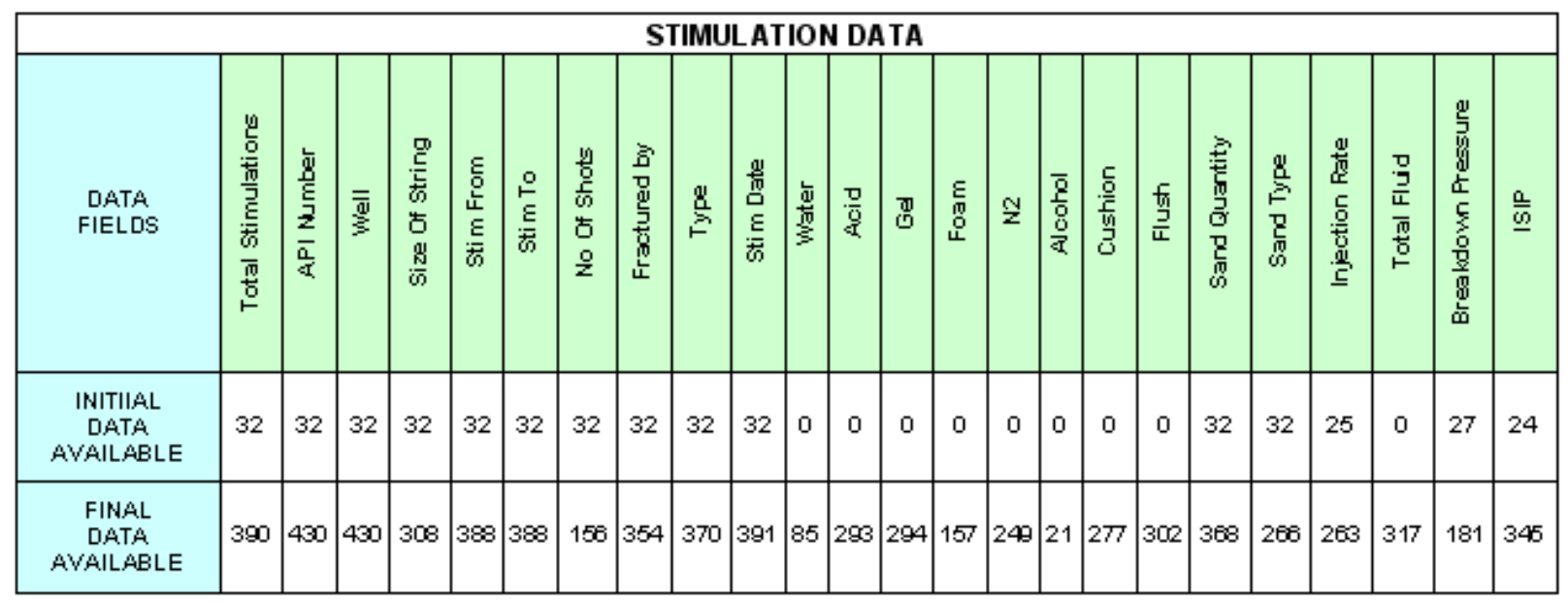

\section{STIMULATION DATA}

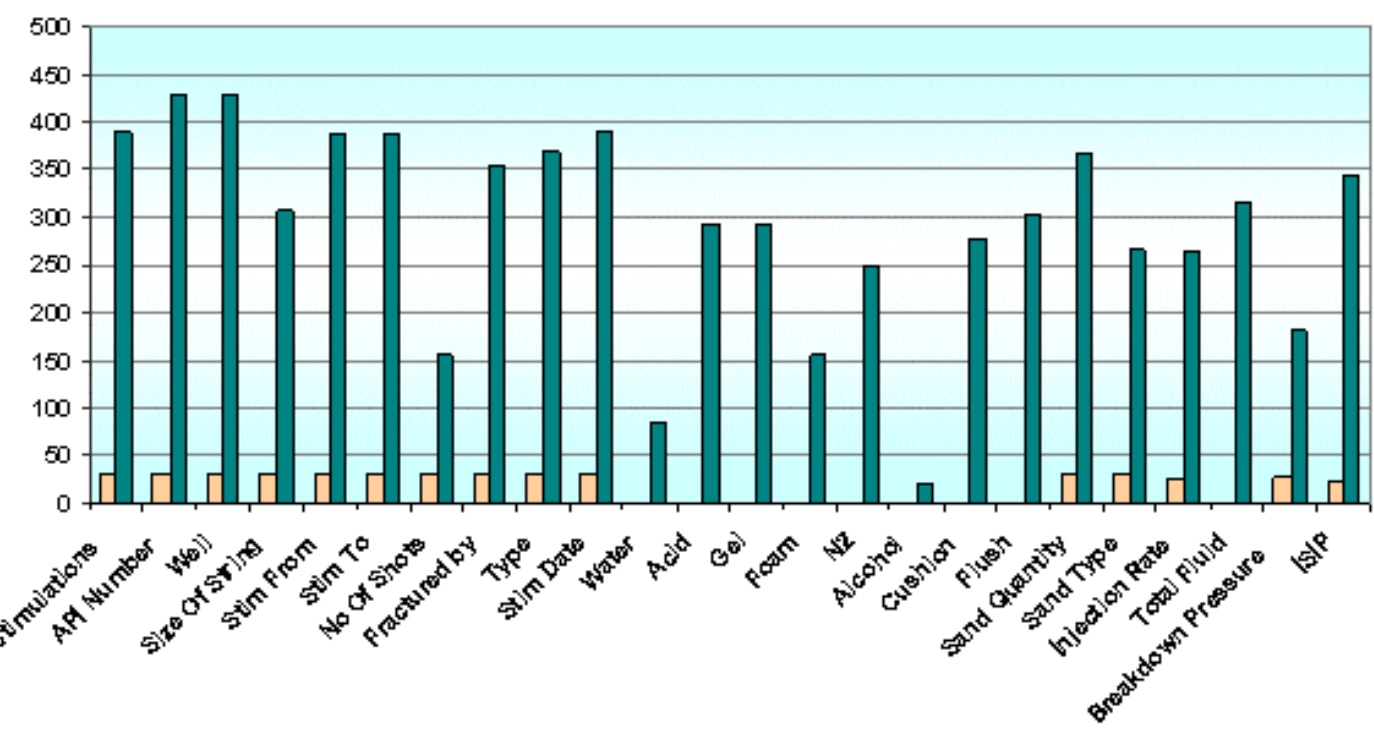

Number of Data Entries

口INITIAL DAT A AVAILABLE

IFINAL DATA

Figure 3.10 Data addition and refinement for Stimulation Data 


\subsubsection{Well Test Data}

Well-test data is the most extensive dataset that I worked on. It has the max amount of records nearly 3365 and 29 data types that control every aspect of a well-test. The data type selected for a well-test representation consists of following

$\begin{array}{llll}\text { 1. } & \text { Well API Number } & 16 . & \text { Rate 3 } \\ \text { 2. } & \text { Field Name } & 17 . & \text { Time Extended } \\ \text { 3. } & \text { Test Date } & 18 . & \text { Field Pressure Extended } \\ \text { 4. } & \text { Test Type } & 19 . & \text { Flowing Pressure Extended } \\ \text { 5. } & \text { Time 1 } & 20 . & \text { Rate Extended } \\ \text { 6. } & \text { Field Pressure 1 } & 21 . & \text { kh } \\ \text { 7. } & \text { Flowing Pressure 1 } & 22 . & \text { Skin } \\ \text { 8. } & \text { Rate 1 } & 23 . & \text { True Skin } \\ \text { 9. } & \text { Time 2 } & 24 . & \text { Non Darcy Co-efficient } \\ \text { 10. } & \text { Field Pressure 2 } & 25 . & \text { n Value } \\ \text { 11. } & \text { Flowing Pressure 2 } & 26 . & \text { C Value } \\ \text { 12. } & \text { Rate 2 } & 27 . & \text { Delta Pressure Squared } \\ \text { 13. } & \text { Time 3 } & 28 . & \text { Peak Day Rate } \\ \text { 14. } & \text { Field Pressure 3 } & 29 . & \text { Absolute Open Flow } \\ \text { 15. } & \text { Flowing Pressure 3 } & & \end{array}$

Lot of data was missing in this dataset so it was decided that values of n, C, Peak Day rate \& AOF will be interpreted manually and on the other side work on software will continue to automatically do this interpretation procedure with little input from user. This program will be discussed in great detail latter. 


\section{Graphical Analysis of Raw Data vs. Refined Data}

\begin{tabular}{|c|c|c|c|c|c|c|c|c|c|c|c|c|c|c|c|c|c|c|c|c|c|c|c|c|c|c|c|c|c|c|}
\hline \multicolumn{31}{|c|}{ WELL TEST DATA } \\
\hline $\begin{array}{l}\text { DATA } \\
\text { FIELDS }\end{array}$ & 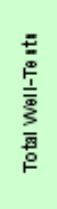 & 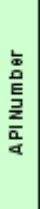 & 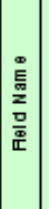 & $\overline{\bar{s}}$ & 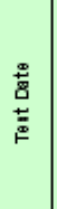 & 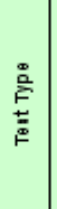 & 可 & 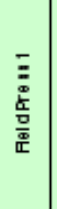 & 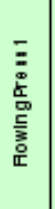 & $\begin{array}{l}\bar{s} \\
\text { s. } \\
\text { s. }\end{array}$ & 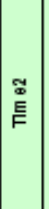 & 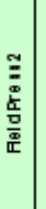 & 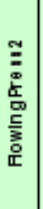 & 茎 & \begin{tabular}{|c|} 
\\
$\Phi$ \\
$E$ \\
$E$ \\
$F$
\end{tabular} & 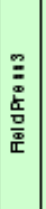 & 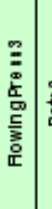 & 象 & 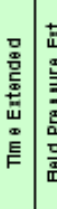 & 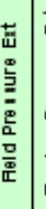 & 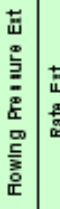 & 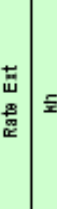 & $\frac{c}{s}$ & \begin{tabular}{|l|} 
돓 \\
0 \\
$o p$ \\
$\vec{p}$ \\
\end{tabular} & 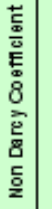 & 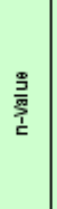 & 氶 & 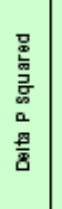 & 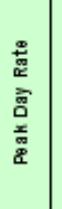 & 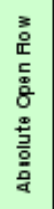 \\
\hline $\begin{array}{c}\text { INIIIAL } \\
\text { DATA } \\
\text { AVAIL ABL E }\end{array}$ & 3223 & 431 & 131 & 431 & 3223 & 3223 & 3223 & 3223 & 3223 & 3223 & 347 & 347 & 347 & 347 & 292 & 292 & 2922 & \begin{tabular}{l|l}
292 & 3
\end{tabular} & $345 \mid 34$ & \begin{tabular}{l|l}
345 & 3
\end{tabular} & $345 \mid 34$ & \begin{tabular}{ll|l}
345 & 19
\end{tabular} & \begin{tabular}{|l|l|}
11 & 182 \\
\end{tabular} & 163 & 163 & 916 & 916 & 916 & 916 & 916 \\
\hline $\begin{array}{c}\text { FINAL } \\
\text { DATA } \\
\text { AVAILABLE }\end{array}$ & 3365 & 431 & 431 & 431 & 3365 & 3365 & 3365 & 3365 & 3365 & 3365 & 347 & 347 & 347 & 367 & 292 & 292 & 292 & $\begin{array}{lll}292 & 3 \\
\end{array}$ & 34534 & 3453 & 34534 & 34519 & 185 & 166 & 166 & 1362 & 1362 & 1362 & 1362 & 1362 \\
\hline
\end{tabular}

WELL TEST DATA

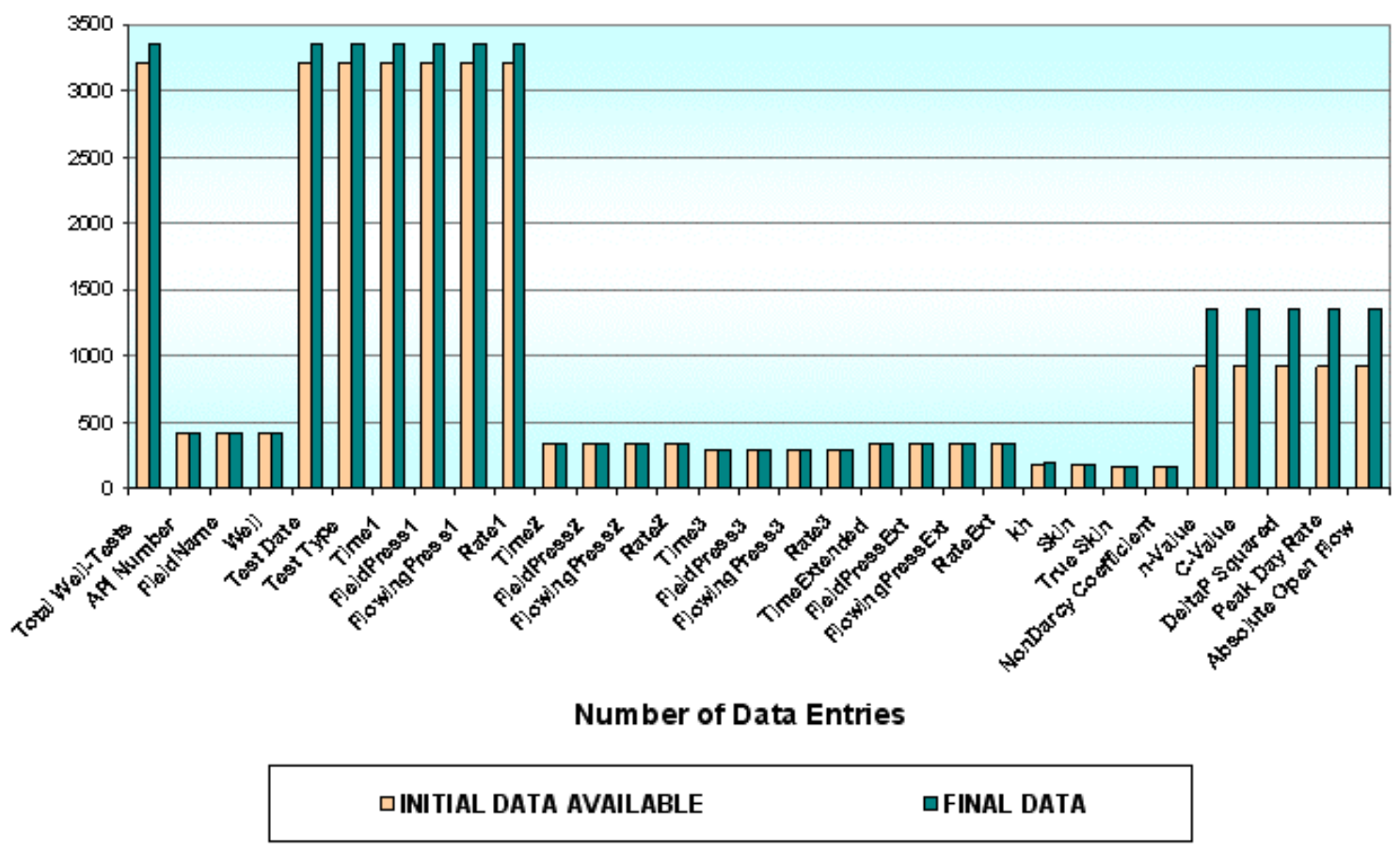

Figure 3.11 Data addition and refinement for Well-Test Data 


\subsection{Software Implementation}

After the database was prepared software was made to not only show all the data but also to add/edit well data in the database and choose the data that you want to look at, for a selected well. It also has a Well Test Analysis tool which calculates the well deliverability parameters like n, C, Peak Day rate \& Absolute Open Flow and perform LIT analysis. Candidate Selection module of this software incorporates the Neural Net and Genetic Optimization tool. Screen shot of the software developed for this study is shown below:

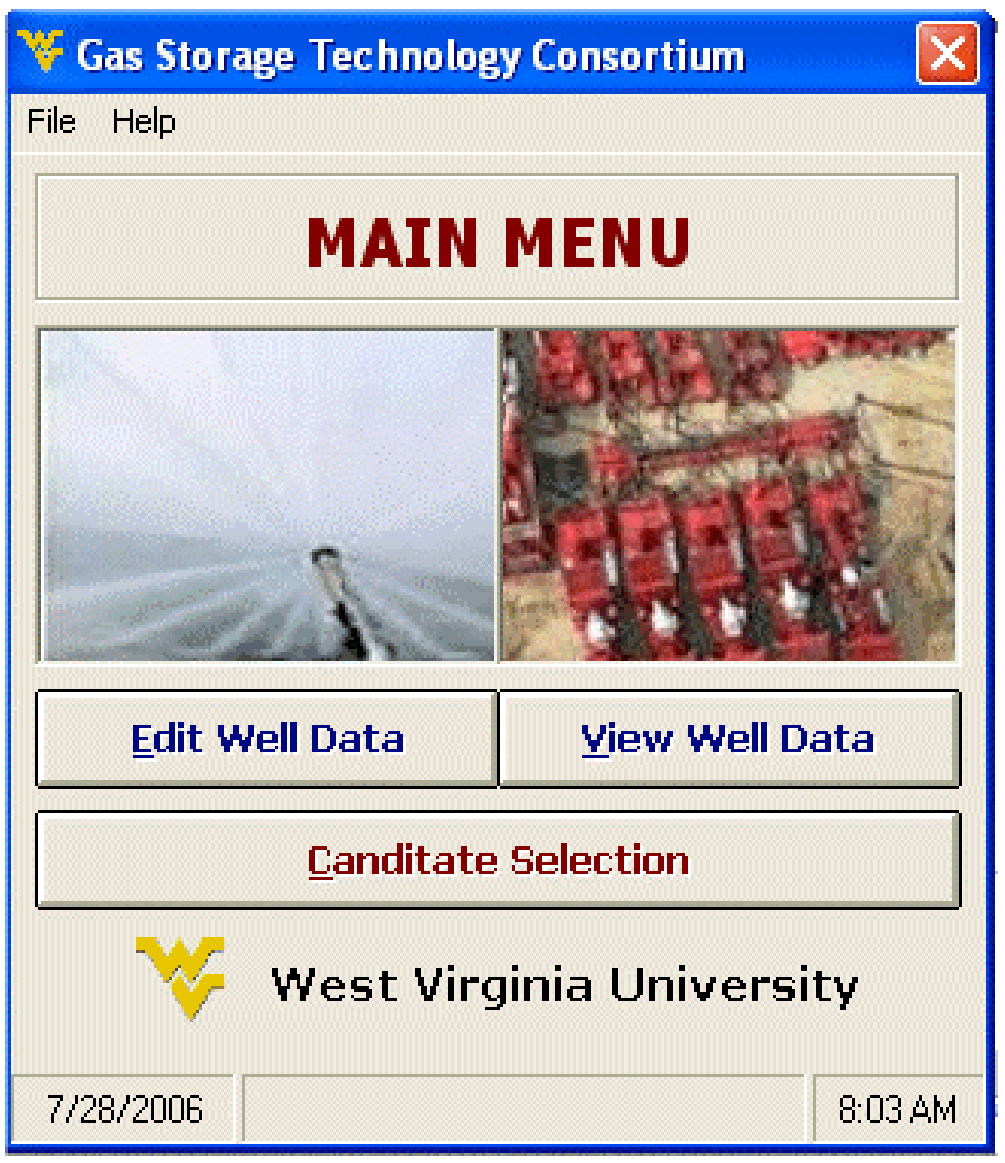

Figure 3.12 Main Screen of software 


\subsubsection{Well-Test Analysis module}

Simplified Analysis: In this part of software the user can perform a simplified well-test analysis. The user selects the points to be drawn on the log-log plot of Flow rate vs. $\Delta^{2} \mathrm{P}$ and draws the line that passes through these points. The slope of the line is calculated by formula: $\frac{1}{n}=\frac{\log \left(\bar{p}^{2}-{p_{w f}}^{2}\right)_{2}-\log \left(\bar{p}^{2}-p_{w f}{ }^{2}\right)_{1}}{\log q_{2}-\log q_{1}}$ And $C$ from the formula: $C=\frac{q_{g}}{\left(\bar{p}^{2}-p_{w f}^{2}\right)^{n}}$ with $A O F=C\left(\bar{p}^{2}-0^{2}\right)^{n} \&$ PDRate $=(C \times 250,000)^{n}$. The values calculated can be saved in the database. Figure 3.13 shows the screen shot of one such calculation done between $6^{\text {th }}$ and $7^{\text {th }}$ well-test.

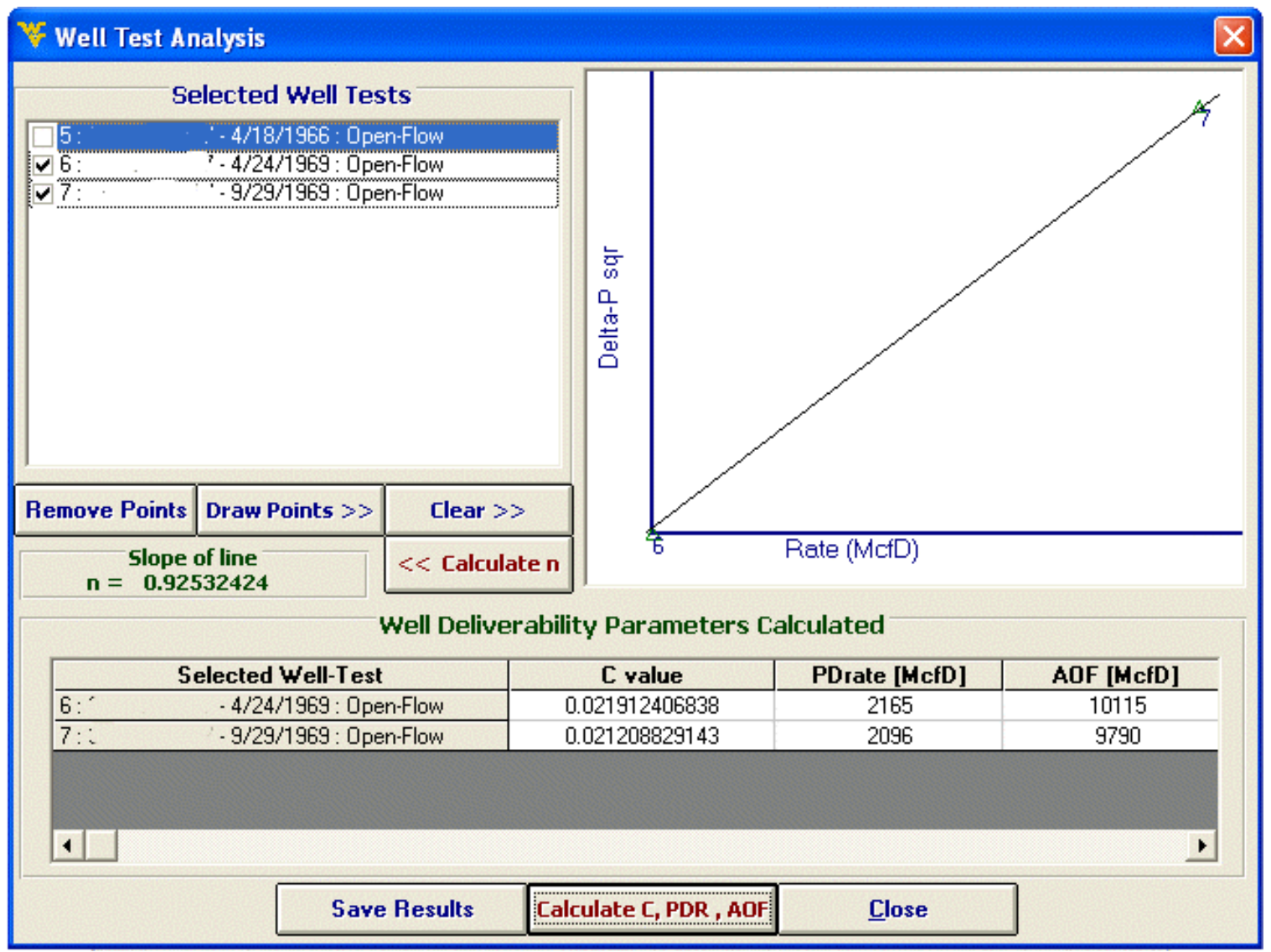

Figure 3.13 Simplified analysis done in the software 
LIT Analysis: The data in the well-test analysis had very few skin calculations So this tool is useful if the permeability value is known for a well. With the known permeability assuming it be same and selecting well-tests that were performed near (approx 2 years) to one and another so that our assumption of same skin for LIT remains valid. Then using LIT method as discussed earlier we interpreted skin values for different well tests as $S=\frac{1}{0.869}\left[a_{t} \times 10^{6} \frac{k h}{1.632 \times 10^{6} T}-\log \left(\frac{k t}{\phi \mu_{i} c_{i} r_{w}{ }^{2}}\right)+3.23\right]$. Figure 3.14 shows one of the LIT analysis done on well-test \# 8 of a well in the gas storage field.

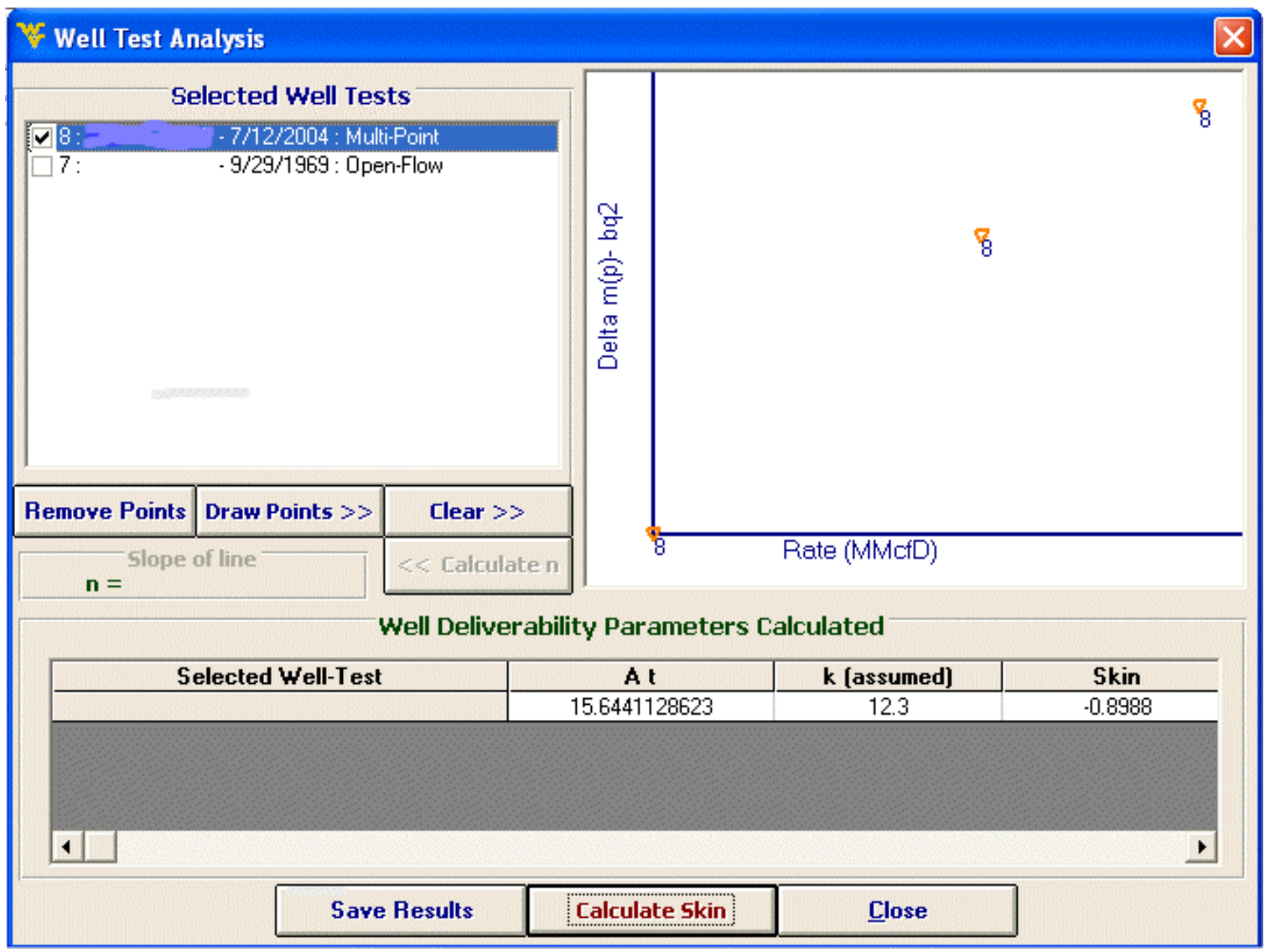

Figure 3.14 LIT analysis done in the software 


\subsubsection{Neural Network as Skin Predictor}

The Neural nets are very powerful in predicting non-linear relationships. As the relationship between skin and stimulation parameters is non-linear and very complicated thus neural nets are used which are very good at it. With skin values before and after the stimulation calculated and stimulation parameters known we can now use these valid stimulations to train the Neural Network to use it as a prediction tool. Intelligent Data Evaluation and Artificial Network IDEA ${ }^{\circledR}$ software by Intelligent Solutions Inc. was used to design the neural network. This software is very versatile in making different nets with different training algorithms. Generalized Regression Neural Net (GRNN) was used to train the neural net. The net had 11 inputs and 1 output as skin. The source of data for the neural net is given in Table 3.4.

\begin{tabular}{|c|c|c|}
\hline & Inputs & Source \\
\hline 1 & Lat & Database \\
\hline 2 & Long & Database \\
\hline 3 & Sum Fluids & $\begin{array}{r}\text { Sum of item } \\
5,6,7,8\end{array}$ \\
\hline 4 & Prior-kh & Database \\
\hline 5 & Water (bbls) & GA \\
\hline 6 & Acid (bbls) & $\mathrm{GA}$ \\
\hline 7 & Gel (bbls) & $\mathrm{GA}$ \\
\hline 8 & Foam (bbls) & $\mathrm{GA}$ \\
\hline 9 & N2(Mcf) & $\mathrm{GA}$ \\
\hline 10 & Sand Quantity (lbs) & $\mathrm{GA}$ \\
\hline 11 & $\begin{array}{c}\text { After-Test Type } \\
\text { 3- Multi-Point } \\
\text { 2- Single-Point } \\
\text { 1-Open-Flow }\end{array}$ & $\mathrm{GA}$ \\
\hline
\end{tabular}

Table 3.5 Neural Network Inputs and their source 
Out of the 78 valid stimulations available, the Neural net was trained on 60 data items while 14 were used as calibration data while 4 as verification data. The Neural network showed very good results for all three types of data. The screen shot taken from the IDEA software for training of the neural net is shown in Figure 3.15. .

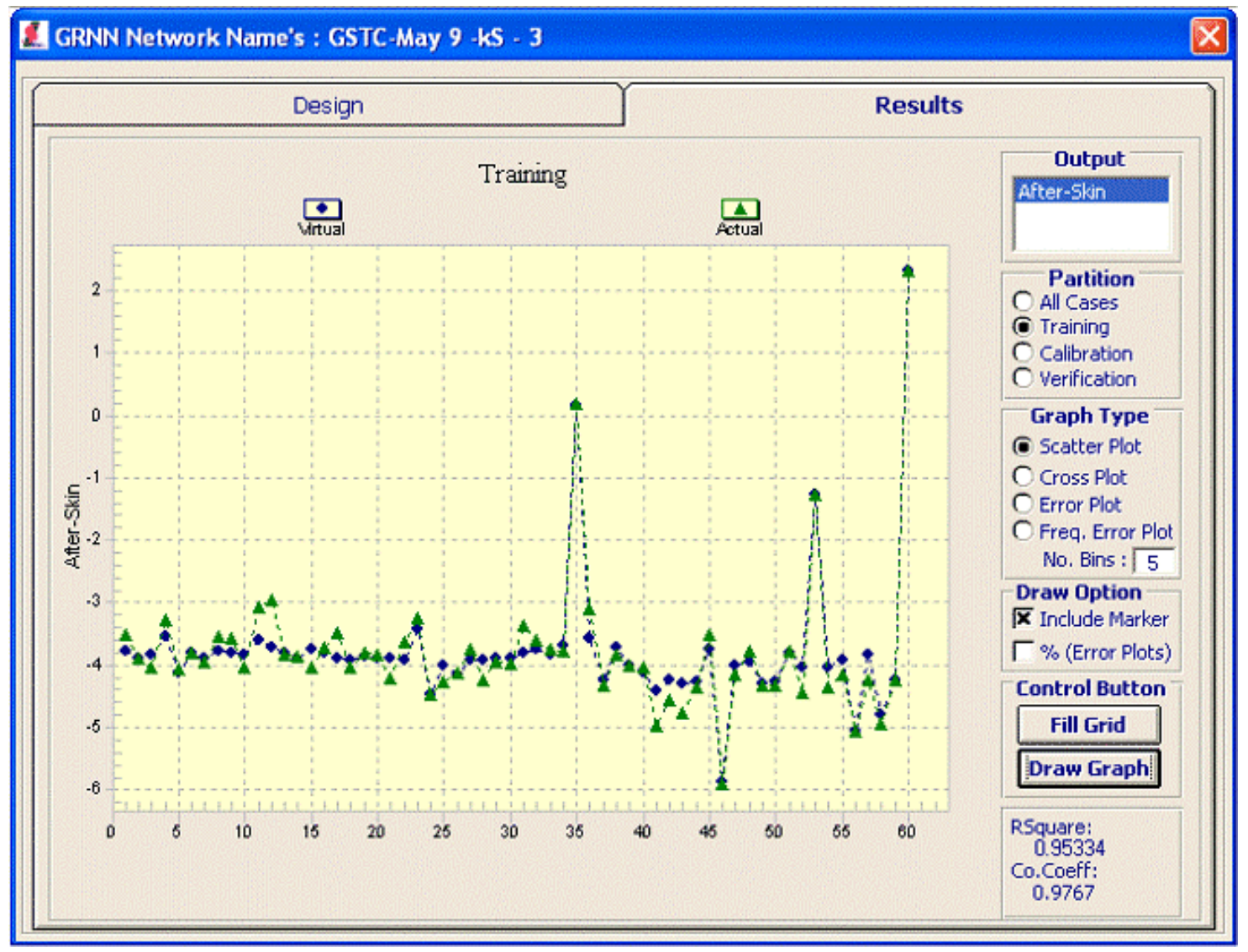

Figure 3.15 Accuracy of training data for the Neural net

The calibration and verification of the Neural net is shown in Figure 3.16 and Figure 3.17 respectively. After the accurate results of this GRNN the software was updated to use the GRNN generated files to be used in the Genetic algorithm. 


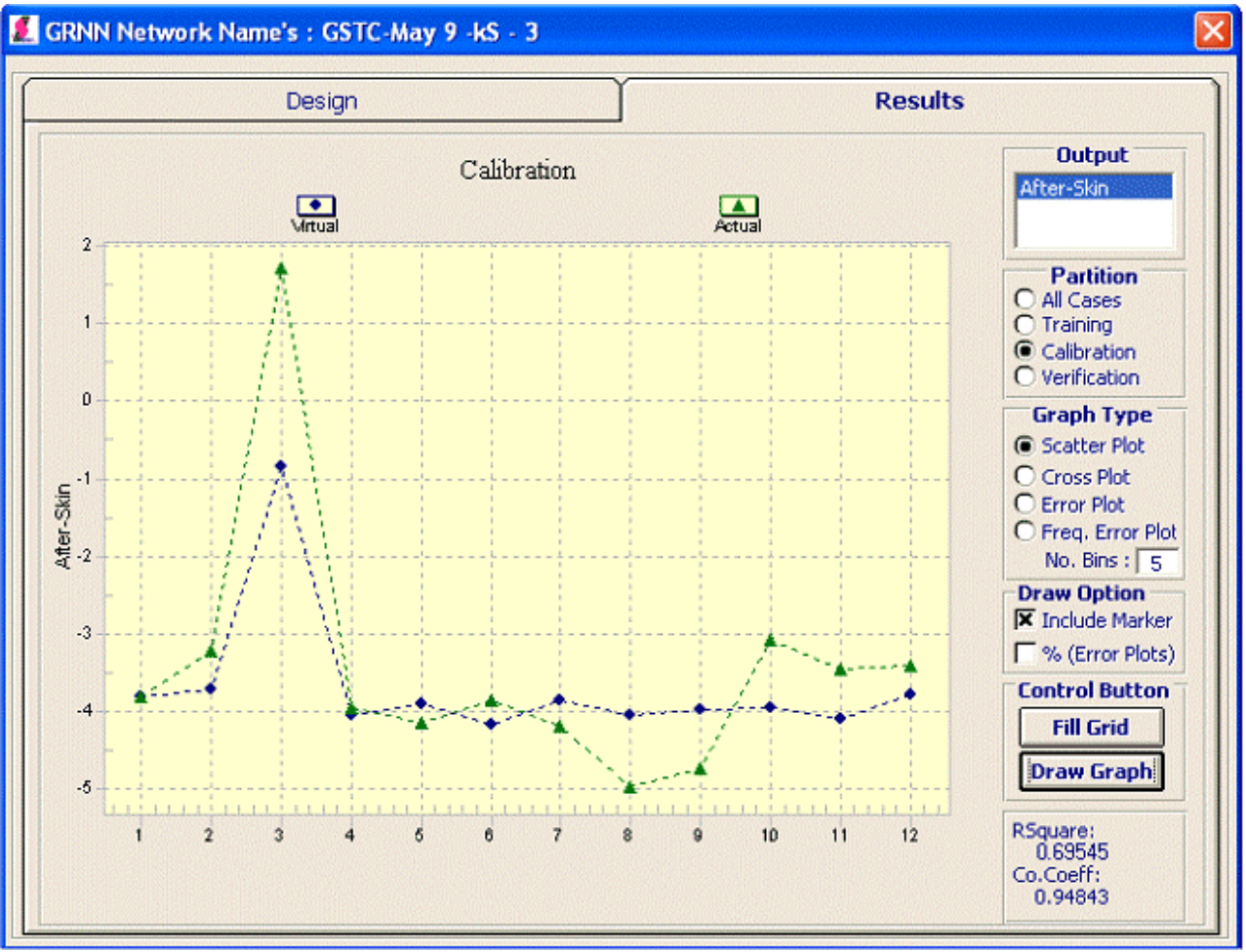

Figure 3.16 Accuracy of calibration data for the Neural net

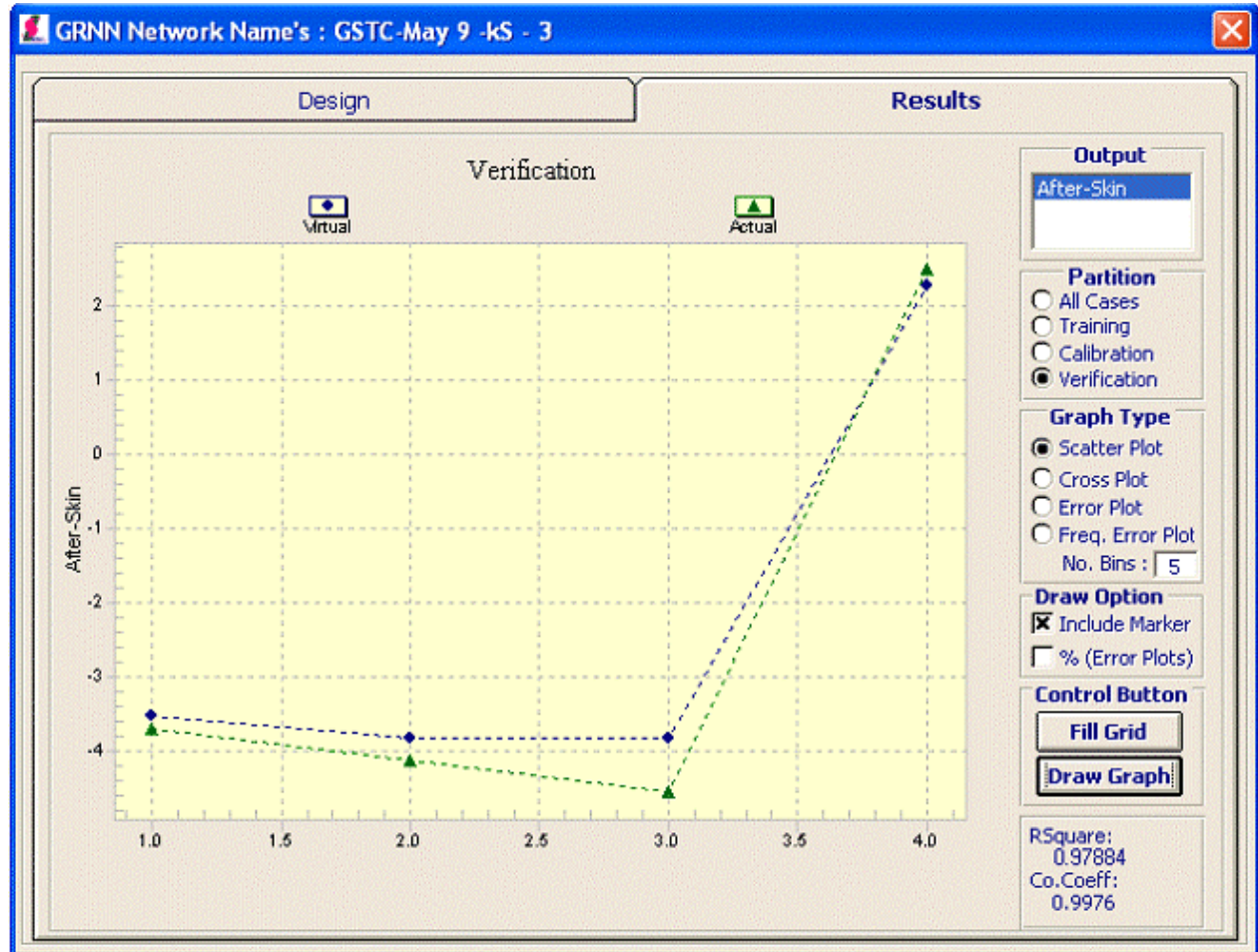

Figure 3.17 Accuracy of verification data for the Neural net 


\subsubsection{Optimization of Stimulations}

Genetic Algorithm was written to optimize the stimulation parameters used in the neural net. Out of the 11 input parameters 7 can be varied to obtain optimum skin. The range of these variables was calculated and accuracy desired was determined to design the length of the chromosome of Genetic Algorithm (GA) that will be required. The calculation is shown in the table. for the chromosome length if all the parameters are selected.

\begin{tabular}{|c|c|c|c|c|c|c|c|c|c|c|}
\hline & $\begin{array}{l}\text { GA Inp ut } \\
\text { Parameter }\end{array}$ & Min & $\operatorname{Max}$ & Range & $\begin{array}{l}\text { Accuracy } \\
\text { Required }\end{array}$ & $\begin{array}{l}\text { Accuracy } \\
\text { Sixe }\end{array}$ & $\begin{array}{l}\text { Range } \\
\text { Size }\end{array}$ & $\begin{array}{l}\text { Chromosome } \\
\text { Size }\end{array}$ & $\begin{array}{l}\text { Min Byte } \\
\text { size }\end{array}$ & $\begin{array}{l}\text { Max Byte } \\
\text { size }\end{array}$ \\
\hline 1 & Water (bbls) & 0 & 345 & 345 & 1 & 1 & 345 & 9 & $2^{\wedge 8}=256$ & $2^{n 9}=512$ \\
\hline 2 & Acil (bb k) & 0 & 11.9 & 11.9 & 0.01 & 100 & 1190 & 11 & $\begin{array}{l}2^{\wedge} 10 \\
=1024\end{array}$ & $2^{\wedge} 11=2048$ \\
\hline 3 & Gel (bbls) & 0 & 535 & 535 & 1 & 1 & 535 & 10 & $2^{N 9}=512$ & $2^{\wedge} 10=1024$ \\
\hline 4 & Foam (bb b) & 0 & 1.7 & 1.7 & 0.01 & 100 & 170 & 8 & $2^{\sim} 7=128$ & $2^{n} 8=256$ \\
\hline 5 & $\mathrm{~N} 2(\mathrm{Mef})$ & 0 & 368 & 368 & 1 & 1 & 368 & 9 & $2^{\wedge} 8=256$ & $2^{n 9}=512$ \\
\hline 6 & Sand Quantity (hs) & 0 & 30000 & 30000 & 100 & 0.01 & 300 & 9 & $2^{\wedge} 8=256$ & $2^{m 9}=512$ \\
\hline 7 & $\begin{array}{l}\text { After-Test Type } \\
\text { 3- Multi-Po int } \\
\text { 2- Single-Point } \\
\text { 1- Open-Fbw }\end{array}$ & 1 & 3 & 3 & 1 & 1 & 3 & 2 & $2^{\wedge} 1=2$ & $2^{\wedge} 2=4$ \\
\hline
\end{tabular}

Table 3.6 Calculations to determine the length of chromosome

The length of chromosome came out to be $9+11+10+8+9+9+2=58$.

The GA characteristics that were used are shown in Table . These were the best but can be changed as desired to suit other neural nets in the future.

\section{GA CHARACTERISTICS}

Crossover rate

Mutation rate

Population size

No of Generations

Next Generation criteria

Crossover criteria

\section{VALUE}

$60 \%$

$10 \%$

500

10

Top $30 \%$ ranked from previous generation

Top $25 \%$ has $75 \%$ chance of Crossover

Table 3.7 GA characteristics 
There are two optimization methods made available in this software. One is optimization just based on skin and other based on both skin and cost. The optimization objective function is calculated using the following formula and GA minimizes this optimization objective function.

OptimizationObjective Function $=\frac{\text { Skin }-S k i n_{\min }}{\text { Skin }_{\max }-S k i n_{\min }} \times$ Skin weight $+\frac{\text { Cost }^{- \text {Cost }_{\min }}}{\text { Cost }_{\max }-\text { Cost }_{\min }} \times$ Cost weight

Software compatibility and variability: In the software user has been given many options to accommodate the particular situation that he has and data availability if different from the data that we have used to verify the results from this software.

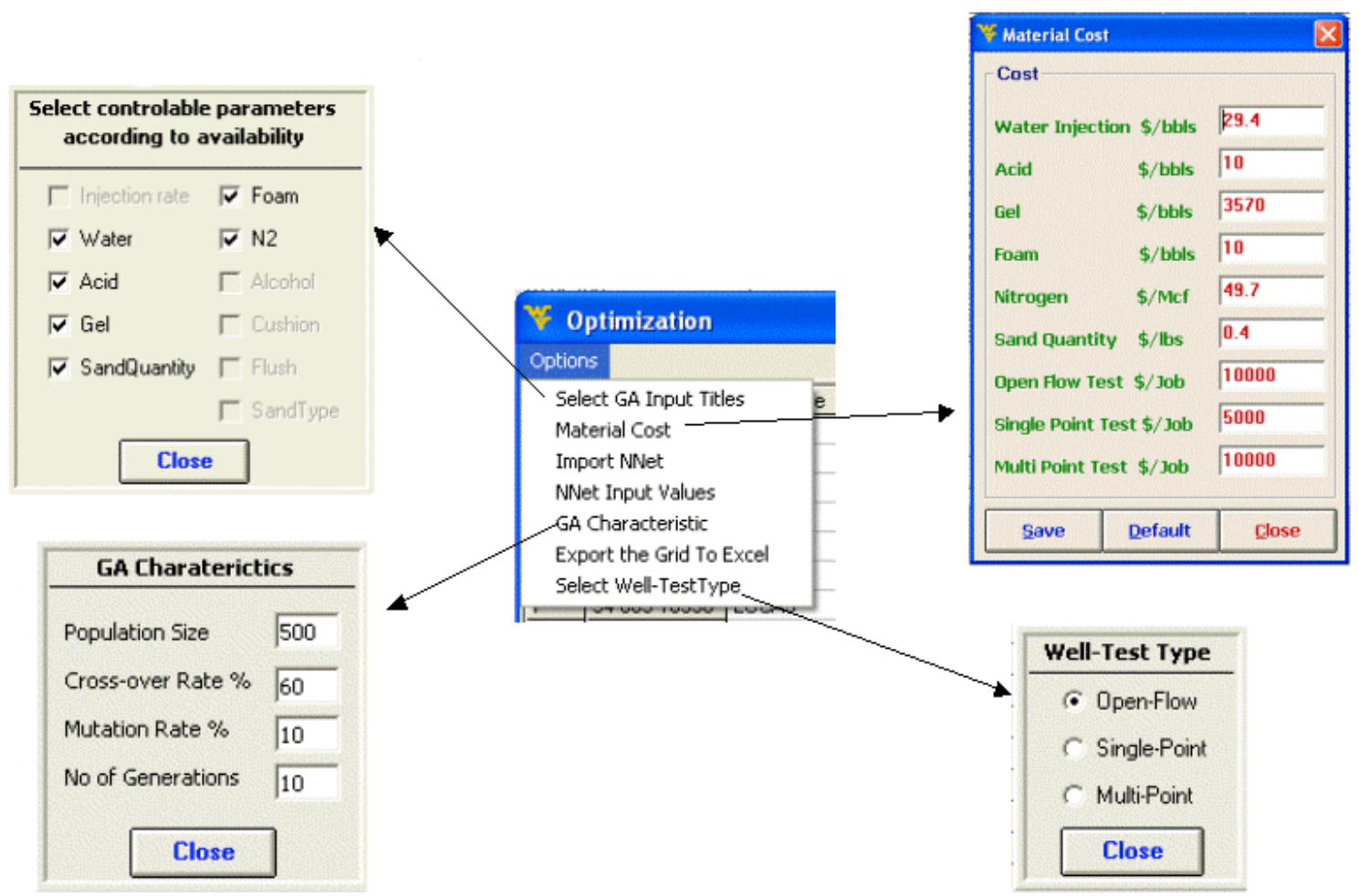

Figure 3.18 Different options in the software that make it versatile

One of such variability introduced is that the software can use any other neural net if it is required. The option menu of the optimization screen has the option to import any other neural network. Plus there is an option to select the available controllable parameters for 
the GA. For example if the user does not want to use or does not have foam and nitrogen then he can unselect them as shown in Figure 3.18. The length of GA will change according to the selection.

As the Neural Net has 'Well-Test Type' as its input so the 'Select Well-Test Type' menu option gives the user an option to choose the test the user wants the neural net to interpret the well-test. With changing price of hydro-carbons the petroleum industry is going through fluctuating material cost. The stimulation material prices change frequently and are a factor of demand and supply in that region. The software has the option to change the price of the stimulation material before applying the GA to the available data. 


\section{Results and Discussion}

The software was tested on the available data and due to the variability of parameters that can be changed for optimization for intelligent candidate selection we tried to come up with the best combination of GA characteristics that are shown in Table 3.6 and Neural Network that has been discussed in previous chapter, but we may like to add that it might not be the best combination but surely one of the best for the data available to us.. We did analysis on two runs. One in which skin was given $100 \%$ weight age in the optimization meaning that we did not cared about the cost but only the skin. Even if several thousand dollars have to be spend to have a slight increase in skin and the other in which skin was given $50 \%$ weight age and rest $50 \%$ to cost in the final result.

\begin{tabular}{|ccc|}
\hline RUN & RUN REFERED IN & RUN DESCRIPTION \\
NUMBER & FIGURES AS & \\
RUN -1 & Skin $100-\operatorname{cost} 0$ & Skin weight age is $100 \%$ - Cost weight age is $0 \%$ \\
RUN - 2 & Skin $50-$ cost 50 & Skin weight age is $50 \%$ - Cost weight age is $50 \%$ \\
\hline
\end{tabular}

Table 4.1 Description of the two runs done for analysis

The Summary of results for these runs is shown in Table 4.3 while Figure 4.1, Figure 4.2, show the comparison between the actual and predicted optimized stimulations results by the two runs: 


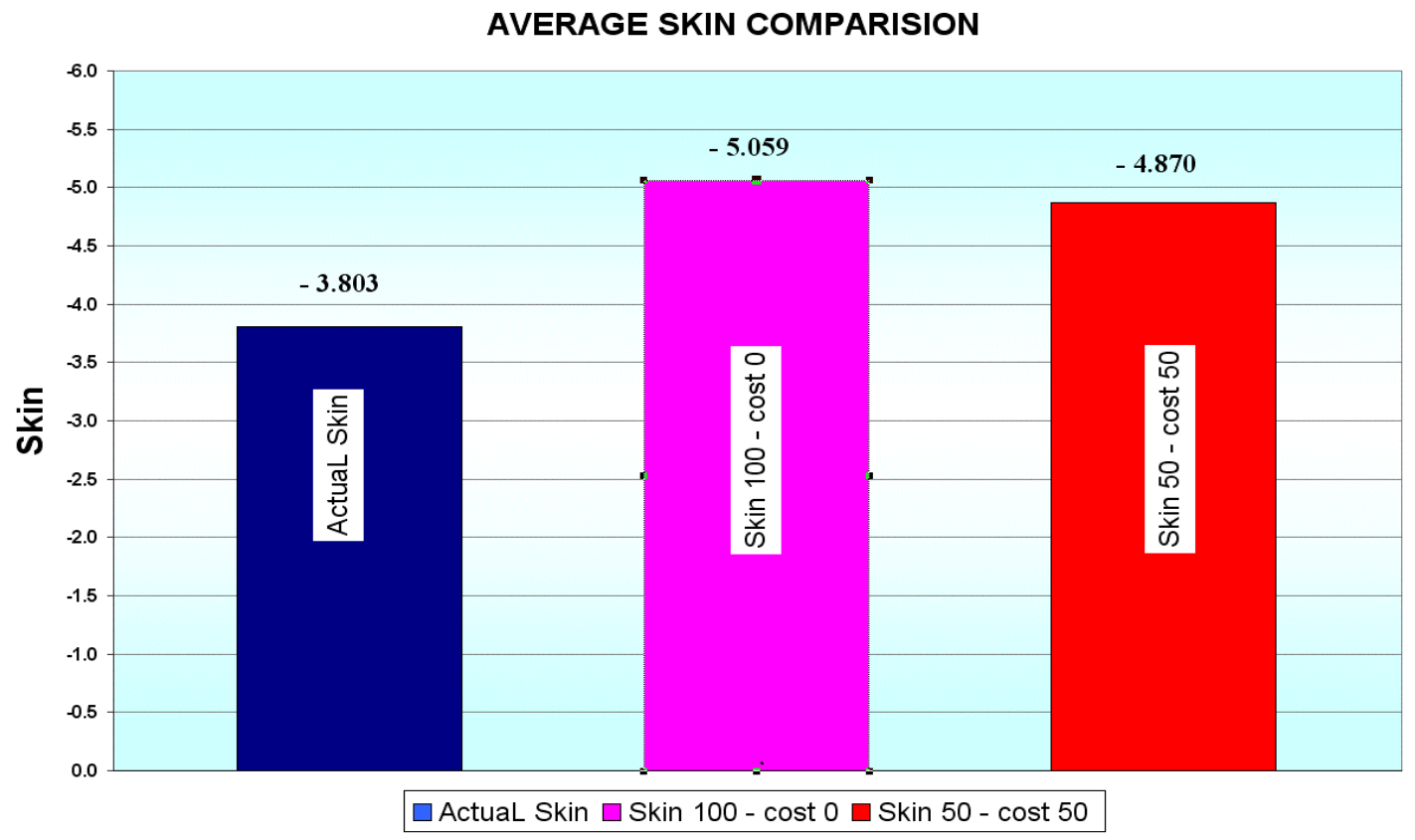

Figure 4.1 Comparison of Average skin after the stimulations

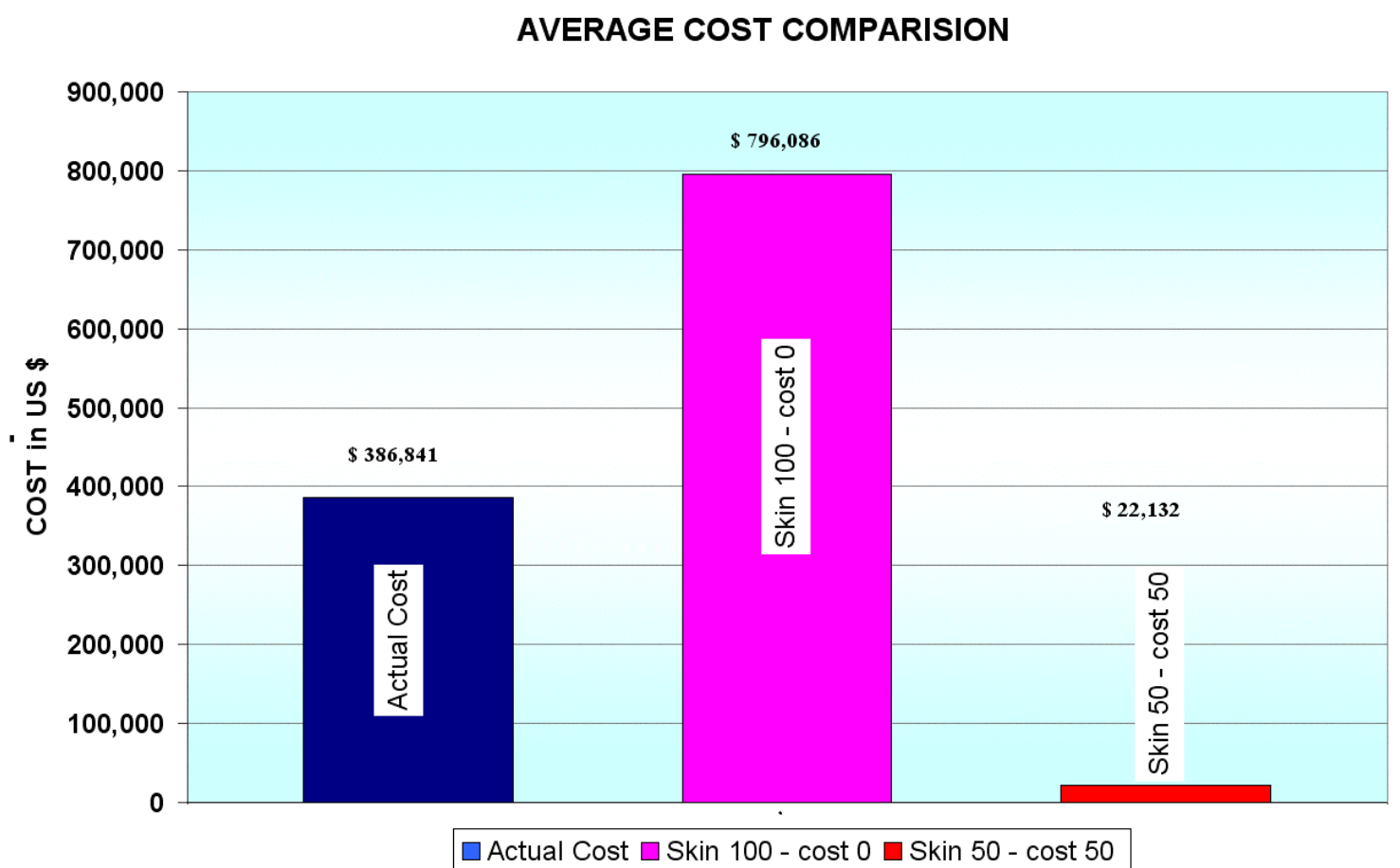

Figure 4.2 Comparison of average cost per stimulation 


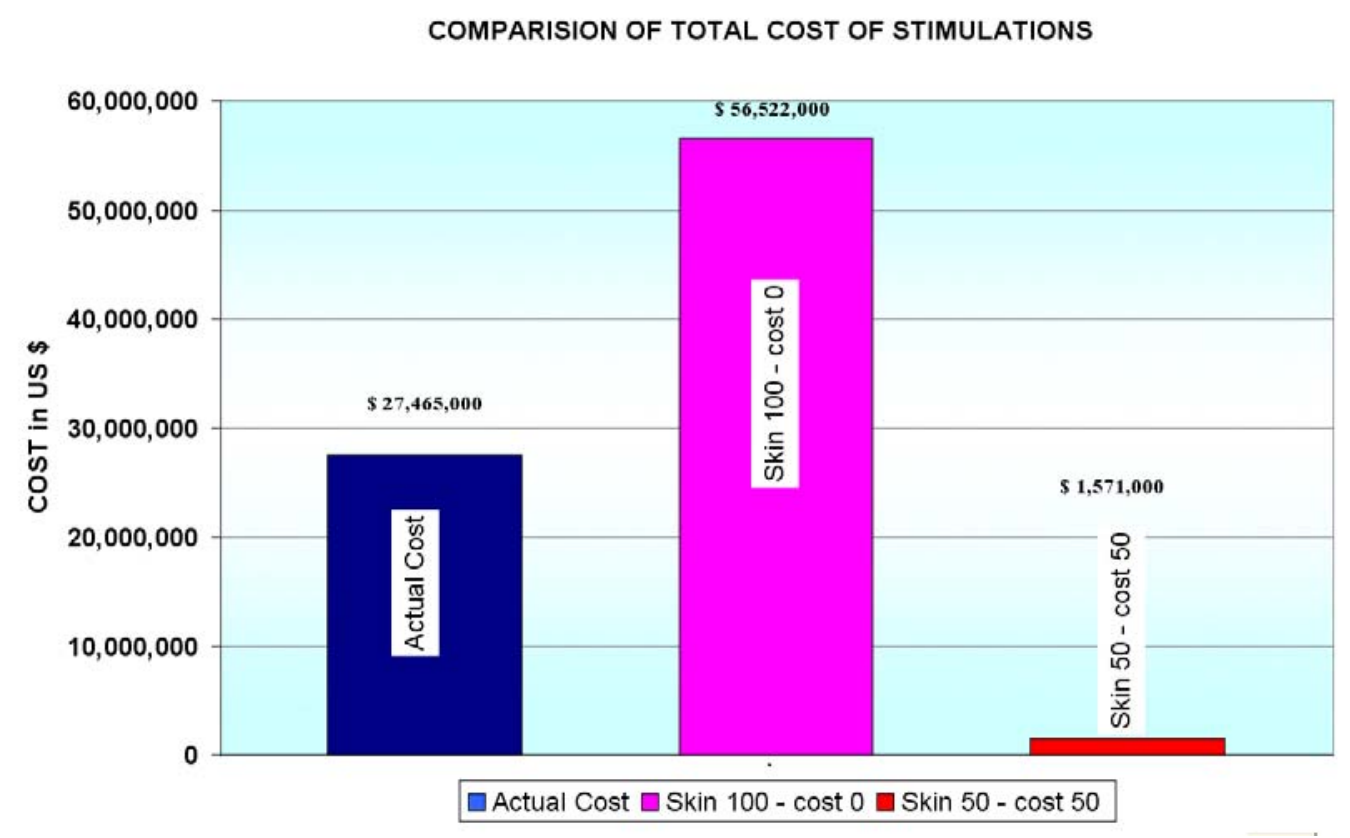

Figure 4.3 Comparison of Total cost of Stimulations

From Table 4.3 it is clear that the skin - after optimization (GA Skin) in run \#1 for skin $100-\operatorname{cost} 0$, is always less than the skin prior stimulation (prior Skin). Only in one case for well \# 61 it came very close to the actual skin, indicating that the stimulation already done on the well \# 61 was excellent resulting in maximum improvement in skin otherwise all stimulations to some degree have chance of improvement. The stimulation slurry predicted in run \# 2 for skin 50 - cost 50 was very similar to the one used except that the optimization in order to reduce cost compromised the skin from -5.91 to -5.723 instead.

\begin{tabular}{c|c|c|c|c|c|c|c|c|c|} 
& Water & Acid & Gel & Foam & II2 & SumFluids & SandQuantity & After-Test Type & GA After-Skin \\
\hline Actual & 146.51 & 11.69 & 533.43 & 0.02 & 366.56 & 691.65 & 28884.54 & 1 & -5.910 \\
\hline Skin 50 - cost 50 & 298.41 & 11.12 & 0.52 & 0.52 & 218.21 & 310.57 & 9041.1 & 1 & -5.723 \\
\hline
\end{tabular}

Table 4.2 Comparison of actual \& predicted skin for Well \# 61

Figure 4.1 shows that the GA optimized the skin and shows that there is potential in the wells to be stimulated again. Figure 4.2 and Figure 4.3 show that the GA has optimized the stimulation cost and the user can stimulate the wells economically. Table 4.3 lists all the results for skin weight age of $100 \%$. The wells can be ranked for any weight age using the software, thus candidate selection can be made based on their rank and skin weight age. 


\begin{tabular}{|c|c|c|c|c|}
\hline \multicolumn{5}{|c|}{ Skin $100-\cos 0$} \\
\hline Rank & Yifll Ho. & GA After-Stin & Prior-Stiv & Del Stie \\
\hline 1 & 63 & -5.476 & 1.410 & -6.886 \\
\hline 2 & 34 & -5.046 & -2.179 & -2.867 \\
\hline 3 & 15 & -5.636 & -3.062 & -2.574 \\
\hline 4 & 42 & -5.049 & -2.828 & -2.221 \\
\hline 5 & 64 & -5.883 & -3.776 & -2.107 \\
\hline 6 & 1 & -5.033 & -2.980 & -2.053 \\
\hline 7 & 60 & -5.898 & -3.852 & -2.046 \\
\hline 8 & 68 & -5.048 & -3.038 & -2.010 \\
\hline 9 & 78 & -5.047 & -3.117 & -1.930 \\
\hline 10 & 66 & -5.529 & -3.605 & -1.924 \\
\hline 11 & 23 & -5.037 & -3.197 & -1.840 \\
\hline 12 & 65 & -5.804 & -3.974 & -1.830 \\
\hline 13 & 18 & -5.880 & -4.064 & -1.816 \\
\hline 14 & 4 & -4.461 & -2.661 & -1.801 \\
\hline 15 & 58 & -5.001 & -3.290 & -1.711 \\
\hline 16 & 19 & -5.019 & -3.338 & -1.681 \\
\hline 17 & 13 & -5.049 & -3.395 & -1.654 \\
\hline 18 & 36 & -5.045 & -3.419 & -1.626 \\
\hline 19 & 40 & -5.012 & -3.399 & -1.613 \\
\hline 20 & 69 & -5.049 & -3.449 & -1.600 \\
\hline 21 & 24 & -4.844 & -3.274 & -1.570 \\
\hline 22 & 22 & -5.046 & -3.519 & -1.527 \\
\hline 23 & 28 & -5.023 & -3.509 & -1.514 \\
\hline 24 & 12 & -5.050 & -3.547 & -1.503 \\
\hline 25 & 7 & -5.043 & -3.553 & -1.490 \\
\hline 26 & 16 & -5.046 & -3.560 & -1.487 \\
\hline 27 & 37 & -4.917 & -3.518 & -1.399 \\
\hline 28 & 3 & -5.048 & -3.661 & -1.387 \\
\hline 29 & 41 & -5.045 & -3.661 & -1.384 \\
\hline 30 & 38 & -4.462 & -3.083 & -1.379 \\
\hline 31 & 39 & -4.754 & -3.416 & -1.338 \\
\hline 32 & 5 & -4.899 & -3.616 & -1.283 \\
\hline 33 & 44 & -4.884 & -3.618 & -1.266 \\
\hline 34 & 20 & -5.044 & -3.793 & -1.251 \\
\hline 35 & 51 & -5.047 & -3.837 & -1.210 \\
\hline 36 & 46 & -4.971 & -3.762 & -1.209 \\
\hline 37 & 48 & -4.962 & -3.791 & -1.171 \\
\hline 38 & 17 & -5.032 & -3.899 & -1.133 \\
\hline 39 & 49 & -4.895 & -3.768 & -1.127 \\
\hline 40 & 26 & -5.042 & -3.921 & -1.121 \\
\hline 41 & 2 & -4.968 & -3.858 & -1.110 \\
\hline 42 & 30 & -5.046 & -3.938 & -1.108 \\
\hline 43 & $\pi 1$ & -5.050 & -3.962 & -1.088 \\
\hline 44 & 29 & -5.044 & -3.967 & -1.077 \\
\hline 45 & 55 & -5.046 & -4.001 & -1.045 \\
\hline 46 & 21 & -5.027 & -3.990 & -1.038 \\
\hline 47 & 10 & -5.041 & -4.016 & -1.025 \\
\hline 48 & 14 & -5.041 & -4.027 & -1.014 \\
\hline 49 & 31 & -5.044 & -4.045 & -0.999 \\
\hline 50 & 74 & -5.049 & -4.058 & -0.991 \\
\hline 51 & 6 & -5.049 & -4.076 & -0.973 \\
\hline 52 & 32 & -5.046 & -4.095 & -0.951 \\
\hline 53 & 27 & -5.023 & -4.094 & -0.929 \\
\hline 54 & 57 & -5.036 & -4.118 & -0.918 \\
\hline 55 & 9 & -5.774 & -4.923 & -0.851 \\
\hline 56 & 54 & -5.047 & -4.214 & -0.833 \\
\hline 57 & 50 & -4.976 & -4.144 & -0.832 \\
\hline 58 & 70 & -5.049 & -4.241 & -0.808 \\
\hline 59 & 76 & -5.050 & -4.256 & -0.794 \\
\hline 60 & 67 & -5.047 & -4.265 & -0.782 \\
\hline 61 & 11 & -5.050 & -4.270 & -0.780 \\
\hline 62 & 25 & -4.982 & -4.212 & -0.770 \\
\hline 63 & $\pi 7$ & -5.513 & -4.745 & -0.768 \\
\hline 64 & 45 & -4.961 & -4.194 & -0.767 \\
\hline 65 & 33 & -4.842 & -4.084 & -0.758 \\
\hline 66 & 59 & -5.048 & -4.301 & -0.747 \\
\hline 67 & 43 & -5.049 & -4.366 & -0.683 \\
\hline 68 & 35 & -5.042 & -4.405 & -0.637 \\
\hline 69 & 73 & -5.910 & -5.278 & -0.632 \\
\hline 70 & 8 & -4.835 & -4.283 & -0.552 \\
\hline 71 & 52 & -5.050 & -4.513 & -0.537 \\
\hline 72 & 56 & -5.021 & -4.533 & -0.488 \\
\hline 73 & 72 & -5.050 & -4.589 & -0.461 \\
\hline 74 & 75 & -5.050 & -4.650 & -0.400 \\
\hline 75 & 47 & -5.028 & -4.785 & -0.243 \\
\hline 76 & 53 & -5.047 & -4.983 & -0.064 \\
\hline$\pi 7$ & 62 & -5.049 & -5.006 & -0.044 \\
\hline 78 & 61 & -5.910 & -5.910 & 0.000 \\
\hline
\end{tabular}

Table 4.3 Results of Optimized Skin and cost 


\section{Conclusions}

The main aim of the study was to find the re-stimulation candidate wells with the given data without trying to spend thousands of dollars on well-test and gas reservoir simulators. Detailed analysis of well-tests performed on the storage field was done and intelligent tools like Neural networks to predict the Skin and Genetic Algorithms to optimize the stimulation were used to select the best stimulations for a well. The following conclusions can be drawn from this research:

1 The Artificial Intelligence Tool can predict Skin with high confidence.

2 The Portfolio Management for re-stimulation candidate well selection with the software made during this research study can be very cost effective.

3 This software is the first successful attempt to combine Data editing, WellTest analysis and Artificial Intelligence in one software package.

\subsection{Future Work}

The future work recommended is related to the improvement in the software so that it can make a simple reservoir model and simulator that can match the pressure profile of the well-test and predict permeability. With the reservoir characterization module this software's capability can be greatly enhanced. 


\section{REFERENCES}

[1] Goldberg, D.E., Genetic Algorithms in Search, Optimization and Machine Learning, Addison Wesley, Reading, MA, 1989.

[2] Zbigniew Michalewicz, Genetic Algorithms + data Structures $=$ Evolution programs, Springer-Verlag, Berlin Heidelberg, 1992.

[3] Back, T., Hoffmeister, F., Extended Selection Mechanisms in Genetics Algorithms, pp.2-9, Morgan Kaufmann publishers, Los Altos, CA, 1991.

[4] http://www-dept.cs.ucl.ac.uk/

[5] http://cs.felk.cvut.cz/ xobitko/ga/index.html

[6] http://www.nd.com

[7] http://en.wikipedia.org/

[8] Laurene Fausett, Fundamentals Of Neural Networks, Prentice Hall, 1994

[9] McCulloch, W.S., \& W.Pitts., (1943). "A Logical Calculus of the Ideas Immanent in Nervous Activity”. Bulleten of Mathematical Biophysics, 5:115-133, Reprinted in Anderson \& Rosenfeld pp. 18-28, [1988],

[10] Kashy Aminian,Petroleum and Natural Gas Engineering 471 v.1, Teacher's Press, 2005

[11] Energy Resources Conservation Board, Theory and Practice of the Testing of Gas Wells, Third edition, Canada, 1975.

[12] NaturalGas.org

[13] Amanat U. Chaudry, Gas Well Testing handbook, Elsevier Science, 2003

[14] Donald Katz, Robert Lee, Natural gas Engineering, McGraw-Hill, 1990

[15] John Ely, Stimulation Treatment Handbook, Pennwell books, 1985

[16] Energy Resources Conservation Board, Theory and Practice of the Testing of Gas Wells, Third Edition 1975.

[17] Shahab Mohaghegh, Scott Reeves, David Hill, Development of an Intelligent System Approach for Restimulation Candidate Selection, SPE 59767, 2000 
[18] Shahab Mohaghegh, Popa, A., Gaskari, R., Ameri, Identification of Successful Practices in Hydraulic Fracturing Using Intelligent Data Mining Tools; Application to the Codell Formation in the DJ-Basin, SPE 77597, 2002

[19] Shahab Mohaghegh.D, Gaskari, Analysis of Best Hydraulic Fracturing Practices in the Golden Trend Fields of Oklahoma, SPE 95942, 2005 
APPENDIX (USER MANUAL)

\section{GAS STORAGE TECHNOLOGY CONSORTIUM SOFTWARE}

\section{USER MANUAL}

West Virginia University

2006 
This document will introduce you to the latest software application for gas storage field data entry, well-test analysis and stimulation optimization. The software application is called 'Intelligent Storage'.

From this software user can edit the data and retrieve the data for different wells according to location or stimulation year. This software can do analysis for typical gas storage well-tests like well-deliverability parameters and well-bore skin. One of the capabilities of this software is that if we get more data or data from different field, and train different Neural Networks, we can still use this software to import and apply Genetic optimization to the well stimulations. It has been developed in a modular form so that more modules can be added as and when required to make it more robust.

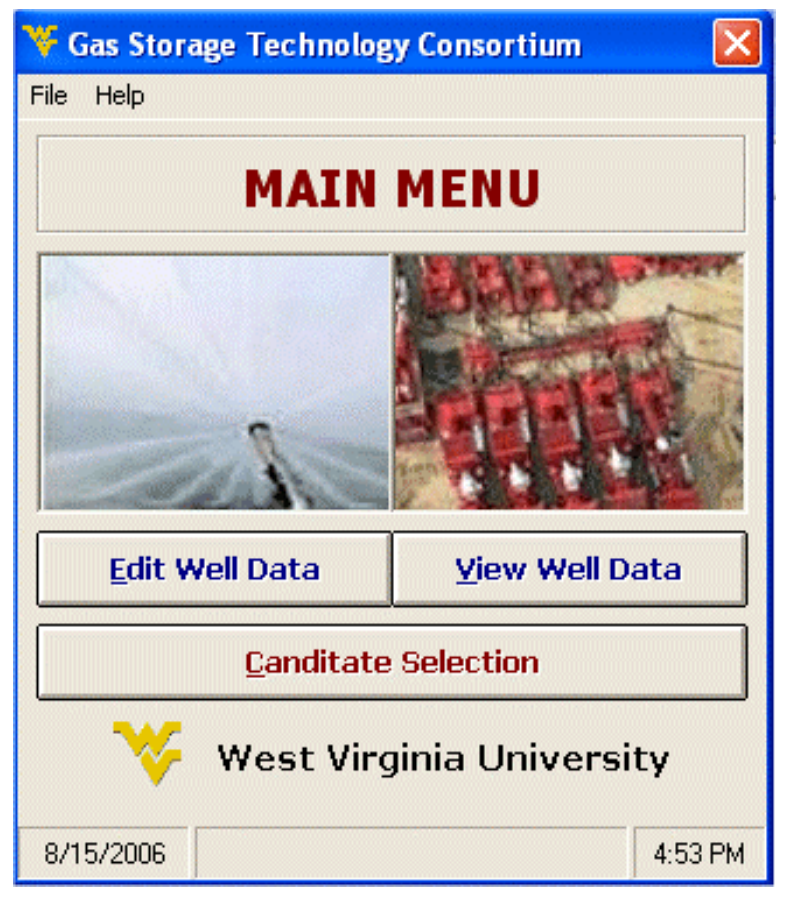


This software is very simple to use and follows three main steps which are also indicative of the first three buttons that you will see when you start the software. First you Add/Edit the data that you want to use, this includes performing Well-test analysis, Secondly you can select any well according to some specific criteria and look at its data, and in last, perform candidate selection. All of these steps will be explained in detail latter.

When you first start the software the interface is the one shown in the picture in next page. All the operations are controlled by Main Menu screen. The software organization is very clear from the interface. It is a step-by-step approach, which makes it really easy for the user to follow the software.

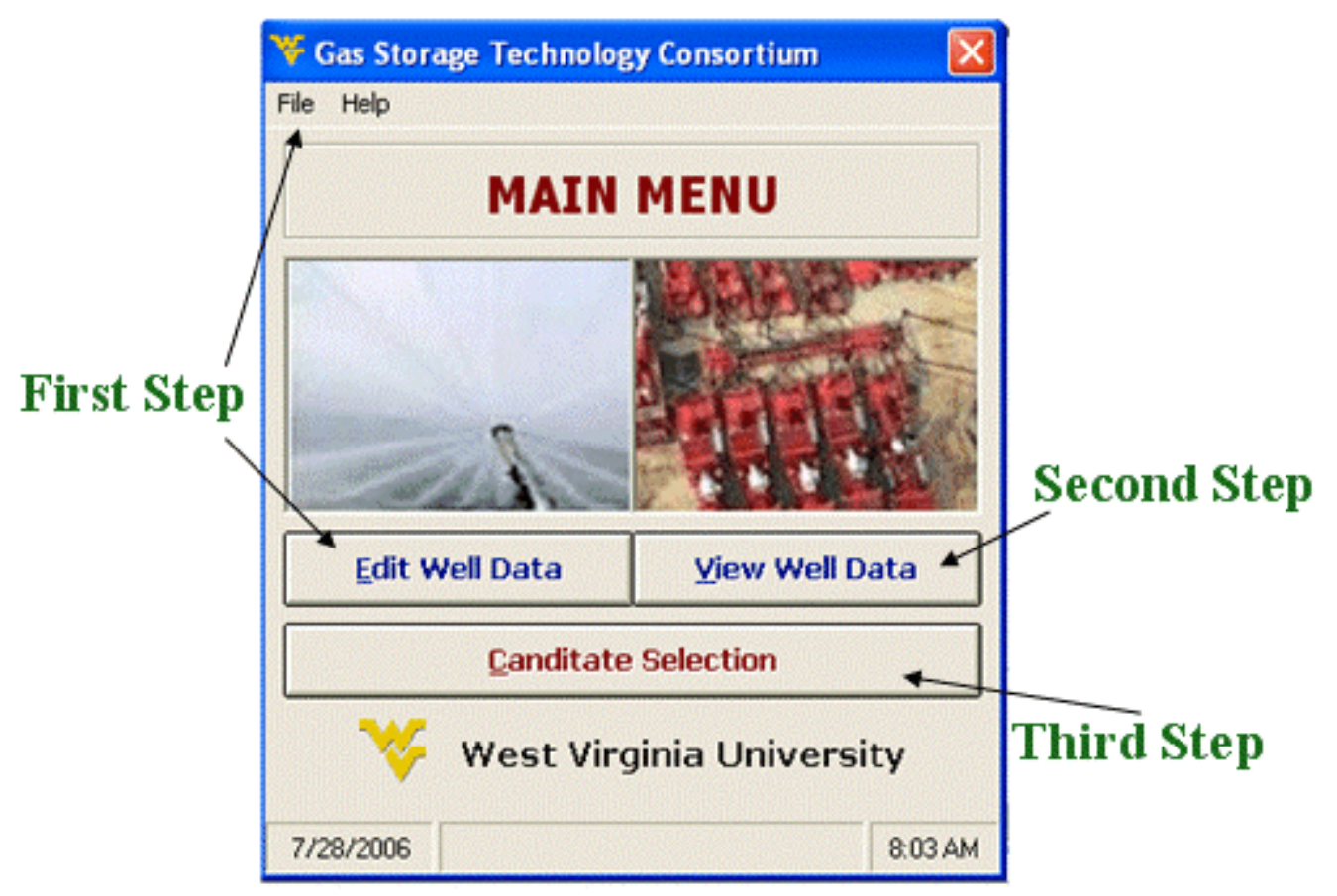


Complete list of items and sub-items in the above command buttons is shown below:

- File

o Create Template

o Import Data from filled-out Template

o Remove all data from database

o Exit

- Help

o User Manual

o Formulas

o About

- Edit Well Data

o Well bore

o Completion

o Stimulation

o Perforation

o Stimulation

o Well Test

- Well Test Analysis Tool

o Reservoir

o Find a Well

- View Well Data

O Select State \& county

o Select Wells

o Selection Options

o Select Well Data

- Candidate Selection 


\section{File}

The file menu can be accessed from the top left corner of menu bar. It contains four options.

o Create Template

o Import Data from filled-out Template

o Remove all data from database

o Exit

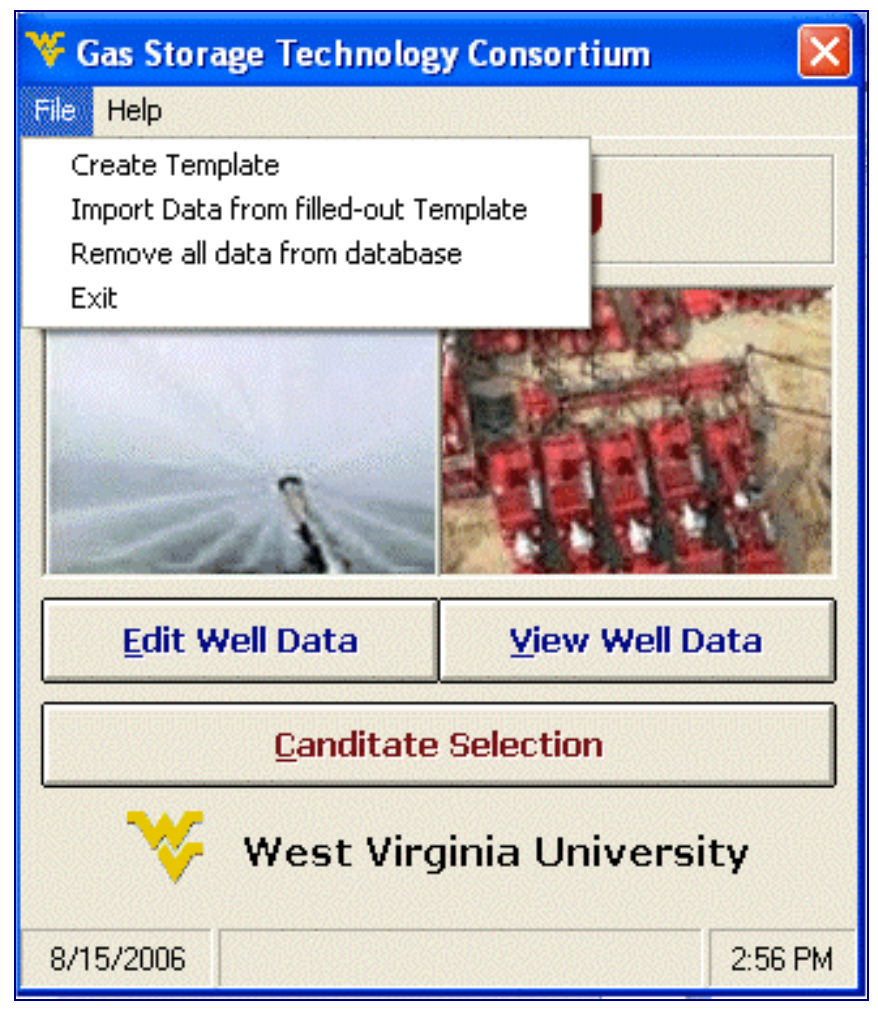

\section{Create Template}

This option if selected will ask the user to select the location on the hard drive where the user wants to save the Template and latter after filling the data import that template instead of entering the values one by one from the software.

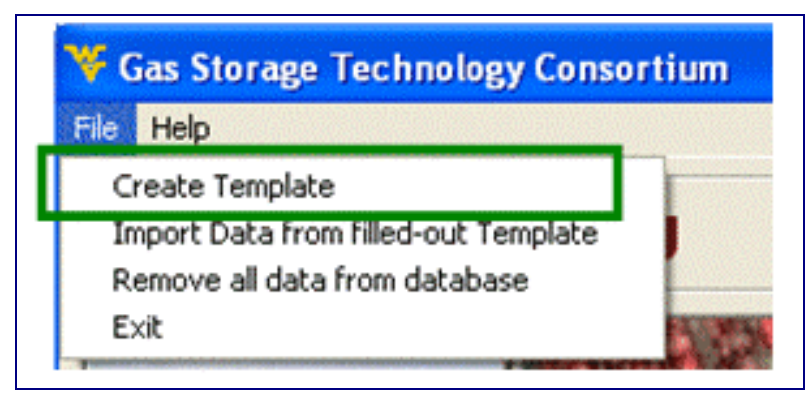


Select the place in the hard drive where you want to create the Template.

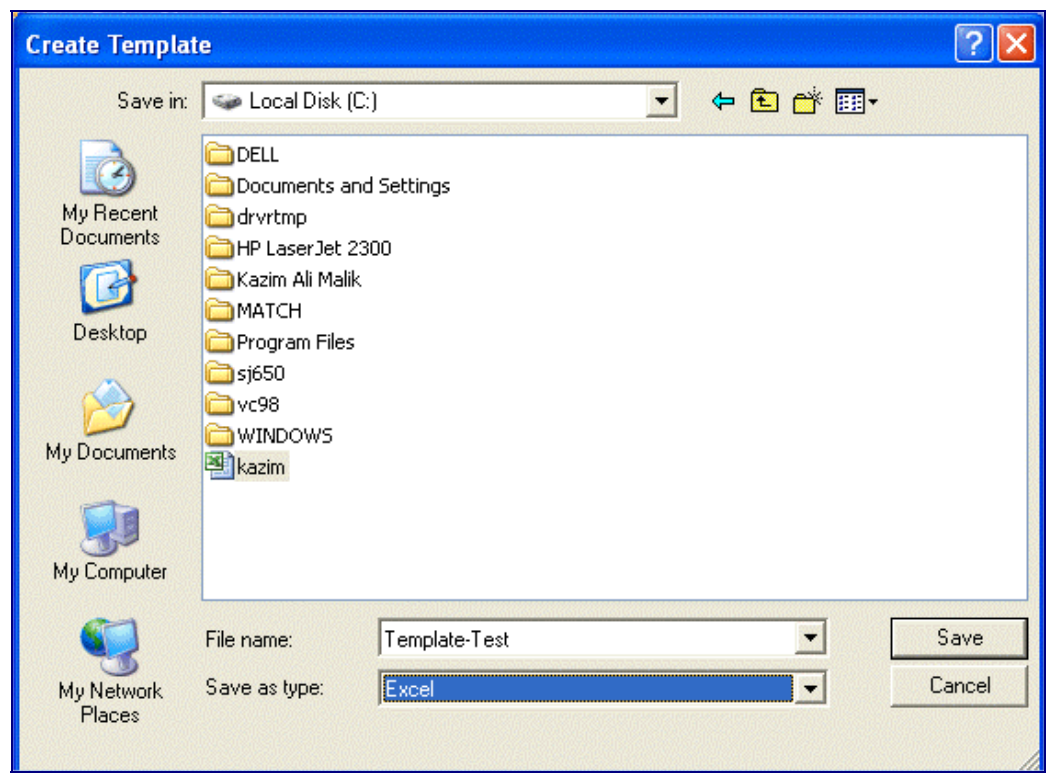

Once the Template is successfully created in the hard drive the following message will appear indicating the user that the template file has been created.

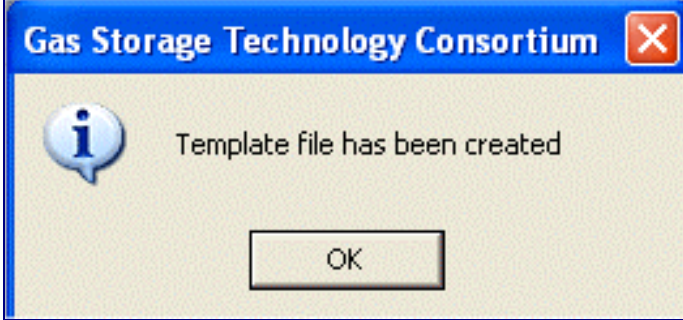

Following is the screen shot of the Template file showing the Well bore data. 


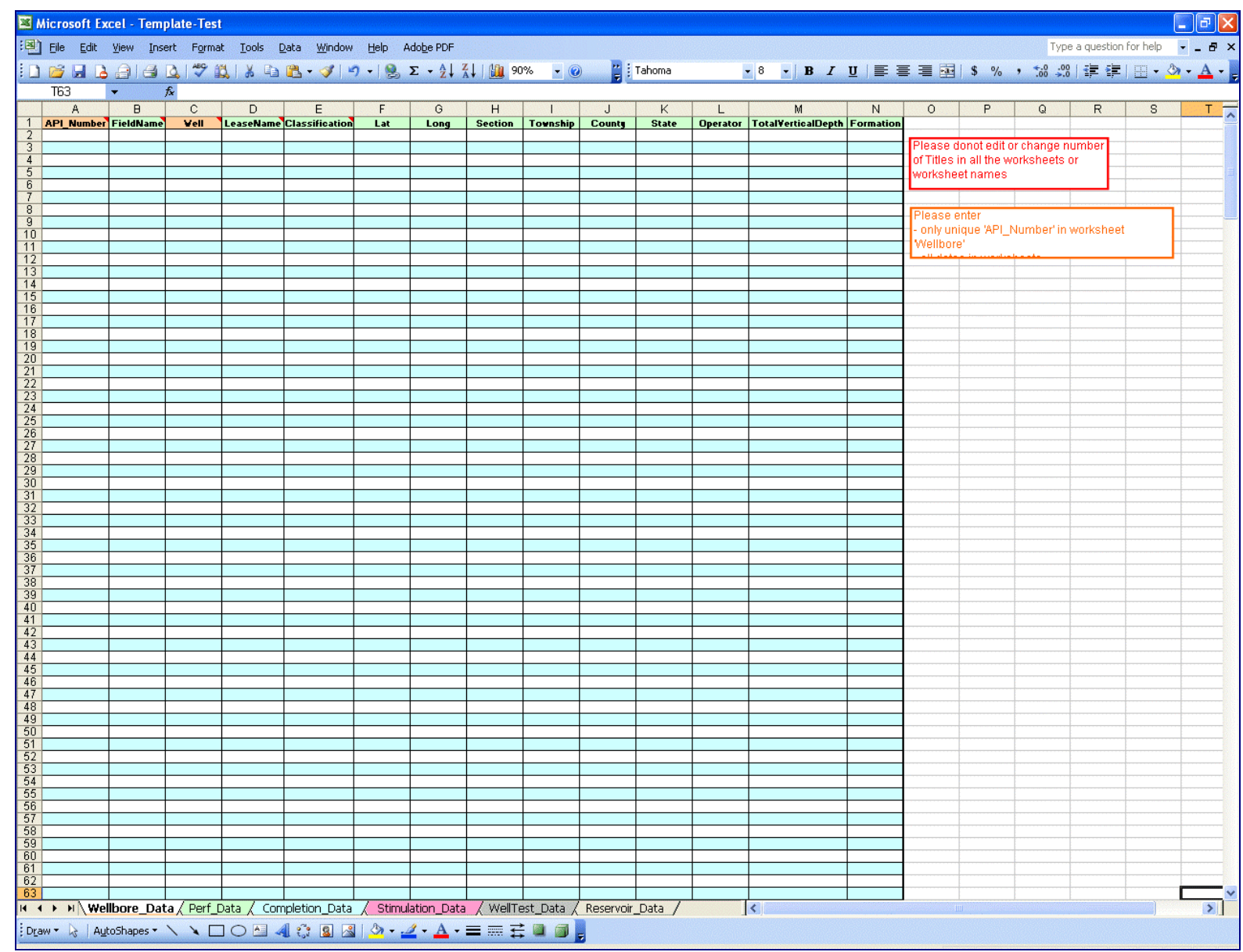

It has six worksheets, each representing the table in the database of the software.

o Well bore Data

o Completion Data

o Stimulation Data

o Perforation Data

o Stimulation Data

o Well Test Data

o Reservoir Data 


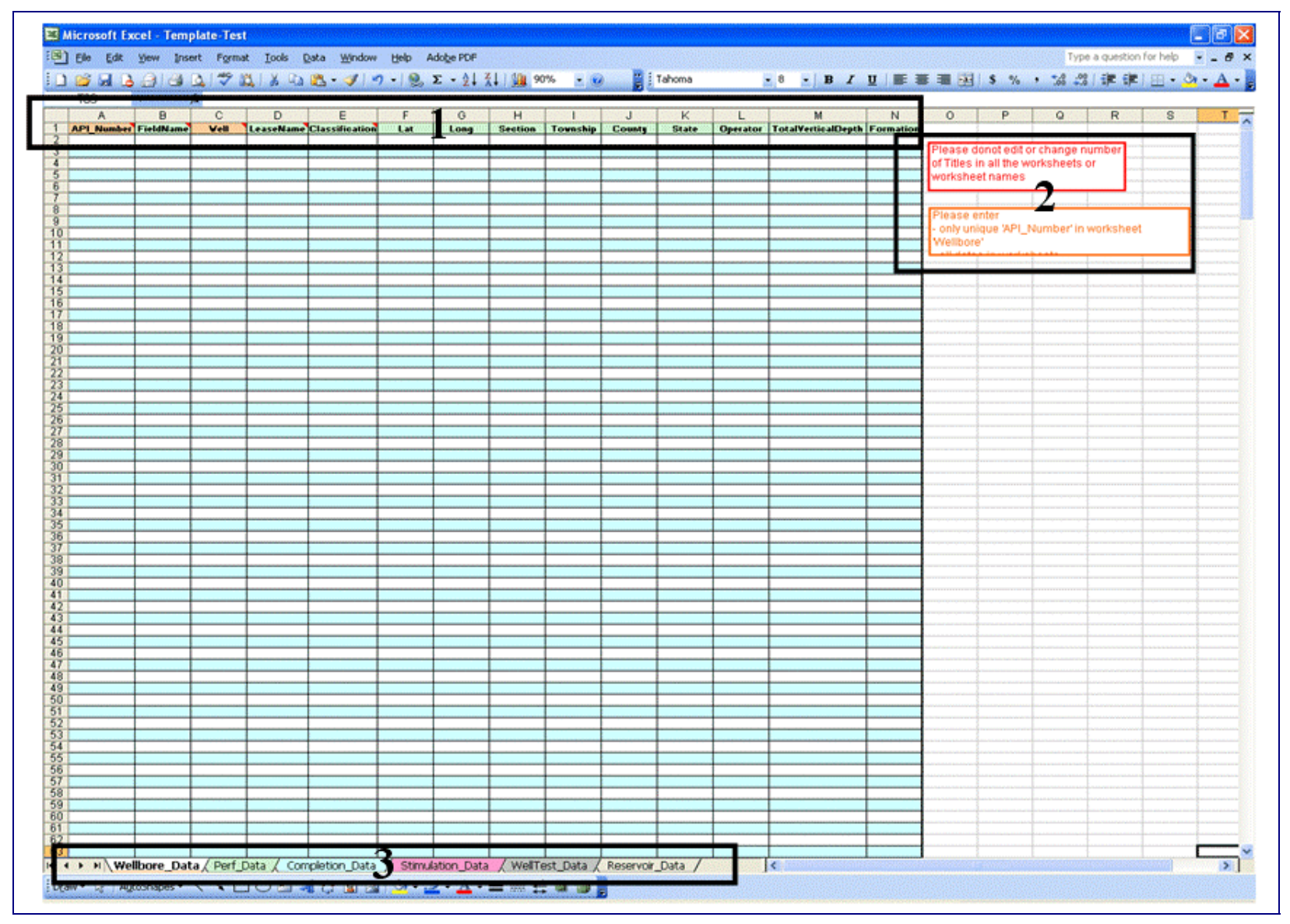

1. These are the fields of the table. Each field represents one characteristic of the table and each row is one record. If the user is not clear about any field then he/she can drag the screen cursor to that field name and the comment will appear like in the picture below where it will give a little explanation, its format and an example so that the user understands what sort of data to enter in each field

\begin{tabular}{|c|c|c|c|c|}
\hline & A & B & C & D \\
\hline 1 & API_Number & \multicolumn{3}{|c|}{ Fie Kazim: } \\
\hline 2 & & \multirow{2}{*}{\multicolumn{3}{|c|}{ Unique API number of the well }} \\
\hline 3 & & & & \\
\hline 4 & & \multicolumn{3}{|c|}{$\begin{array}{l}\text { Format: \#\#-\#\#\#-\#\#\#\#\# } \\
\text { Example: } 12-345-67890\end{array}$} \\
\hline
\end{tabular}


2. This section has two set of warnings for the user entering data. One is to not edit or change number of Titles in all the worksheets or worksheet names and other to add only unique 'API Number' in worksheet 'Well bore Data' and all dates in worksheets where required should be entered.

This has been done as the data is retrieved from the template according to some specific format and non presence of any data in elementary field might stop program from using that record. All the elementary fields' background is orange/red while others are in green.

3. This section shows all the worksheets in the Template file.

\section{Import Data from filled-out Template}

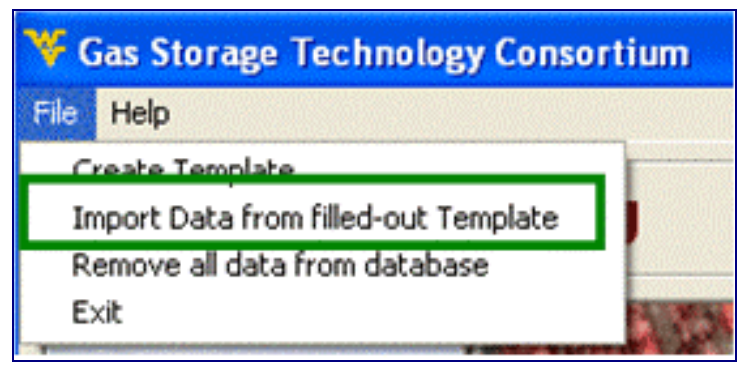

If this option is selected from the file menu then the program will ask the user to select the filled Template file from the location. The new data will be appended to the existing data. 


\section{Remove all data from database}

If the user doesn't want to append the data to previous database but instead want to up-load a whole new data then there is an option in file menu as highlighted in the snapshot below. This option will remove all data in the previous database. After removing the data from previous database the user can up-load the updated data from the template or enter it in the software.

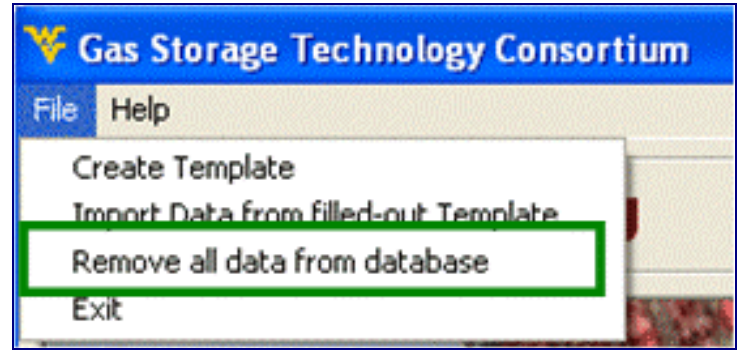

\section{Exit}

The program can be exited by two options. One is to exit by using the file menu and selecting 'Exit' while other is to select the cross on the top right corner as in normal windows based applications.

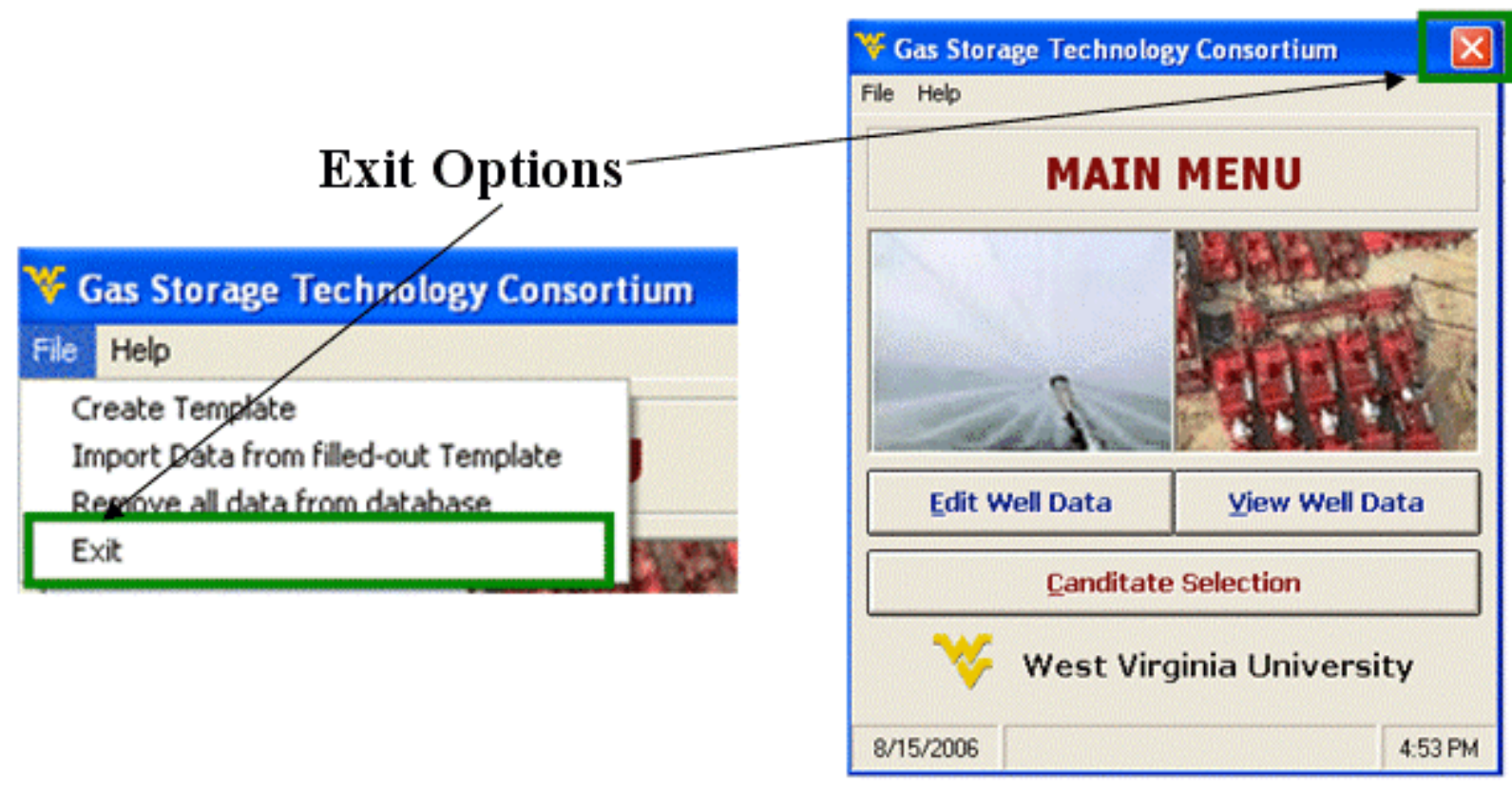




\section{Help}

Another option that can be accessed from the menu bar on top of the main menu screen is the Help menu option.

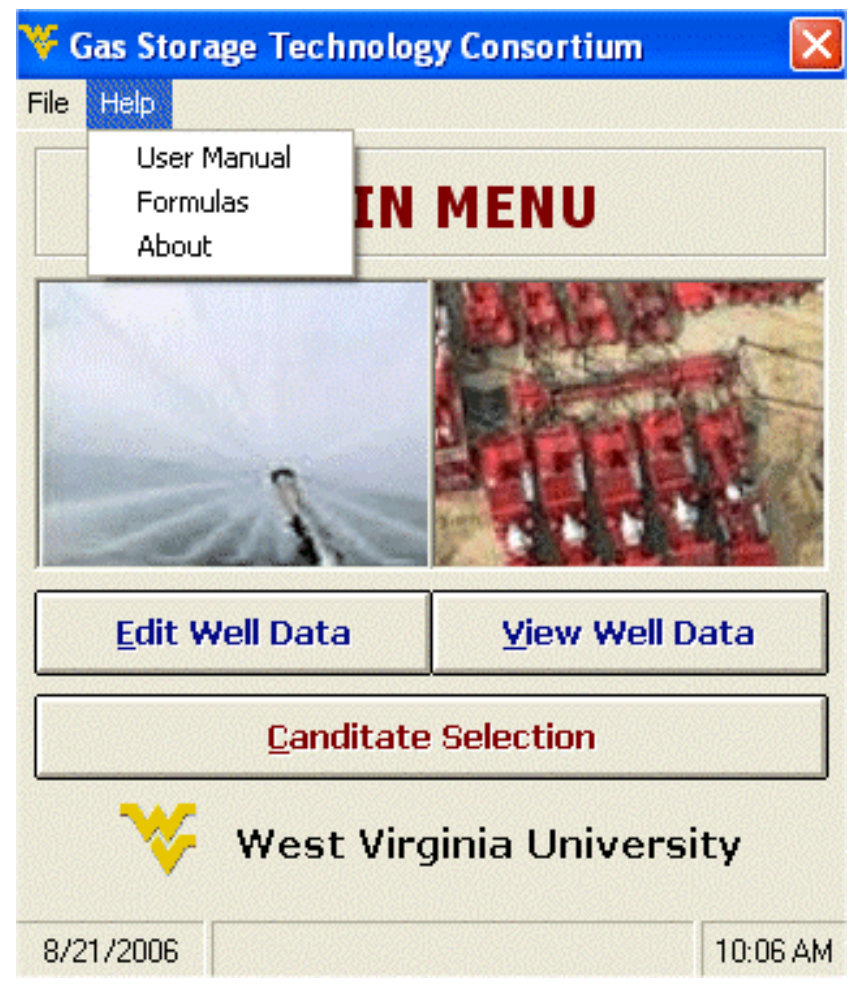

It contains three types of information one is the User Manual for this software and second is the Formulas used in this software and third 'About' form which shows the system information and software contributors.

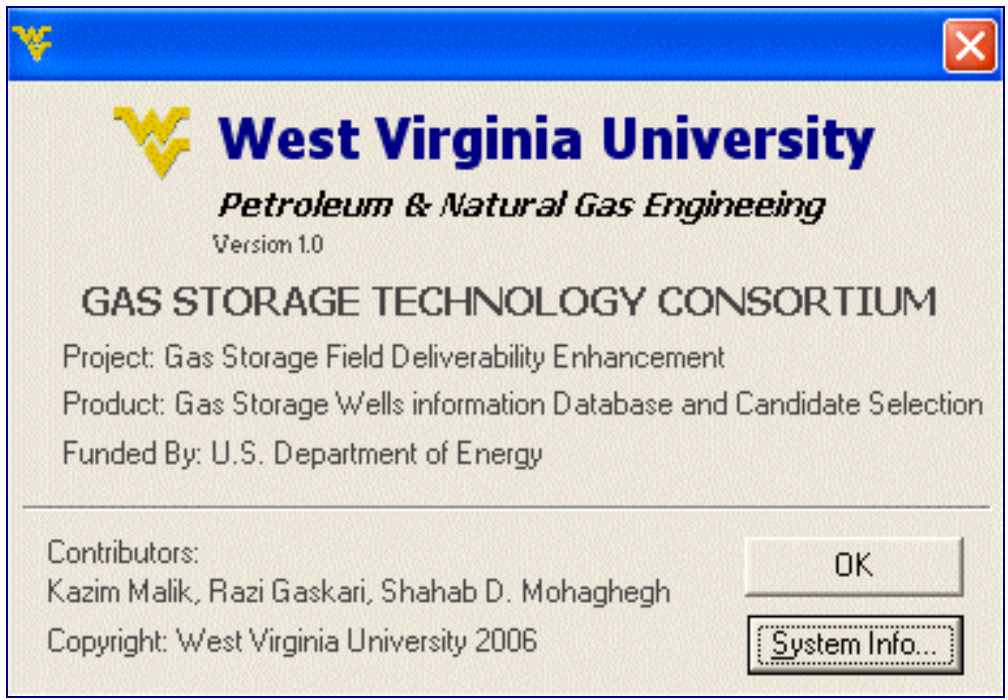




\section{Edit Well Data}

The objective of this interface is to Edit the database and do well-test analysis for each well based on the data entered or already saved.

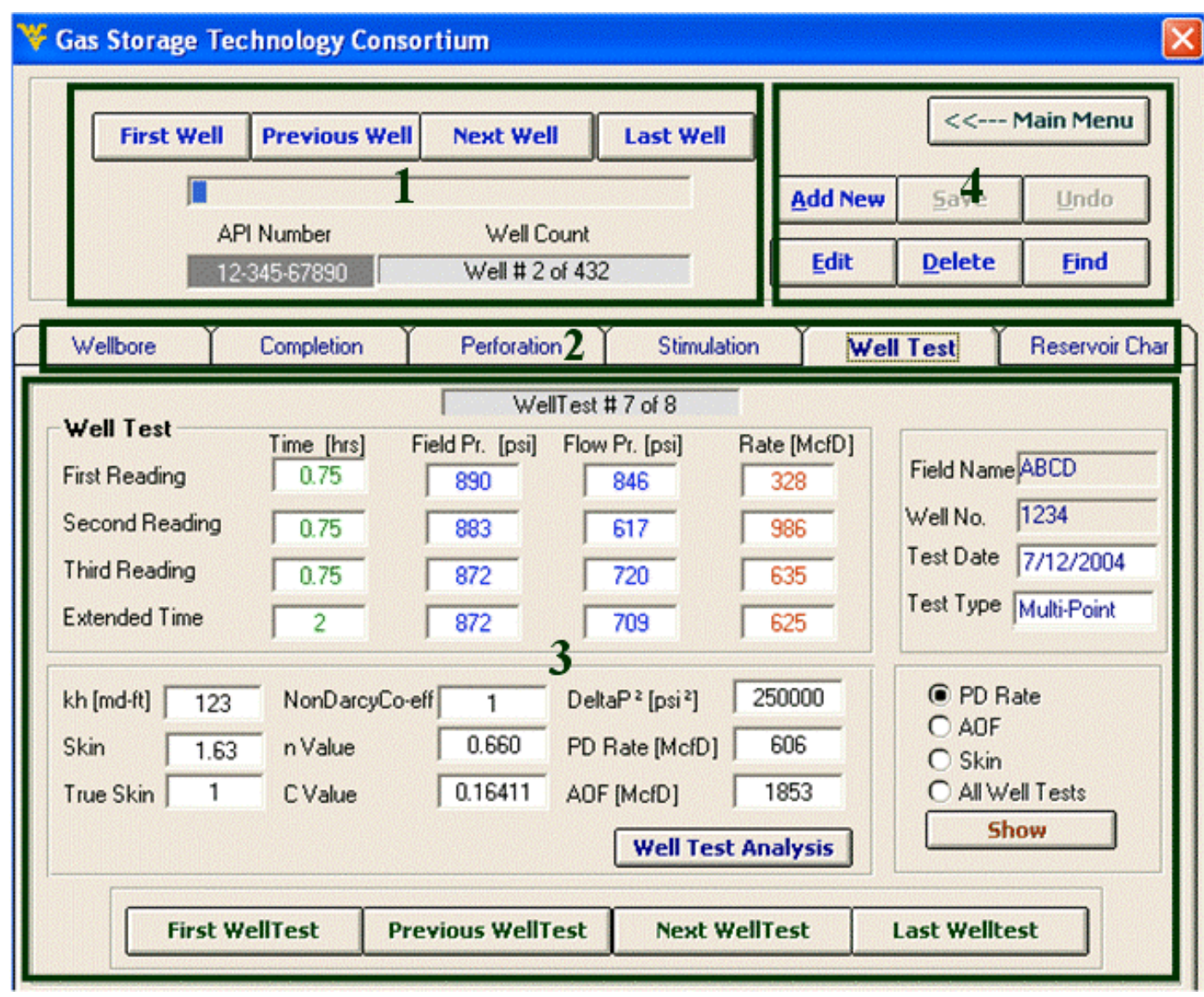

1. To move to the first well, previous well, next well $\&$ the last well in the record the user has to click on the button assigned to it. The wells are assorted in ascending order according to well API Number which is itself displayed in the 'textbox' below the 'API Number' label.

The 'progress bar' gives a visual aide to know the relative position of the well in database as the user browse through the database it will add or reduce the blue segments indicating current well position in the well bore database.

Below the 'well count' label the position of well out of the total records is indicated.

2. These are six tabs which represent six different tables in the database.

1- Well-bore 


\section{2- Completion}

3- Perforation

4- Stimulation

5- Well-Test

6- Reservoir Char

3. The user can edit/view the data in these text boxes. They correspond to the value of that parameter in the database. The Well-bore tab is used to create a new well and then data is entered one by one in all the following tabs. If you press other tabs, they will open up as in the pictures below
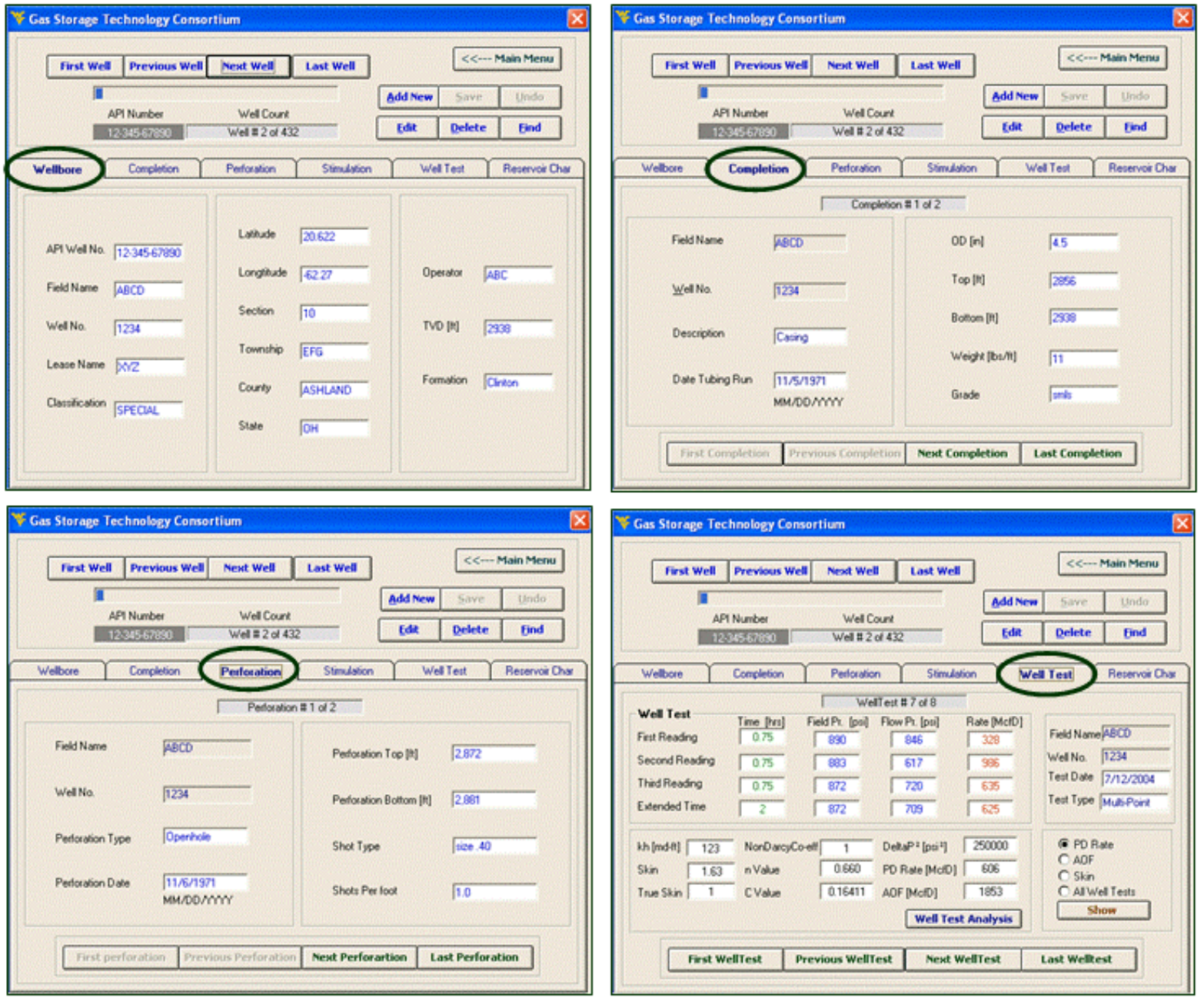

In the end of each tab except Well-bore and Reservoir Char there are browsing buttons for each tab. Browsing buttons for Well Test tab are shown in the picture below 
If you want to move to the first Well Test, previous Well Test, next Well Test $\mathrm{n}$ or the last Well Test in the record, click on the button assigned to it. All the records are assorted in ascending order according to time.

4. With these command buttons you can add, edit, save, delete, undo \& find a record. Where ever 'Main Menu' command button $\ll<--$ Main Menu appears in this software means that if you select it, it will take you to the Main Menu interface.

Controls in section $1,2 \& 4$ are same for all the tabs. If you want to add a new well then 'Well-bore tab' should be active and similarly if you want to add stimulation then 'Stimulation' tab should be active.

Note: The only way you can add a new well in the database is when you press 'Add New' button while the 'well-bore' tab is active. This way a new well will be created with corresponding Reservoir Char data and you can enter data in all the rest four tabs. Otherwise 'Add New' will only add new completion, perforation, stimulation or well-Test depending on which tab is active.

When a completely new well is being added in the database, all the tabs except Well bore tab will become inactive and the background color of all text boxes of Well Test tab will be yellow, indicating that they are ready for entering data. Notice in the following two pictures with all the tabs are inactive except 'Well bore' and 'Well count label' reading 'Adding New Well-bore data' and that all the textboxes are empty with yellow background. After entering the data 'Save' button is selected. 

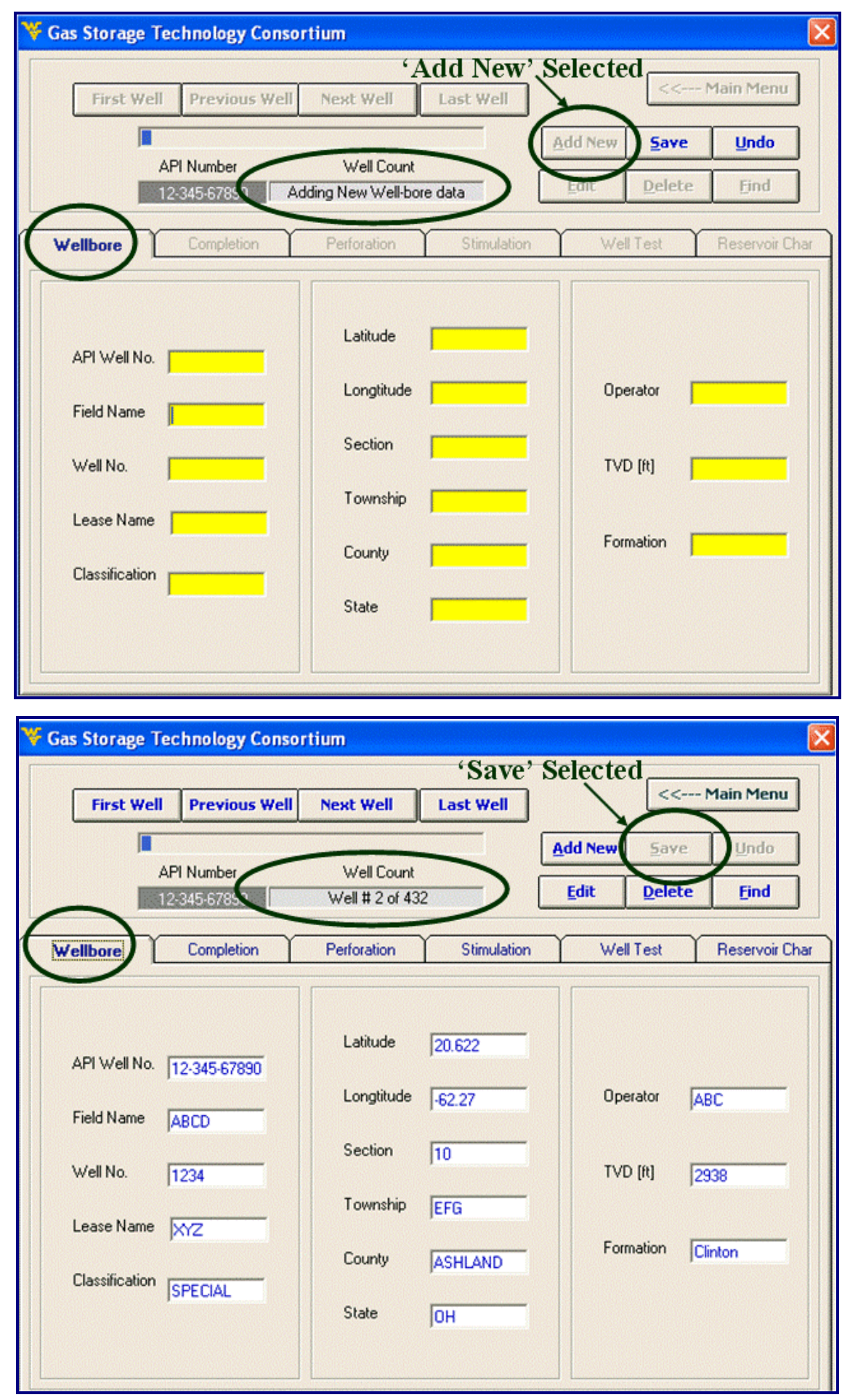
Instead of selecting 'Save' button if the user doesn't want to save the changes or add new well then 'Undo' button can be selected. It will cancel the previous Add new or edit command.

Note: $\quad$ The dates for completion, perforation, stimulation \& well test should always be entered as the output of the software is directly dependent on the chronology of events. The format of date is also specified for the user where required. A close picture of that format is below

\begin{tabular}{|c|c|}
\hline \multirow[t]{2}{*}{ Perforation Date } & $11 / 06 / 1971$ \\
\hline & $\mathrm{MM} / \mathrm{DD} / \mathrm{MY}$ \\
\hline
\end{tabular}

You need to enter API well no only once in the well-bore tab and it will be automatically copied in the rest of tabs and procedure is the same for editing. The format for entering well API Number is below

$$
\text { API Well No. } \longdiv { 1 2 - 3 4 5 - 6 7 8 9 0 }
$$

If wrong format or well API number is not entered for a new well then you will be greeted with the following message

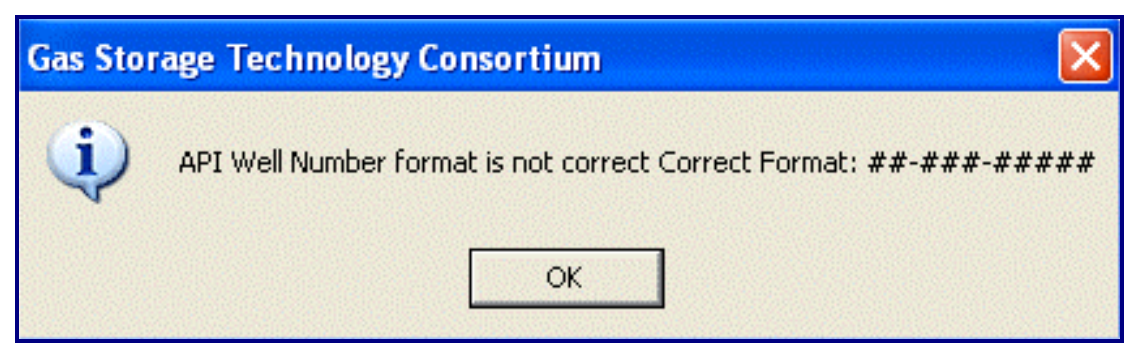

If the well API Number that you tried to enter is already in the database then you will be greeted by following message

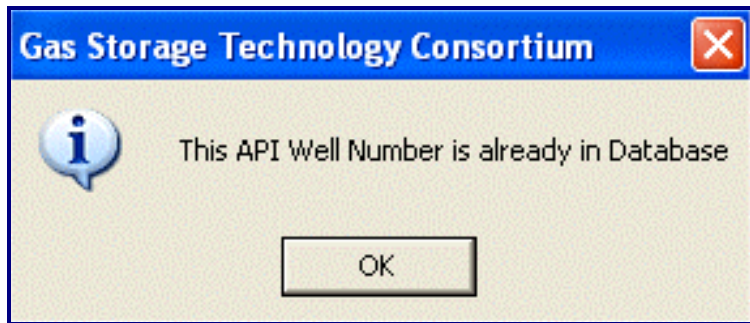




\section{Find a Well}

If you know the well API Number and want to find that well then 'Find' command button will be of great help to you. Just click it and new screen will pop-up. Enter the well 'API number' in the text box or scroll the well API Number list box and double click the well for which you want the data to be retrieved.

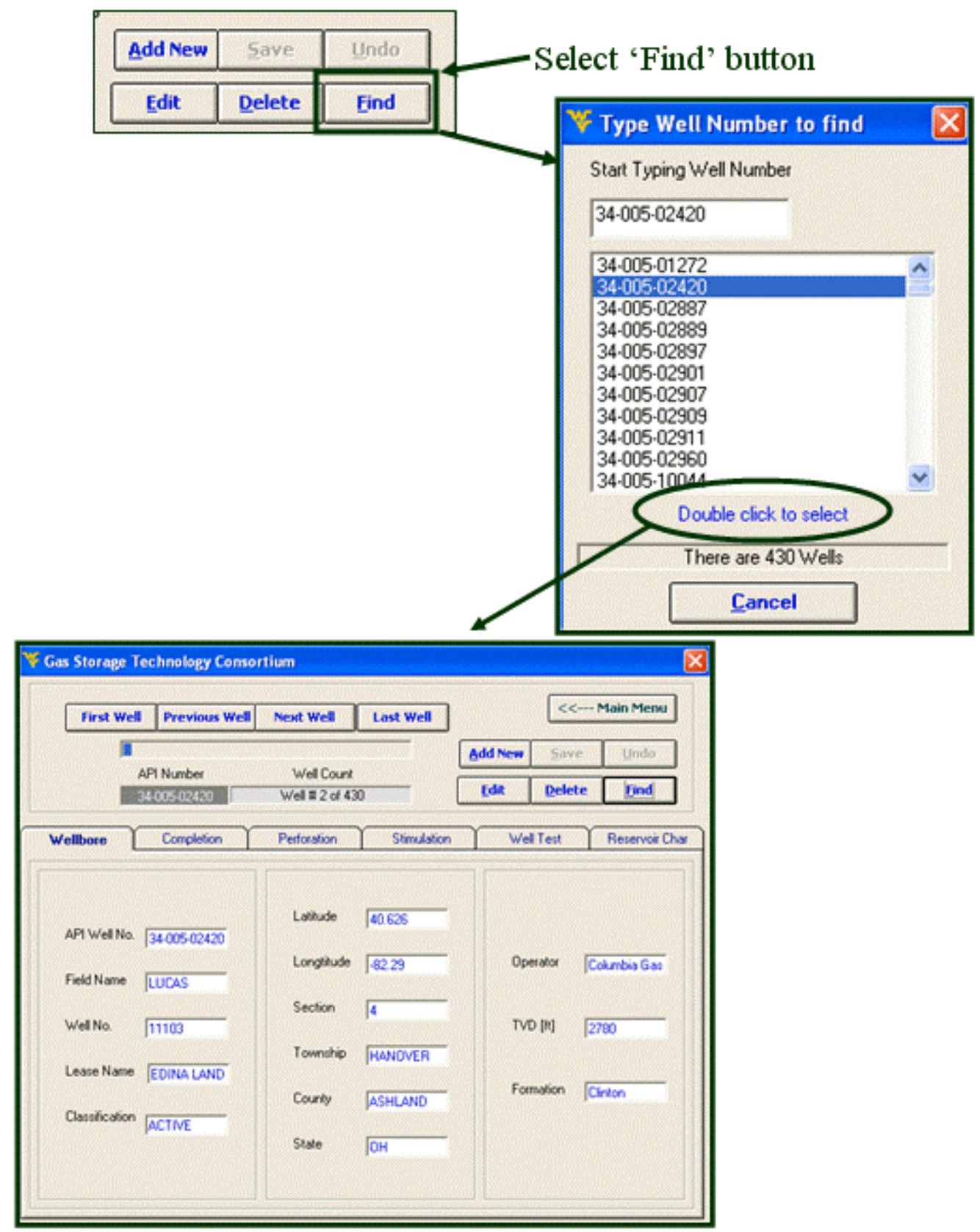




\section{Show}

If you want to see the Peak day rate, Absolute open flow, Skin Values and All Well Tests performed on a well verses time then the 'Show' button should be selected with the respective graph from the option buttons as shown below.

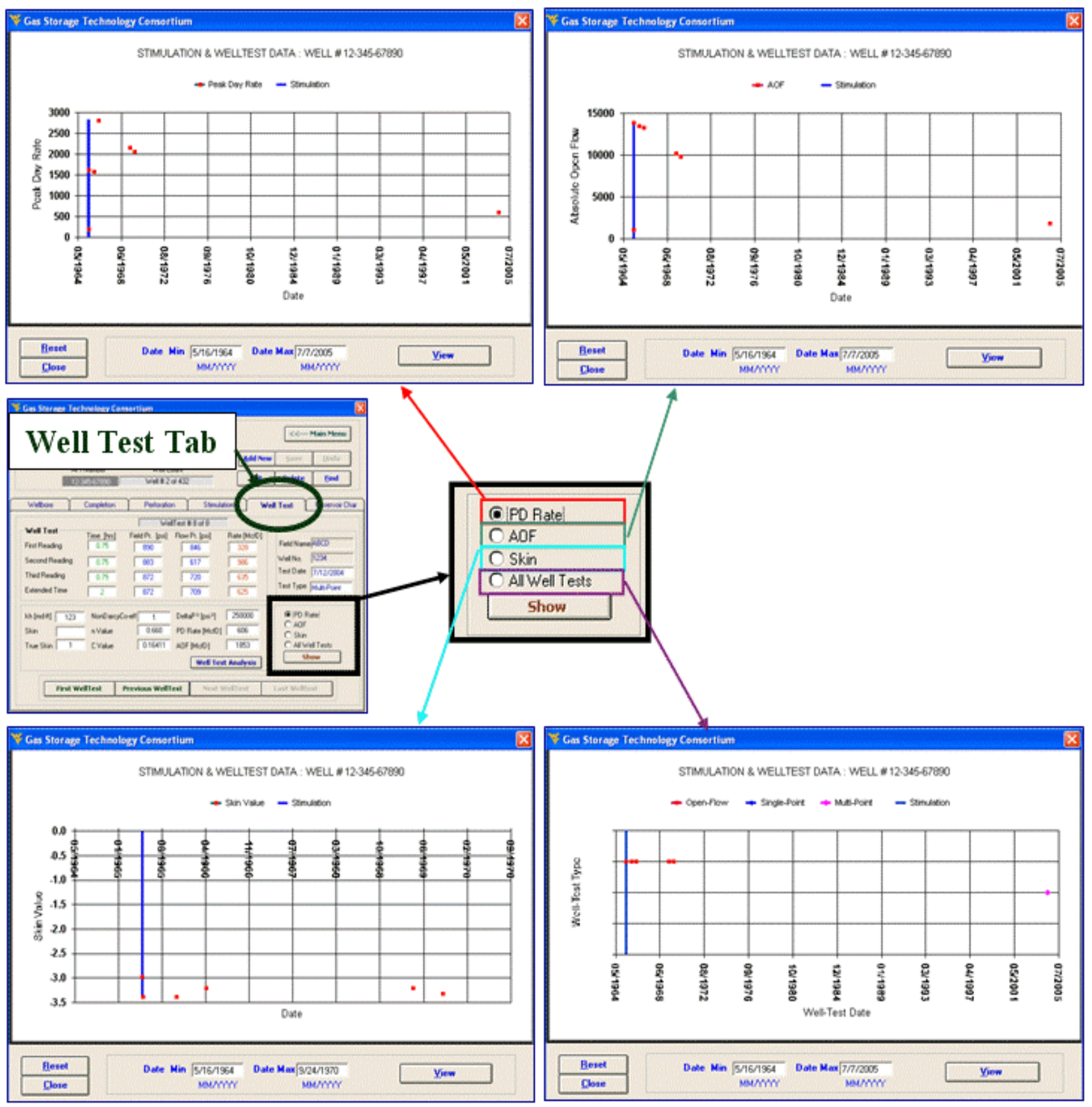




\section{Well Test Analysis}

The user can do three types of Well Test Analysis in this software:

1- Simplified Analysis (for calculating n, C, PD rate \& AOF)

2- LIT Analysis (for calculating Skin if ' $\mathrm{k}$ ' is known)

3- Build-up Test Analysis (If Detailed Multi-Point Test data is available)

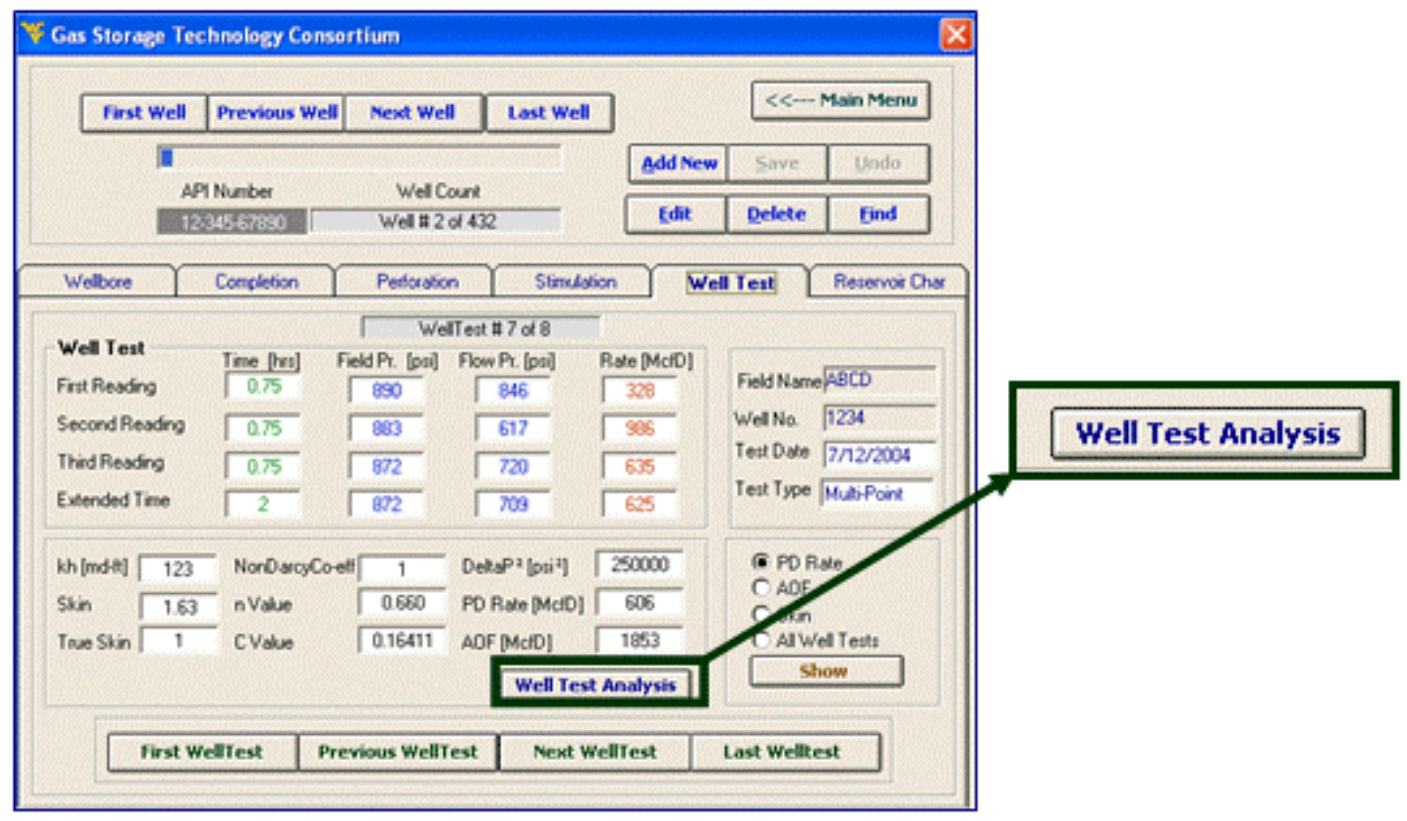

The analysis tools are very similar for Simplified and LIT Analysis except were mentioned. The interface below will appear when you select 'Well Test Analysis' button. It will give you a glimpse of what has happened on the well since it was drilled. 


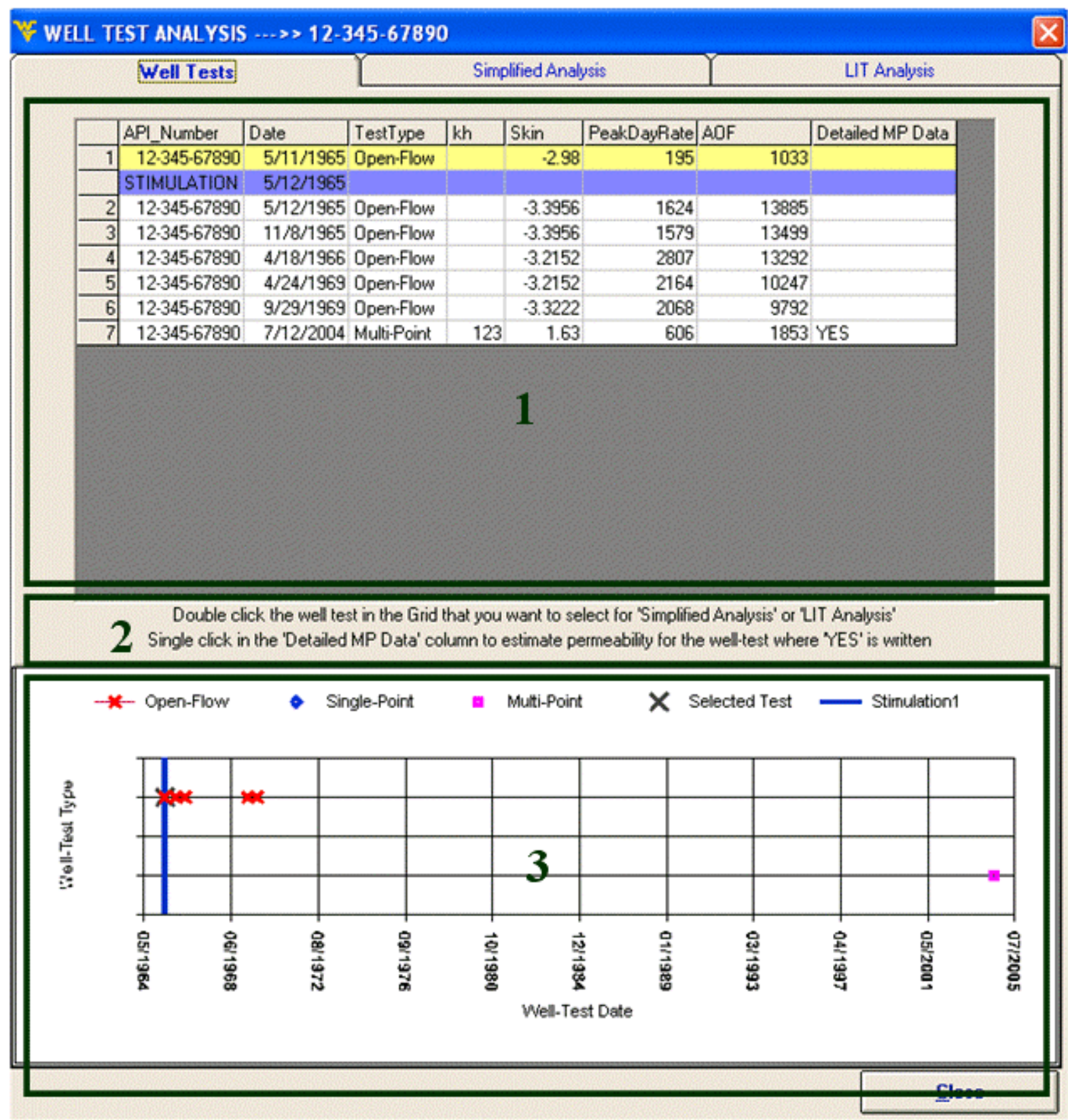

1. This sections contains all the data in a grid form with API Number, Date of well test, Test Type, kh value, Skin value, Peak Day rate, Absolute Open Flow and information in 'YES' or 'NO' form if the Detailed Multi-point data (Pressure profile \& flow-rate vs. time) is available for a given test or not. The back color of selected well-test is yellow while of stimulation is purple. The first well-test is selected by default. 
2. This section contains instructions as how to select well-tests for analysis. Single click on any well-test will make it the current well-test with background changed to yellow and by double click it will be selected for Simplified and LIT Analysis. If the Detailed MP Data for a well-test is given then it can be selected for permeability analysis (build-up test) by single click on the cell where 'YES' is written. This way the build-up test analysis module will show up.

3. This section shows the time of different well tests which are indicated by three types of markers and stimulations on a well which are represented by straight blue vertical lines. The selected well have the similar marker according to its test-type but its color is dark green.

Once any well-test is double clicked, it is selected and added in the list box of simplified and LIT Analysis. 


\section{1- Simplified Analysis}

The screen shot of Simplified Analysis tab is below with Well-test \# 2 to \# 7 selected for analysis.

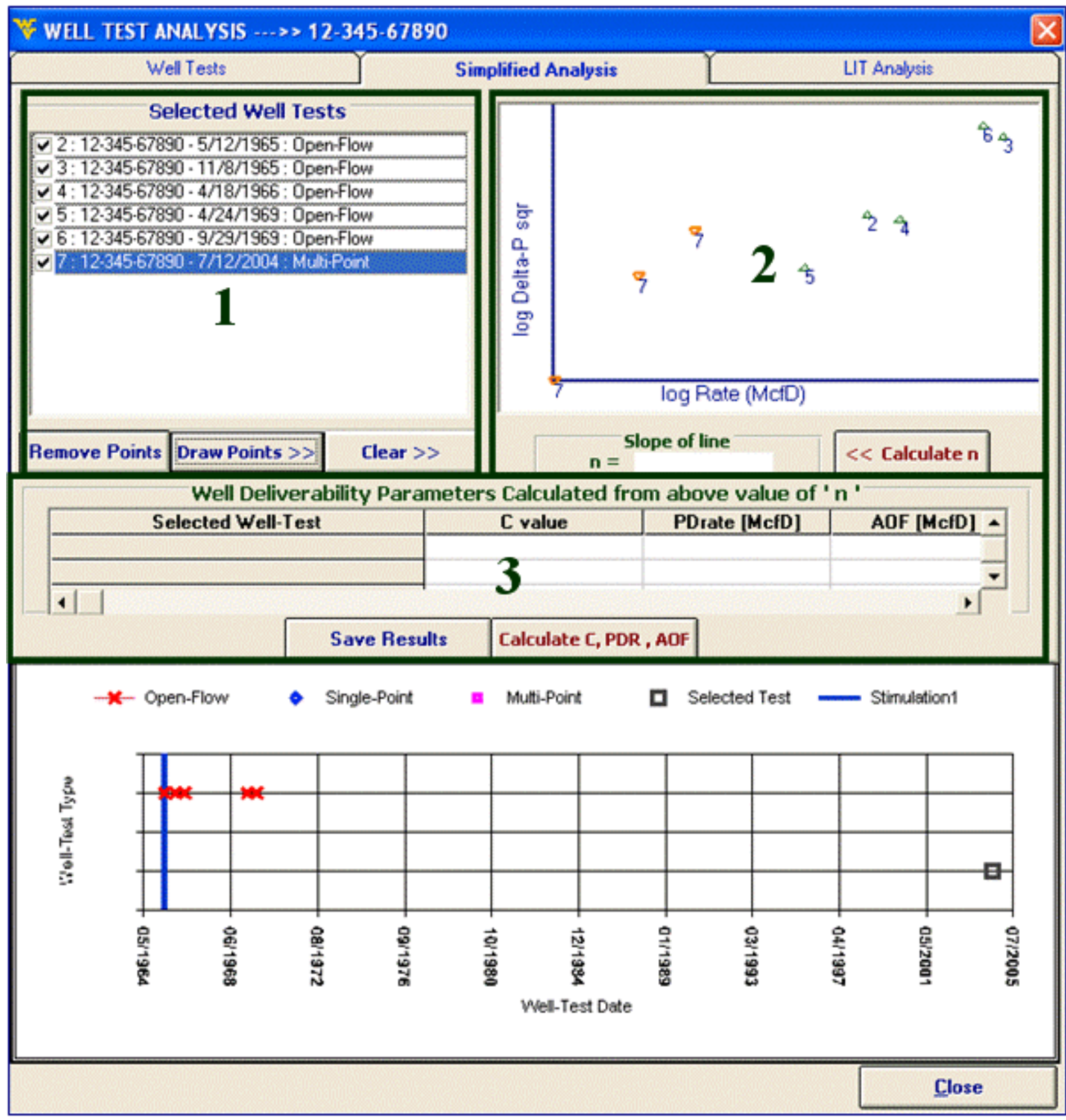

1. This sections contains the list box which has the entire well-tests selected for an analysis. Any test now again can be selected or de-selected by using the check-box in front of it. Once the well-tests are selected then they can drawn on log-log graph of Flow-rate 
(McfD) vs. Delta Pressure Square (Delta P sqr) by selecting the 'Draw Points' button. This graph can be cleared by selecting the 'Clear>>' button also if the well-tests drawn need to be changed.

2. When the data points have been drawn the user can draw a line in the picture box keeping left mouse button held down like shown below

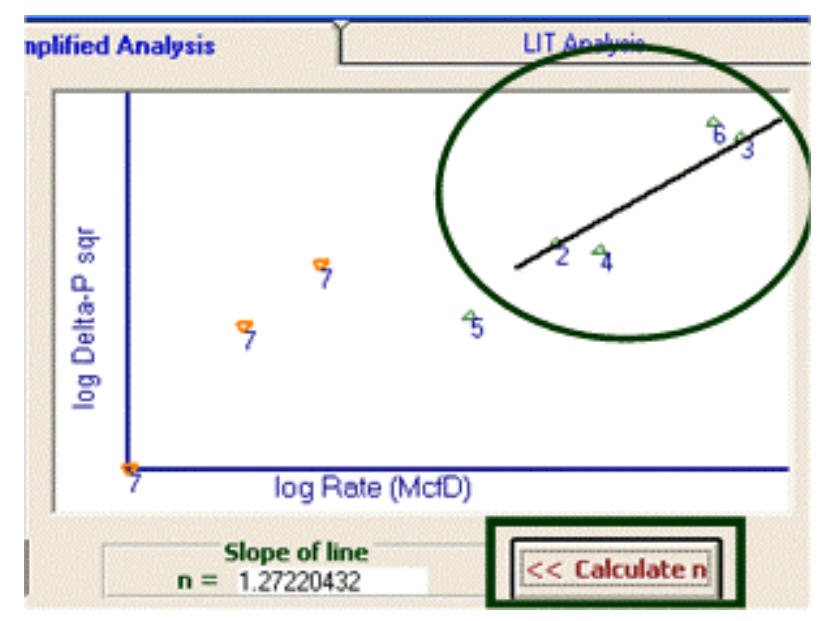

Select 'Calculate n' button to find the slope of the drawn line. The slope will be calculated in front of ' $n$ ' text box.

3. Now the user can select the well-tests in the list box to which he/she wants to apply this calculated slope. Like in the snap shot as the slope was drawn between well-test points 2 and 3 thus the same were selected and the 'Calculate C, PDrate, AOF' button was selected. The values of C, Peak Day Rate and Absolute Open Flow will be calculated and shown in the grid as shown in the picture shot on next page. Theses results can be saved in the database by selecting the 'Save' button. 


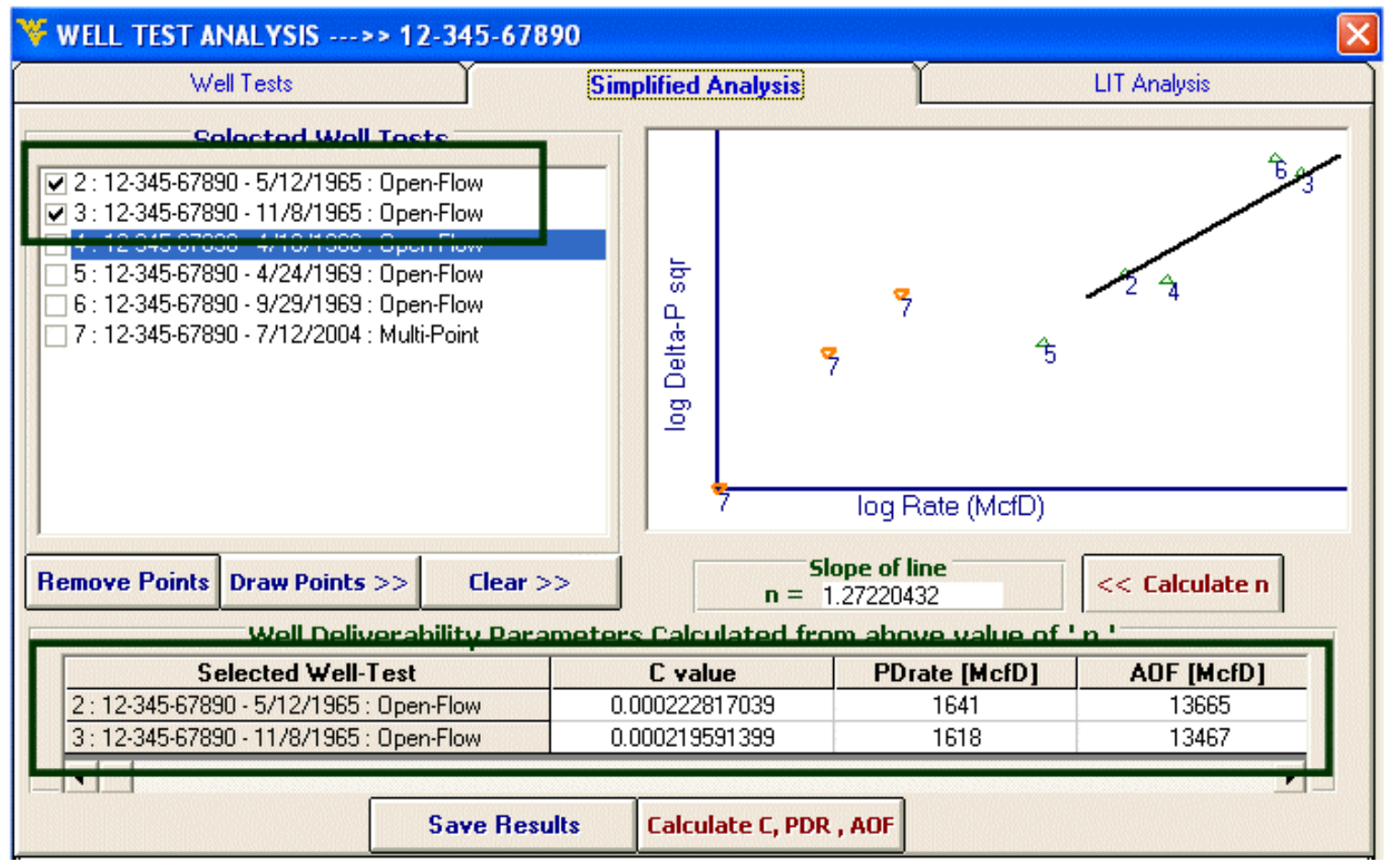

Note: If there is only one well-test before or after the stimulation then the value of $\mathrm{n}$ can be assumed and written in the textbox in front of label ' $n$ ' as shown in the picture below. The value of ' $n$ ' cannot be assumed for more than one well at a time so if there is more than one well-test for which the value of ' $n$ ' has to be assumed then they should be selected one by one.

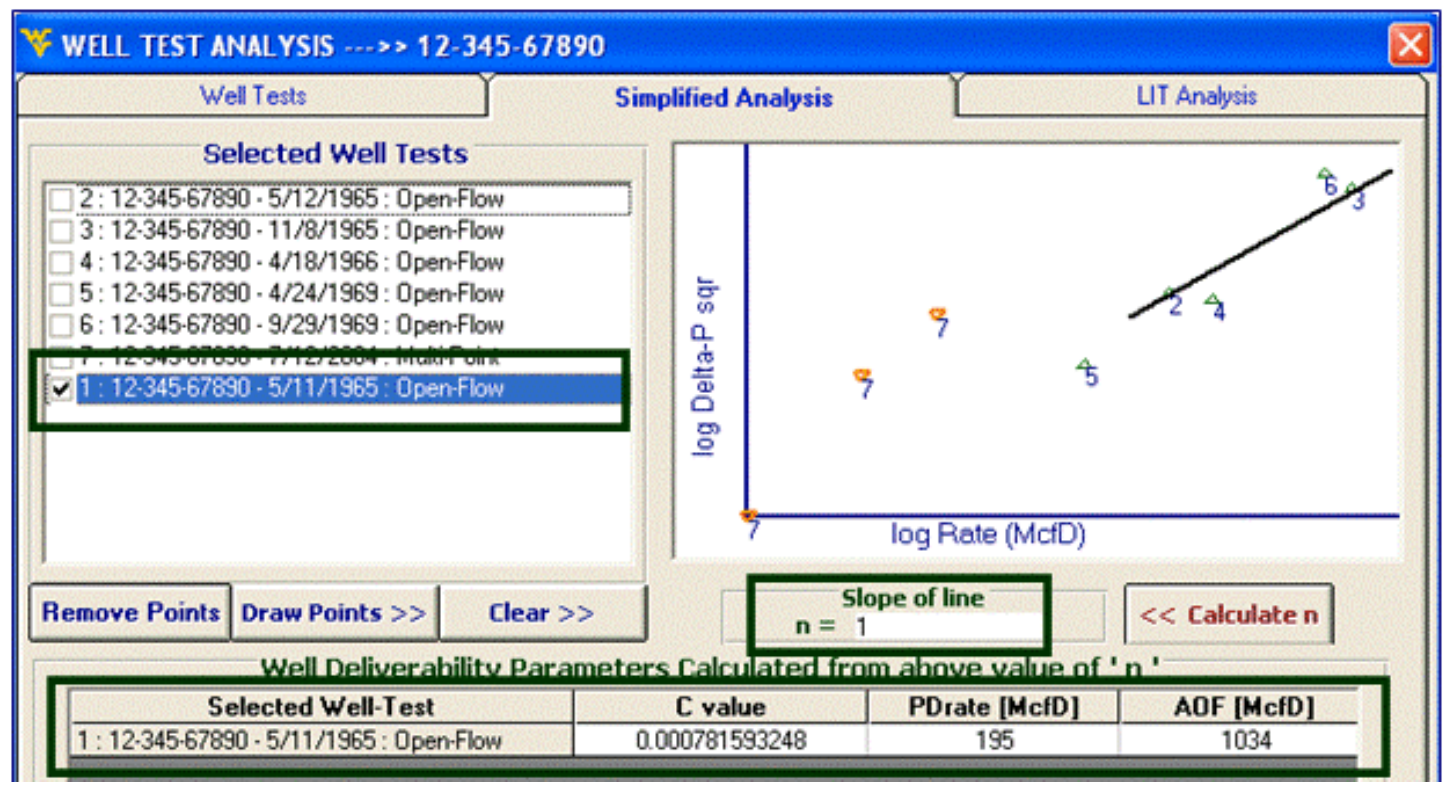




\section{2- LIT Analysis}

The screen shot of the LIT analysis is below:

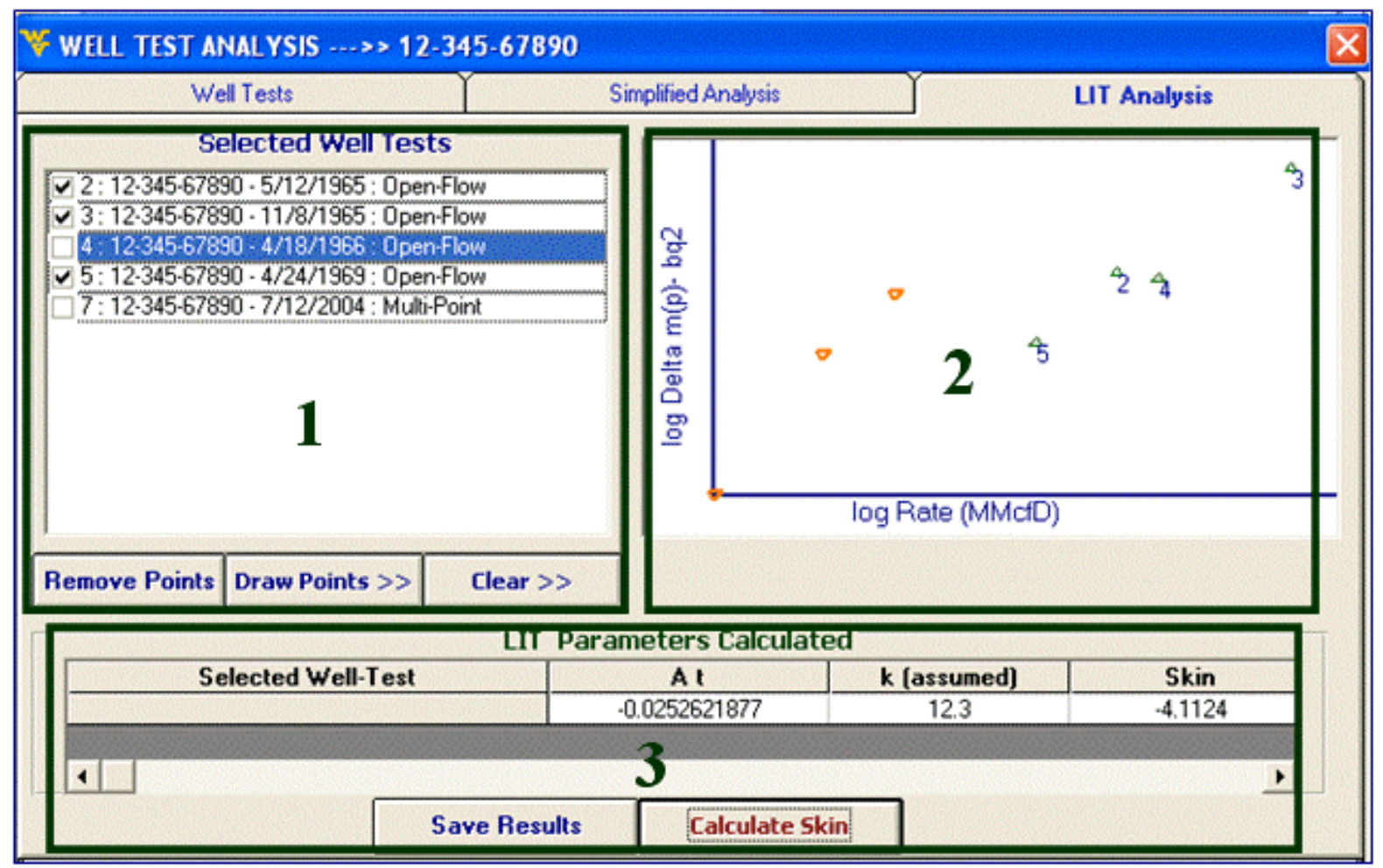

1. This section is the same as for Simplified Analysis.

2. In this section the well-test points are drawn on $\log -\log$ plot of 'Flow rate (MMcfD) vs. Delta pseudo pressure $-\mathrm{bq}^{2}$, There is no need to draw a slope line in this plot. Instead the points can be selected by visual inspection that they form a straight line and that they were conducted preferably with-in 2 years. In the snap shot above well test points 2,3 and 5 have been selected to calculate Skin.

3. When the 'Calculate' button is pressed the program uses the permeability value ' $\mathrm{k}$ ' from the nearest well-test and calculates skin. The new value of skin can be saved in the database by selecting 'Save Results' button. 
Note: Multi-point test points give erroneous calculations if selected with other well-tests as they are recorded one flow after another simultaneously not like Open Flow and single point tests which are recorded once a year.

If the selected well-tests are not with in 2 years then the following message will appear giving the user choice either to select other well-tests or continue with the well-tests selected.

\section{WELL TEST ANALYSIS -.. >> 12-345-67890}

? The time between the well-tests is more than 2 years, Do you want to continue?

$$
\text { Yes }
$$
No 


\section{3- Build-up Test Analysis}

If any Multi-point well test has a detailed data (pressure and flow-rate profile vs. time) then the 'Detailed MP Data' column in front of that test will show 'YES'. It means that the data for this well-test can be analyzed to estimate a value of permeability.

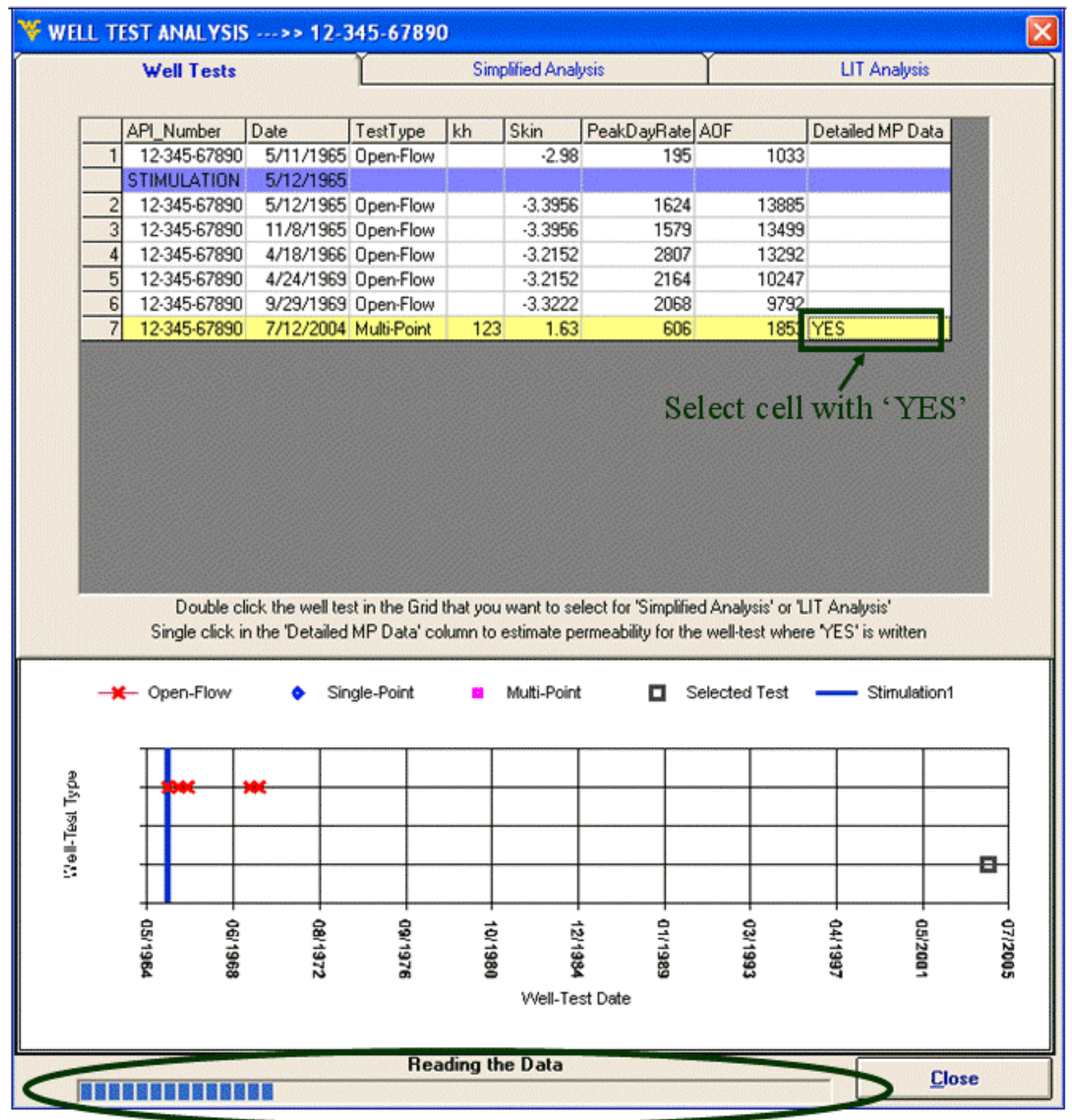


If the cell with value 'YES' is selected the software will read the data from the excel file and progress bar will become visible like in the picture shot above showing that the data is being read.

After the complete data has been read by the software the following screen will appear showing the pressure profile of the well-test.

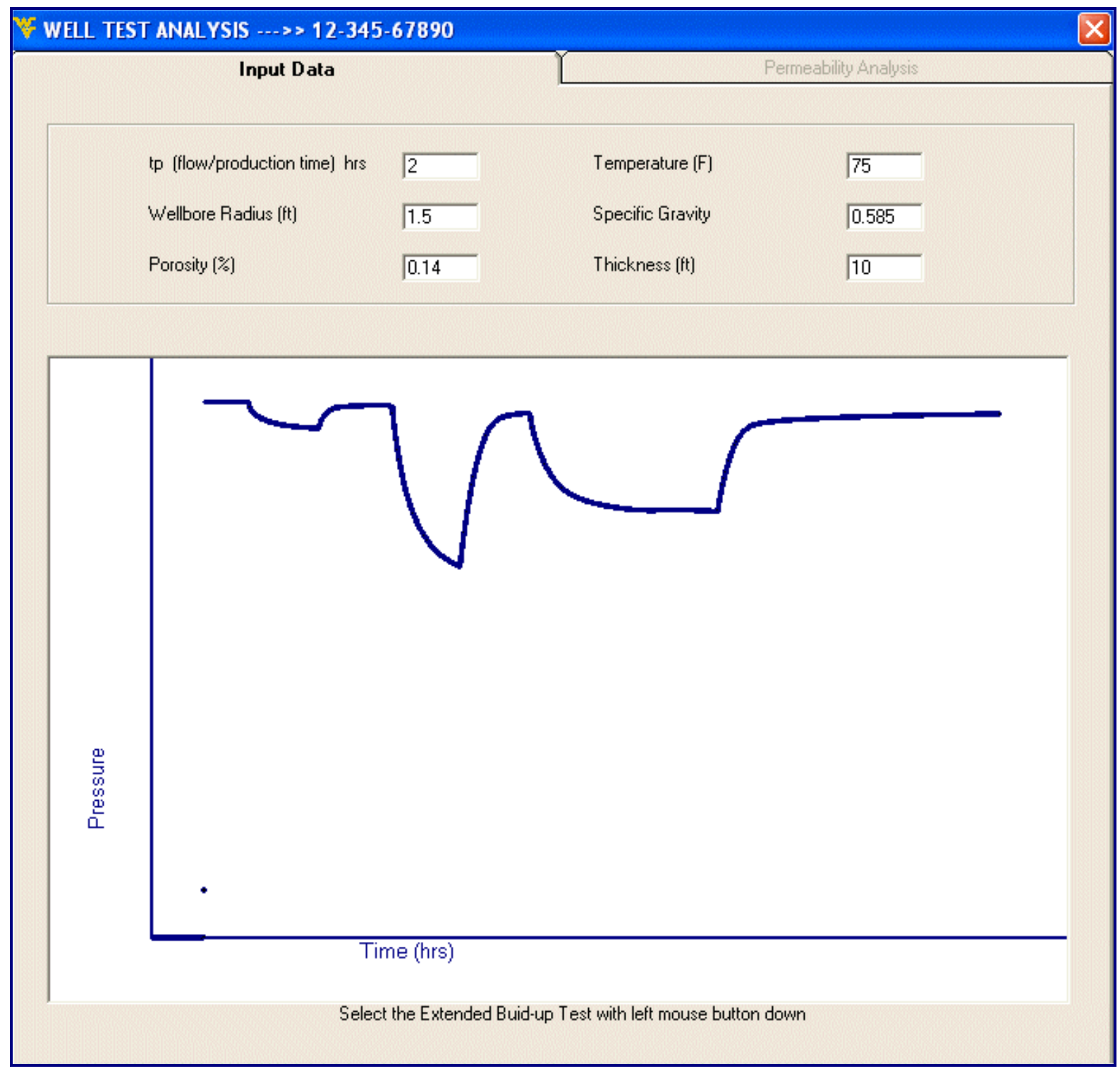

All the Input data is retrieved from the database and if is not found then default values are inserted. The value 'tp (flow/production time' is $2 \mathrm{hrs}$ by default but can be changed by the user. 
The Extended build-up test for 2 or more hours should be selected by keeping the left mouse button down. The green lines will indicate portion of build-up test selected.

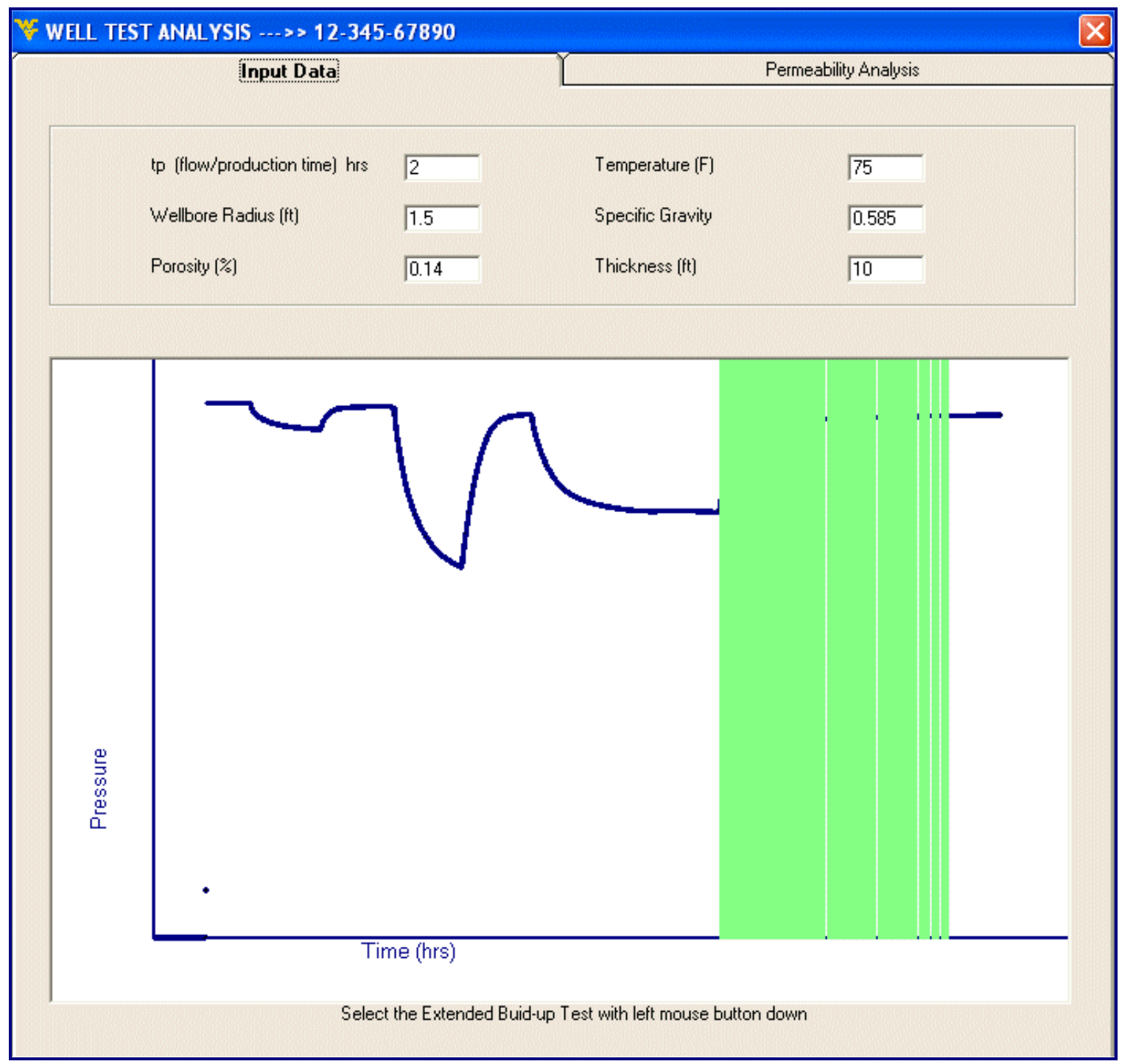

If by mistake draw-down data is selected then the following message will appear informing the user to select build-up data again.

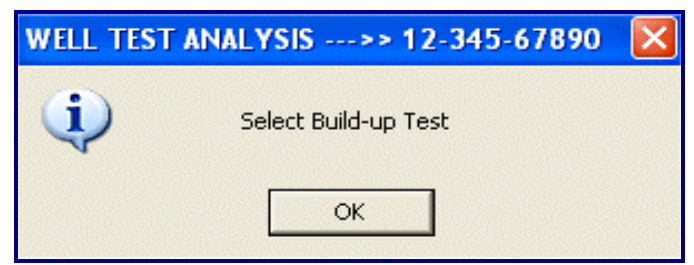


After the portion of build-up data has been correctly selected the permeability analysis tab will show following graphs. The first one is the log-log diagnostic plot between 'Del Pressure' and 'Del Time'. The user should select the first point which does not fall on the unit slope line drawn by holding the left mouse button down. The initial pressure ' $\mathrm{Pi}$ ' and flow rate text box values will be selected from the build-up portion of the extended well-test selected. The graphs will be drawn again with a green line drawn on the Horner plot indicating the end of well-bore storage (tewbs).

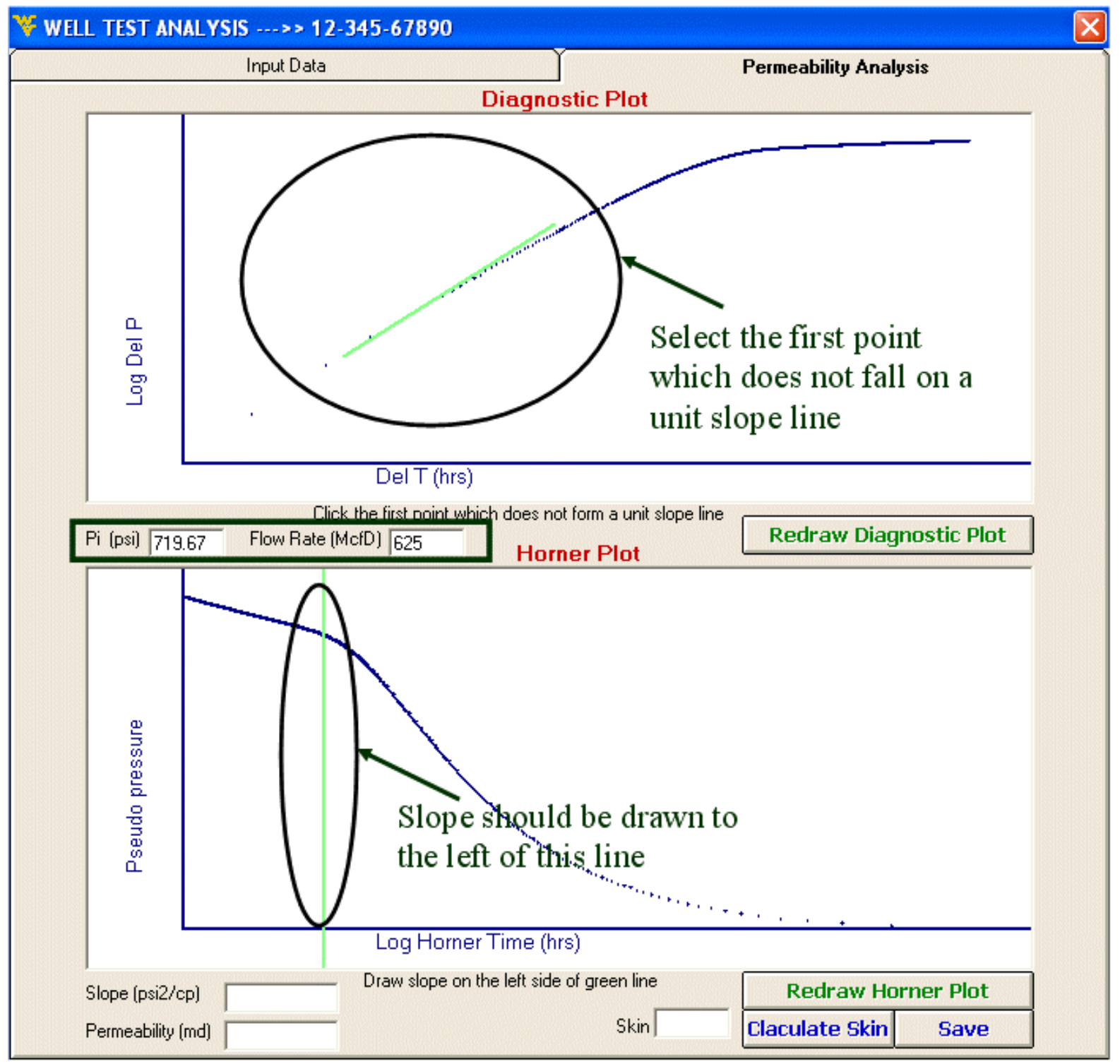

The slope should be drawn on the Horner plot on the left side of the end of well bore storage line shown in green on Horner plot. 


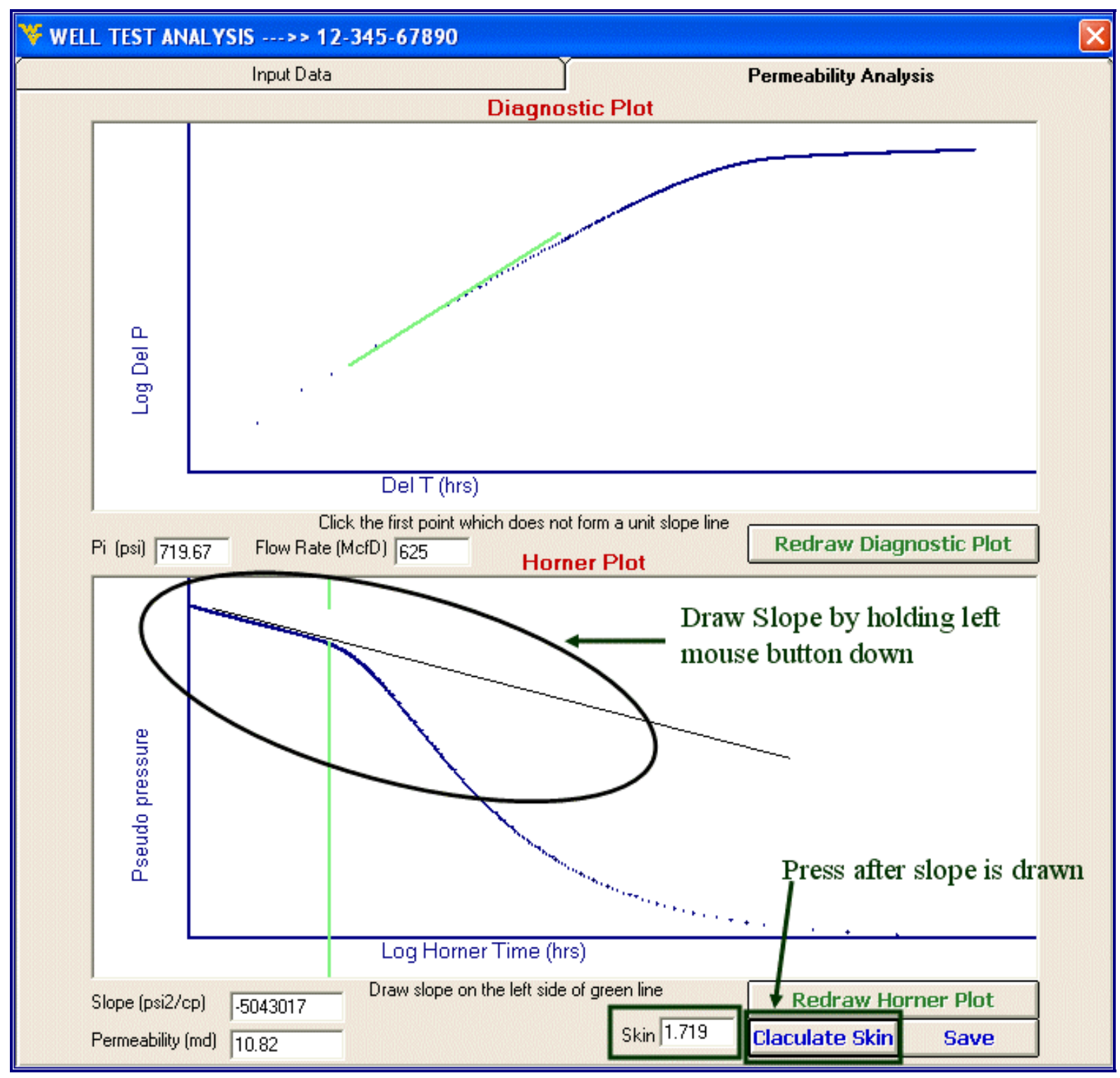

After the slope is drawn the user can select 'Calculate Skin' button to find the skin of the well. The respective graphs can be redrawn any time by selecting the 'Redraw Diagnostic Plot' or 'Redraw Horner Plot'.

The value of permeability and Skin can be saved in the database by selecting 'Save' button. 


\section{View Well Data}

One of the capabilities of this software is that user can query data according to location and stimulation year. In this module the user can search for the well data in database according to following criteria's
1- State
2- County
3- Stimulation year
4- Off-set wells

And then choose the parameters like (well number, location, completion date, AOF value, etc ....) to view. The picture of this module is below

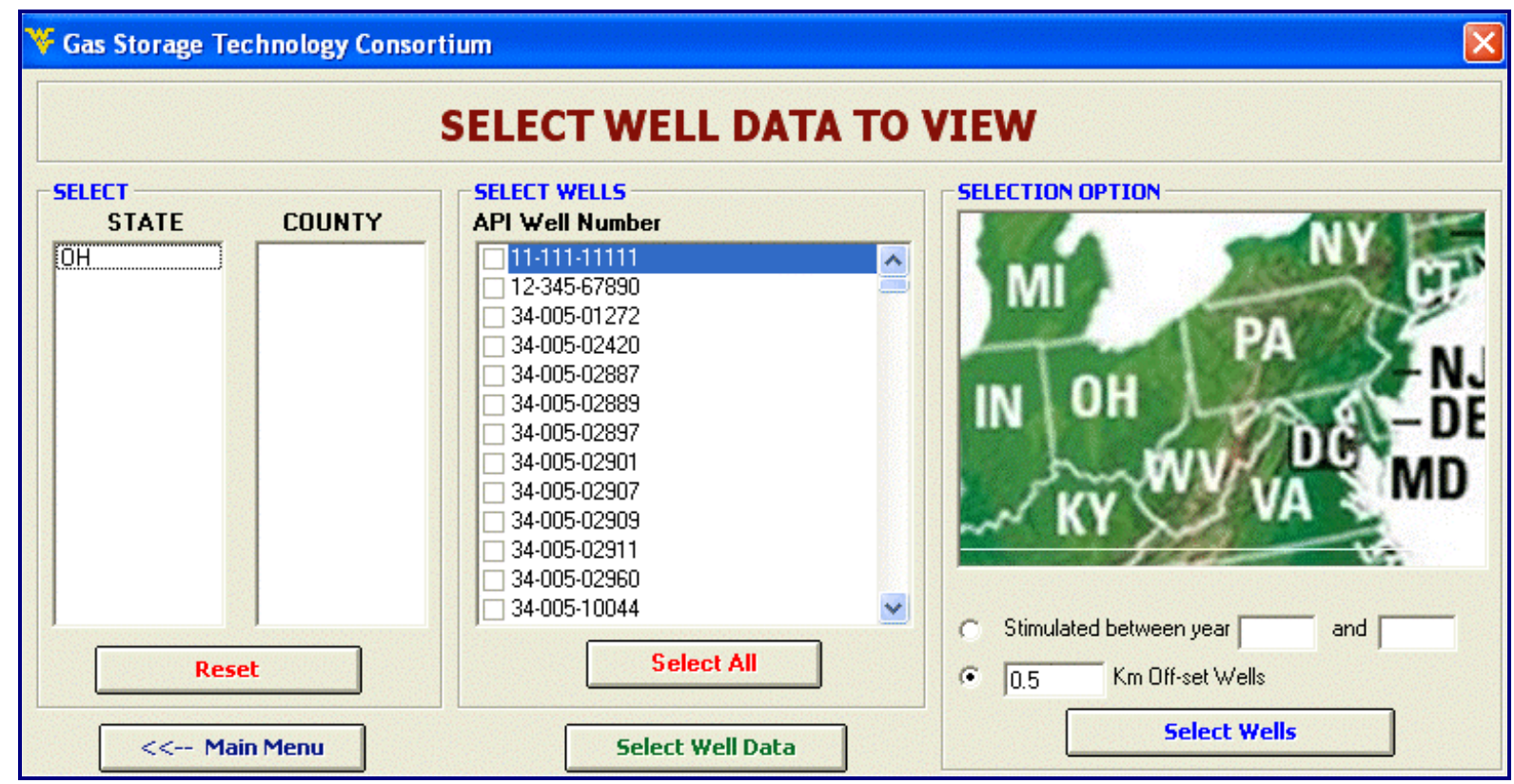




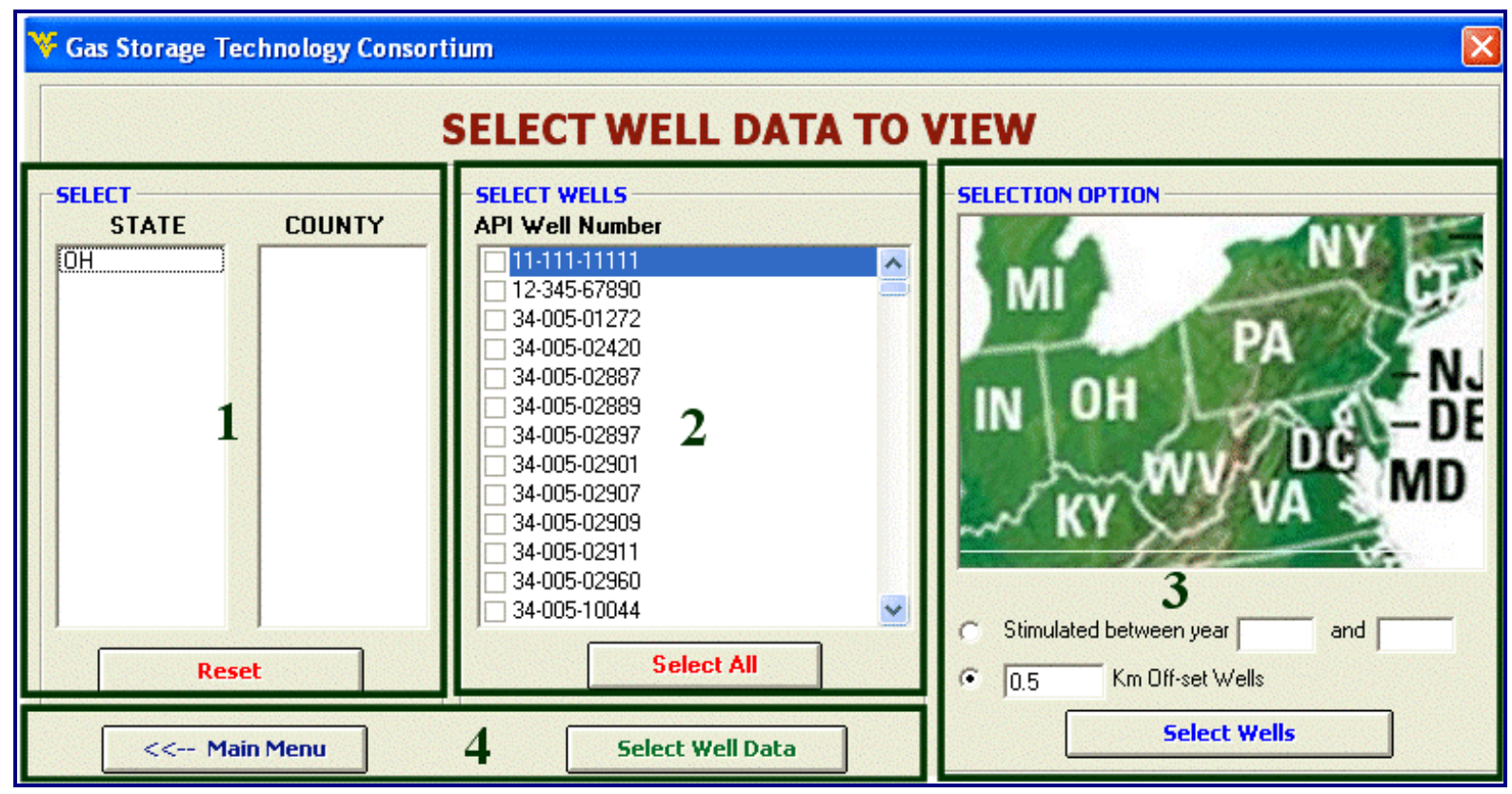

1. In this section there are two list boxes with labels which read 'STATE' and 'COUNTY'. You can select the location like state $\&$ then the county of well. When a state is selected from the list box on the left then all the counties of that state in the database will be shown in the list box in the right. The labels of both list boxes will change to show the selection made as shown in the picture below

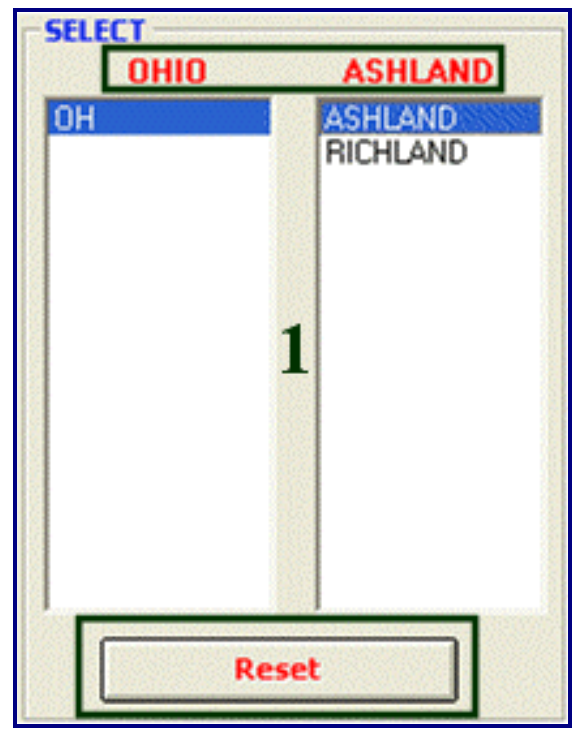

Note: If a wrong selection is made or you want to see all the wells after a selection has been made, press the 'Reset' button. 
2. This list box is named 'API Well Number' and as you change the selection in any of the two list boxes on the left the API well Numbers in this list box will change accordingly. There will be a small check box in front of all the well numbers. To select the wells you can select on the check boxes or if you want to select all of them then click 'Select All' command button in the lower side of the list box.

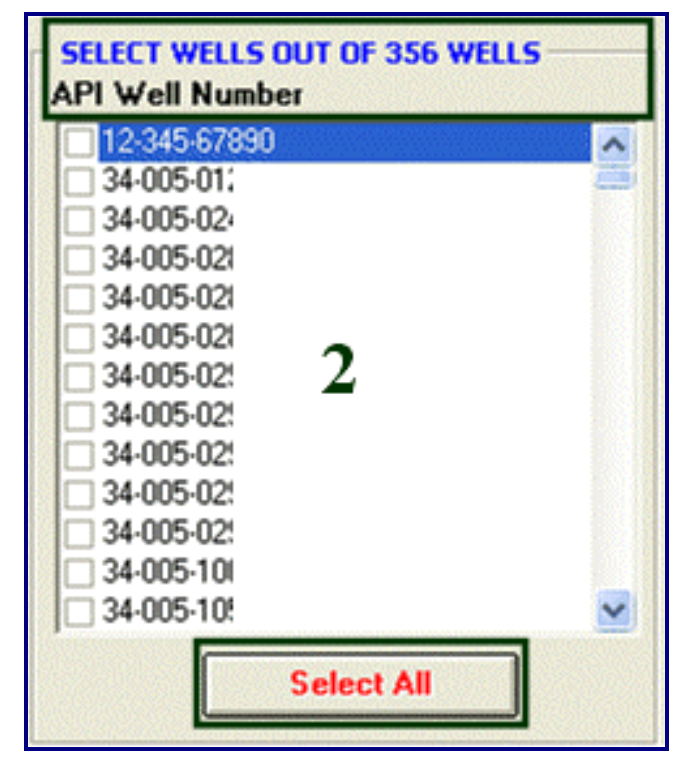

3. This frame is labeled 'Selection Option' and contains two search options in the form of option buttons. One is by stimulation year and other by off-set well. The picture on the top of this frame shows the north eastern part of United States. You can click anywhere on this picture as an alternative to selecting states from the list box in 1 . 


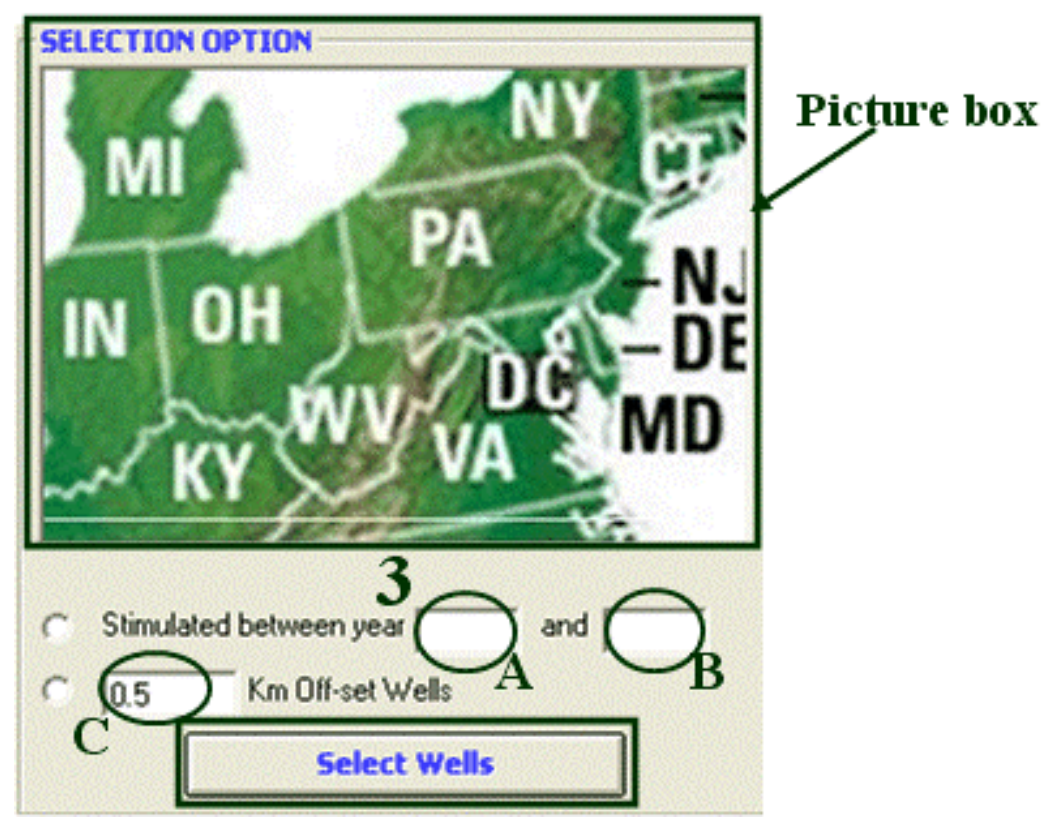

Note: 'Select Wells' command button should be pressed when either of the two search options has been selected to see the result.

If any value is entered in text box A or B then the first option i.e. by stimulation year will be selected. This will change the interface on the left and section 1 will become hidden as search by stimulation years doesn't take into account state or county of the well.

Following is the screen shot when selection by stimulation year between 1992 and 1996 is made.

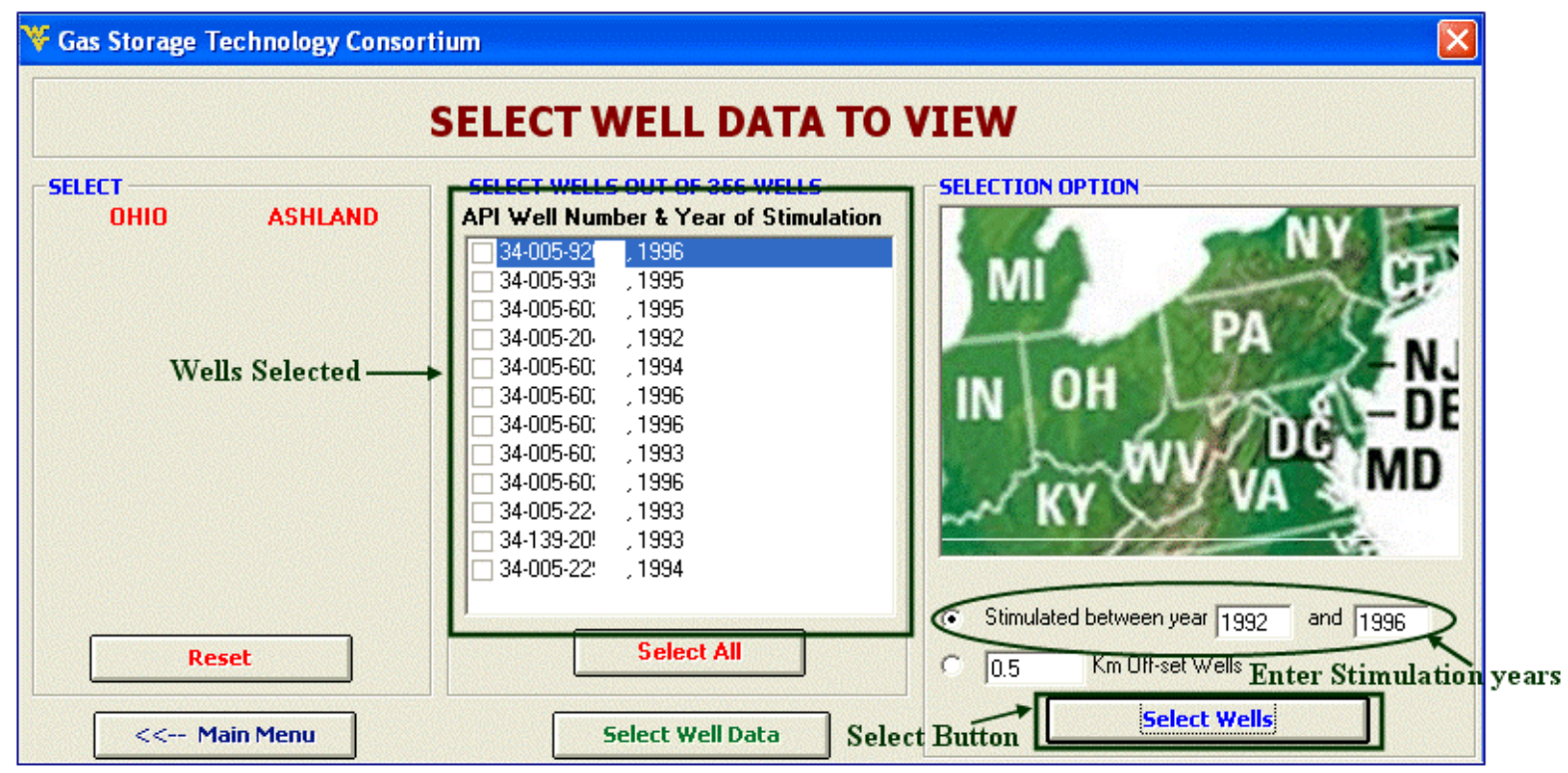


If you want to search by off-set wells then you can either enter value in text box marked as $\mathrm{C}$ or select the option button next to it. This option button is always selected and the value in text box $\mathrm{C}$ which is off-set distance is 0.5 when the interface loads. A well must be selected from the API Well Number list box for which we want to know the off-set wells.

Note: If a well is not selected then a message informing you of that will appear and the software will not execute your command

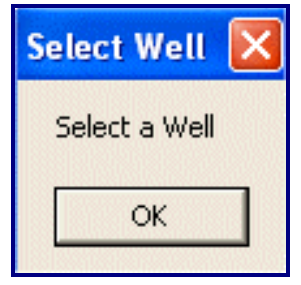

4. This button should be pressed when you have selected the wells in the API Number list box for which you want to see the data. If you press it another screen will appear with six list boxes showing parameters of following six tables

1- Well Bore Data

2- Completion Data

3- Perforation Data

4- Stimulation Data

5- Well-Test Data

6- Reservoir Data

Select the parameters by clicking the check box in front of it or if you want to select all parameters then press command button $\mathrm{D}$ in the bottom of each list box accordingly as explained in the following picture 
Table Names

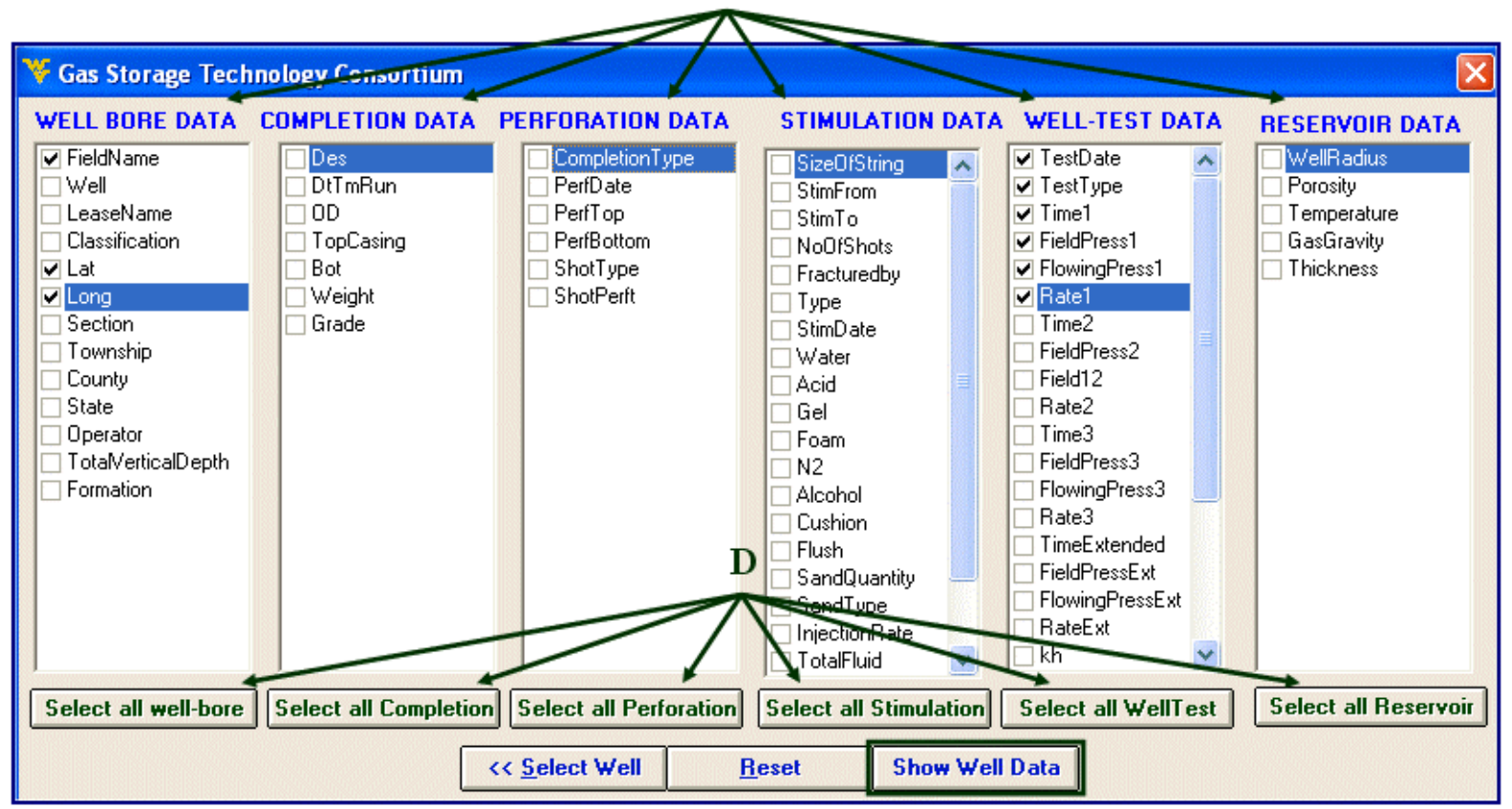

Press 'Show Well Data' command button when the parameters have been selected. This will bring you to the following form which displays the wells \& their parameters selected. The Screen shot on the next page shows the data selected above for API Well \# 12-345-6789.

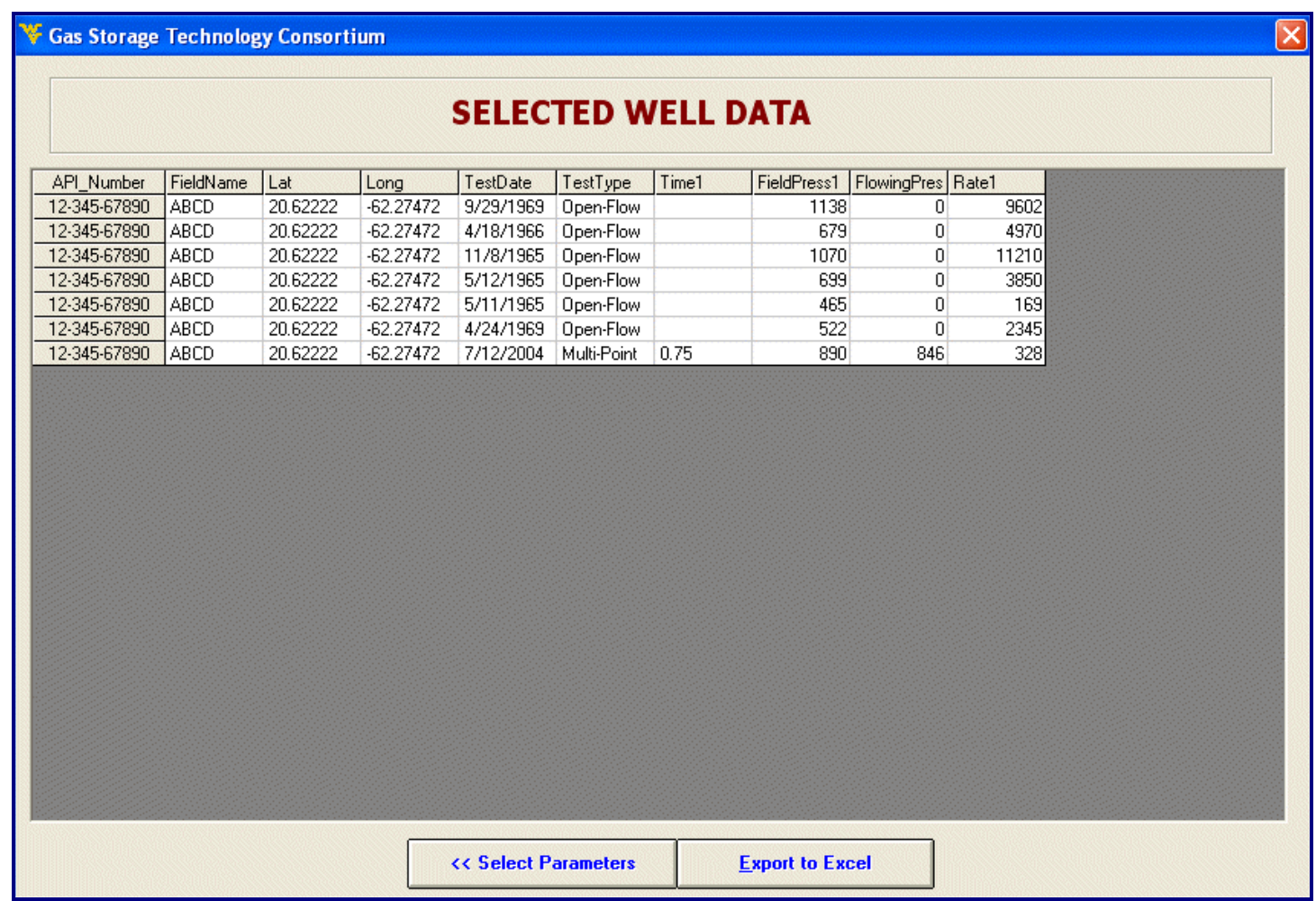


If user select 'Select Parameters' button, you will be taken back to the previous form of this module from where you selected the parameters. User can export the grid to MS Excel by selecting the 'Export to Excel' button. 


\section{Candidate Selection}

This module will appear on selecting the 'Candidate Selection' button from Main Menu.

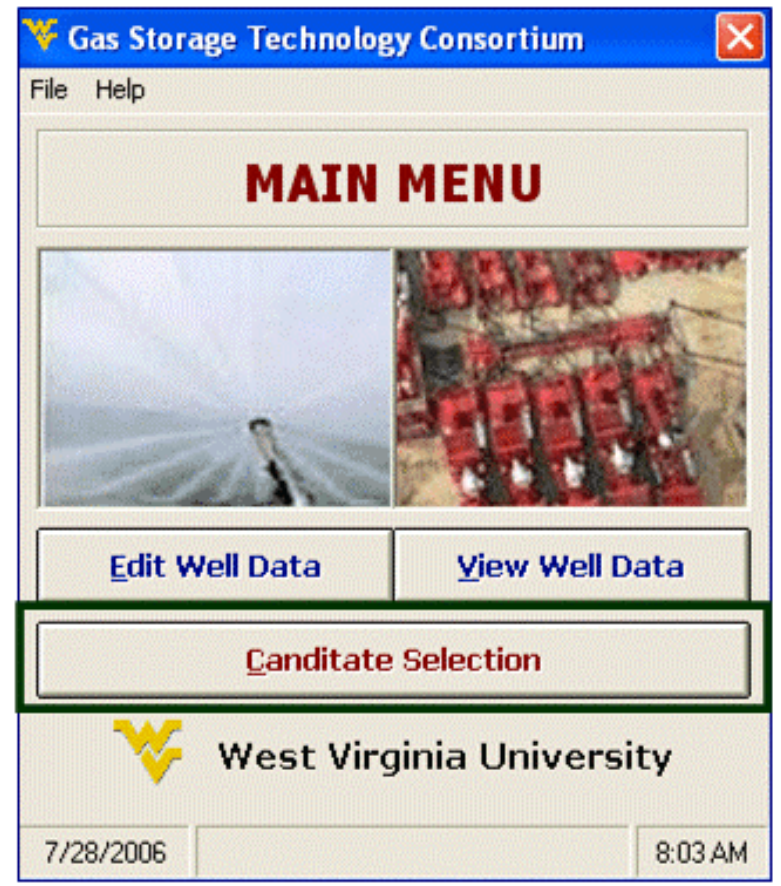

For intelligent candidate selection of wells it is very important that only valid data is given to the Neural Network (NN) for training. Valid data is one which will not degrade the performance of the $\mathrm{NN}$ and is useful in NN training. 


\begin{tabular}{|c|c|c|c|c|c|c|c|c|}
\hline \multicolumn{9}{|c|}{ W Optimization } \\
\hline \multicolumn{9}{|c|}{ Options } \\
\hline \multirow{2}{*}{ No. } & API_Number & FieldName & Well & LeaseName & Classificatior & Lat & Long & Section \\
\hline & $12-345-67890$ & $\mathrm{ABCD}$ & 1234 & $X Y Z$ & SPECIAL & -52222 & -.27472 & 10 \\
\hline \multirow{2}{*}{$\frac{2}{3}$} & 34-005-10517 & & 10517 & L. \& E. JENP & ACTIVE & 70333 & .285 & 9 \\
\hline & $34-005-10527$ & & 10527 & E. M. DAHL & ACTIVE & 7075 & .25833 & 11 \\
\hline \multirow{2}{*}{5} & 34-005-10549 & & 10549 & ZADA GUTP & I ACTIVE & 58472 & .31611 & 17 \\
\hline & 34-005-10552 & & 10552 & W. C. SCH $\Delta$ & $\triangle$ ACTIVE & 71222 & .22444 & 1 \\
\hline 5 & 34-005-10575 & & 10575 & ZELLABITT & T ACTIVE & 70972 & .2525 & 11 \\
\hline \multirow{2}{*}{8} & $34-005-10657$ & & 10657 & JOHN THOH & I ACTIVE & 34472 & .30611 & 32 \\
\hline & $34-005-10676$ & & 10676 & BERNARD I & I ACTIVE & 59833 & .29806 & 9 \\
\hline 9 & 34-005-10795 & & 10795 & ROGER F. & ACTIVE & 74889 & .27472 & 27 \\
\hline \multirow{2}{*}{$\frac{10}{11}$} & 34-005-10898 & & 10898 & FOREST E. & ACTIVE & 72778 & .30945 & 32 \\
\hline & $34-005-11029$ & & 11029 & OHIO FUEL & ACTIVE & 72778 & .32777 & 31 \\
\hline 12 & 34-005-20202 & & 7359 & E. HUNGEF & $=$ ACTIVE & 57694 & .33667 & 19 \\
\hline 13 & $34-005-20370$ & & 8549 & H. D. KEYSI & I ACTIVE & 36917 & .3375 & 19 \\
\hline \multirow{2}{*}{$\frac{14}{15}$} & $34-005-20373$ & & 8538 & ESTHER HI & I ACTIVE & 57861 & .33639 & 19 \\
\hline & $34-005-20388$ & & 8817 & C. C. LEIBO & ACTIVE & 71806 & .31194 & 5 \\
\hline If. & 24-nก5-2n517 & 1.... & 8947 & $M$ HINFS \# & ATTIMF & $\ldots 77582$ & 32389 & F \\
\hline \multicolumn{3}{|c|}{ Type of Analysis } & \multicolumn{6}{|c|}{ Optimization Method } \\
\hline \multirow{2}{*}{\multicolumn{3}{|c|}{$\begin{array}{l}\text { O All Wells } \\
\text { O Single Well }\end{array}$}} & \multirow{2}{*}{\multicolumn{4}{|c|}{$\begin{array}{l}\text { GA based on Skin } 3 \\
\text { GA based on Cost And Skin }\end{array}$}} & \multicolumn{2}{|c|}{ Apply GA } \\
\hline & & & & & Cost And Skin & & $<<-M$ & in Menu \\
\hline \multicolumn{3}{|c|}{ Select W/ell } & \multicolumn{3}{|c|}{$\begin{array}{l}\text { Cost } \\
\text { Weightage } \% \text { Skin } \\
\text { Weiqhtaqe } \% \\
50\end{array}$} & & & \\
\hline
\end{tabular}

1. When this module is loaded each row in this section of the grid represents a valid stimulation as shown in figure above. Following is the criteria for valid stimulation selection:

Valid Stimulation -

Valid perforation -

Valid Completion -

Valid Well-test -
It should have skin value before \& after stimulation

perforation just before the stimulation

the smallest size completion run before stimulation

well-test having skin value just before or after the well-test 
2. Two types of analysis can be done on the wells. One option is to apply Genetic optimization on wells one at a time and other is to apply it on all wells. If the 'All Wells' option is selected then the 'Select Well' button will be enabled and the user can select the well the same way as shown in the previous section of the user Manual for - Find a well.

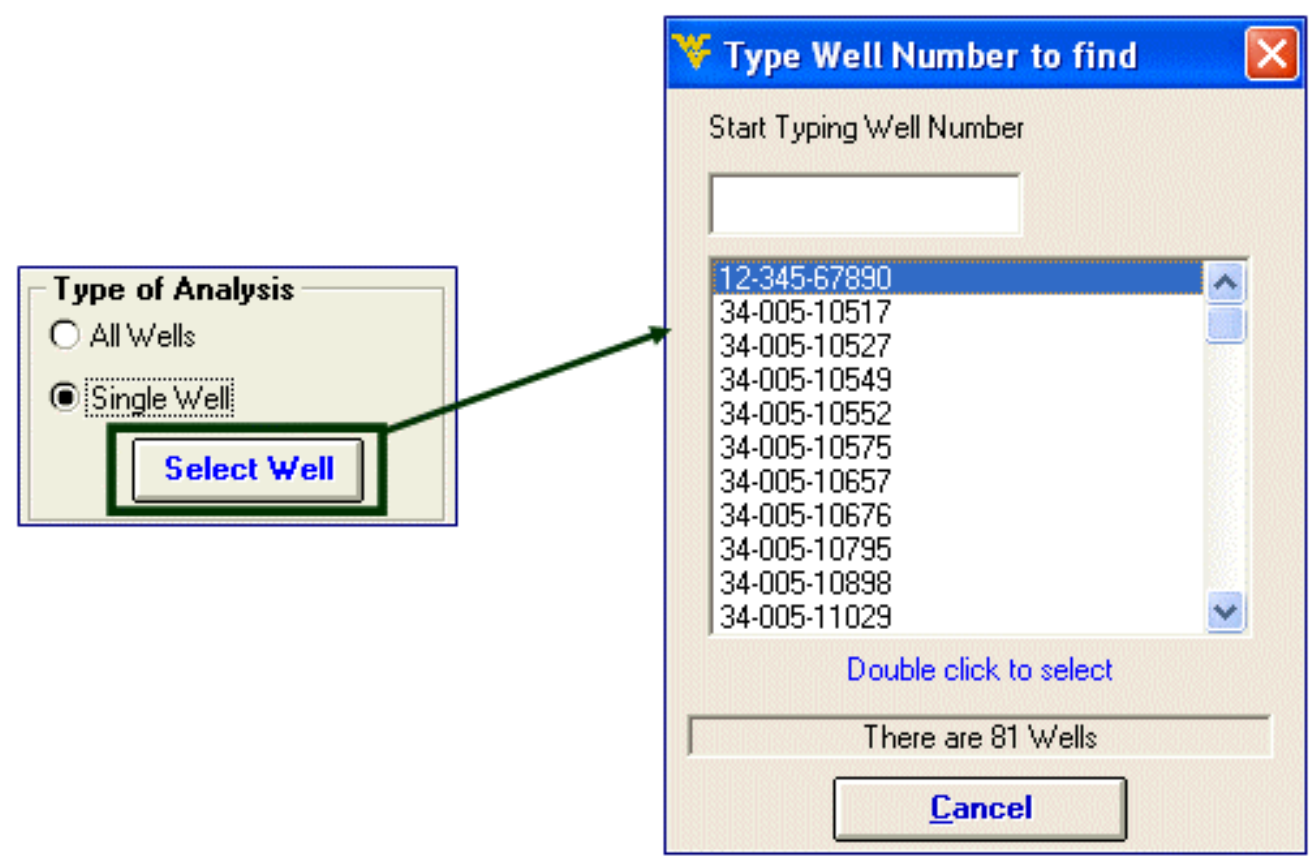

3. This section of module relates to the Optimization methods available. User can optimize the stimulations according to only change in skin criteria or may choose to select the 'GA based on cost and skin' option where he/she can give different weight ages to cost and skin.

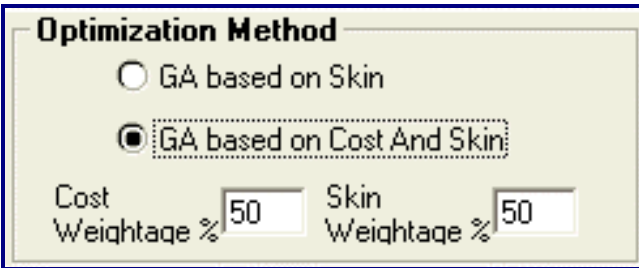




\section{Options Menu}

This software can cater for many varied situations. This all options can be selected from the 'options' menu bar on the top of the form. It contains following items:

- Select controllable parameters

- Material cost

- Import NNet

- NNet Input values

- GA characteristic

- Export the Grid to Excel

- Select Well-Test Type

Following is a screen shot of the items in the Options menu tool bar.

\begin{tabular}{|l|}
\hline W Optimization \\
Options \\
\hline Select controlable parameters \\
Material Cost
\end{tabular}

Material cost can be changed by the user as the prices fluctuate. These prices can be saved in the database by selecting 'Save' button and Default values can be retrieved by selecting 'Default' button. The screen shot of material cost is shown below and price is just an estimate and can be changed by user. 


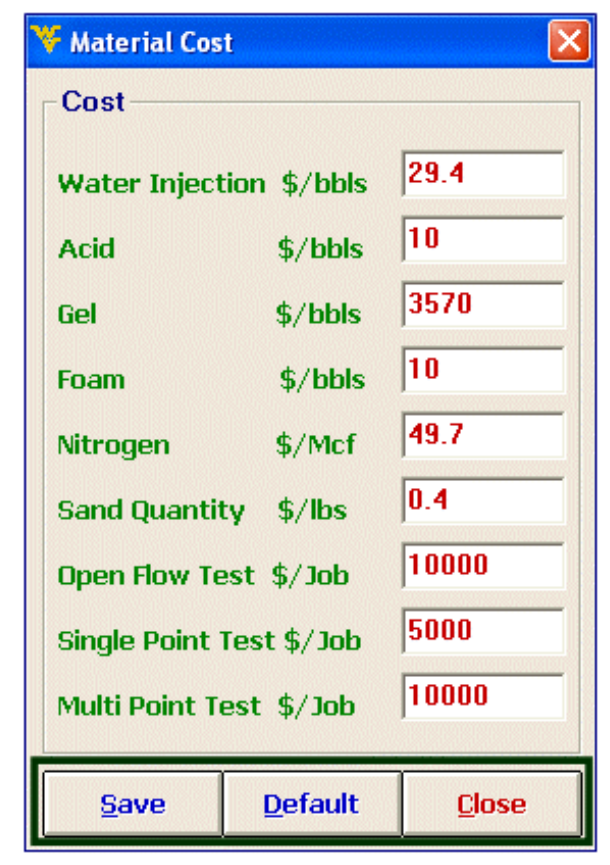

\begin{tabular}{|c|c|c|c|c|c|c|c|c|c|c|c|c|c|}
\hline \multicolumn{13}{|c|}{ F Net Input } & \multirow{2}{*}{$x$} \\
\hline No. & API_Number & Lat & Long & Water & Acid & Gel & Foam & N2 & SumFluids & SandQuantil & Prior-kh & After-TestTy & \\
\hline 1 & $12-345-1$ & 222 & 172 & 255 & 1.2 & 131 & 0 & 50 & & 12100 & 123 & Open-Flow & \\
\hline 2 & 34-005: & 333 & 5 & 255 & 1.2 & 131 & 0 & 50 & & 12100 & 123 & Open-Flow & \\
\hline 3 & 34-005: & 75 & 333 & 255 & 2.4 & 136 & 1.6 & 80 & & 13600 & 395 & Open-Flow & \\
\hline 4 & 34-005: & 472 & 311 & 0 & 1.2 & 75 & 0 & 0 & & 6000 & 378 & Open-Flow & \\
\hline 5 & 34-005: & 222 & 144 & 265 & 2.4 & 140 & 0.2 & 85 & & 13650 & 100 & Open-Flow & \\
\hline 6 & 34-005: & 372 & 25 & 255 & 1.2 & 130 & 0 & 45 & & 9500 & 523.3 & Open-Flow & \\
\hline 7 & 34-005: & 472 & 311 & 0 & 4.8 & 375 & 0.1 & 125 & & 13100 & 362 & Open-Flow & \\
\hline 8 & 34-005: & 333 & 306 & 234 & 2.4 & 129 & 0.2 & 60 & & 11000 & 210 & Open-Flow & \\
\hline 9 & 34-005: & 389 & 172 & 0 & 4.8 & 155 & 0.3 & 83.7 & & 13900 & 557 & Open-Flow & \\
\hline 10 & 34-005: & 778 & 345 & 0 & 2.4 & 435 & 0.1 & 75 & & 24400 & 1374 & Open-Flow & \\
\hline 11 & 34-005: & 778 & 777 & 0 & 6 & 435 & 0.1 & 75 & & 20000 & 288 & Open-Flow & \\
\hline 12 & 34-005: & 394 & 367 & 0 & 0 & 0 & 0 & 0 & & 2000 & 793 & Open-Flow & \\
\hline 13 & 34-005: & 317 & 75 & 0 & 1.2 & 24 & 0 & 0 & & 2000 & 134 & Open-Flow & \\
\hline 14 & 34-005: & 361 & 339 & 0 & 0 & 0 & 0 & 0 & & 2000 & 120 & Open-Flow & \\
\hline 15 & 34-005: & 306 & 194 & 0 & 0 & 0 & 0 & 0 & & 1700 & 141 & Open-Flow & \\
\hline 16 & 34-005: & 583 & 389 & 0 & 0 & 150 & 0 & 0 & & 2000 & 1210 & Open-Flow & $\checkmark$ \\
\hline & & & & & & & se & & & & & & \\
\hline
\end{tabular}

If the user wants to look at the Neural Network inputs being used then 'NNet Input' option will take the user to a new form as shown above where all the inputs are shown. Keep in mind that this grid can only be seen once and that only after the Genetic optimization has been applied.

If some material is not available for stimulation then still the user can optimize the stimulation by de-selecting that material from the 'Select controllable parameters' option. The materials not enabled are the ones that are not being used by the Neural Network in use. 


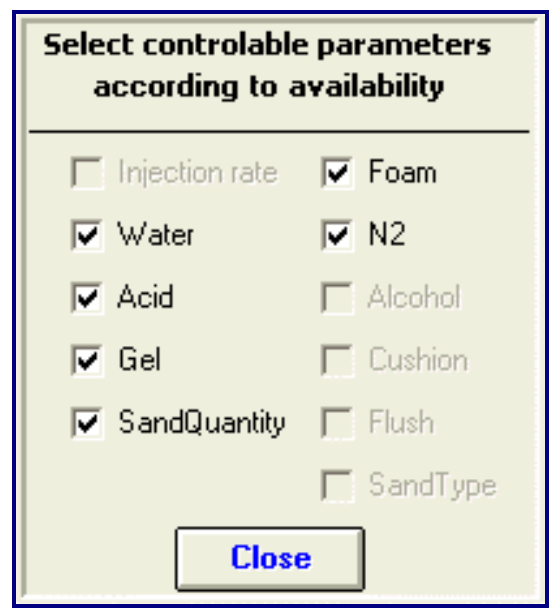

A new Neural Network can be used if the data is changed or appended by importing its 'ida' file. When a new Neural Network is imported it might change the optimum GA parameters. The user can change them from 'GA characteristic' option. The default values are always loaded at startup as shown in figure below but can be changed by user.

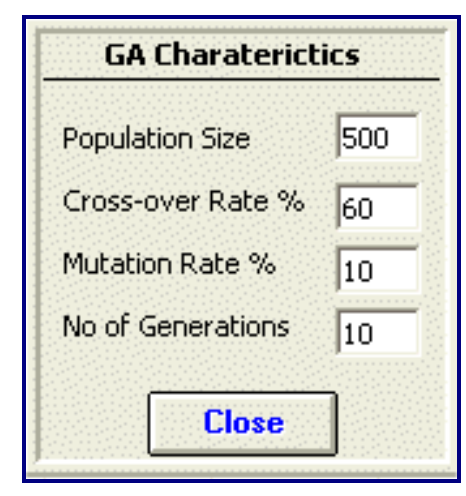

As one of the input for Neural Net also includes 'Well-Test Type' after the stimulation so option has been given to the user to select the well-test they want to use for optimization.

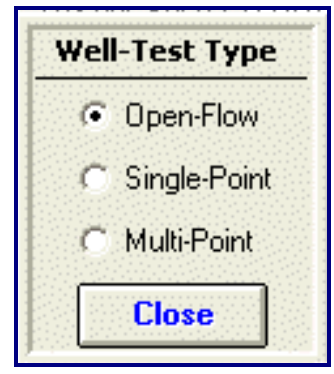


When all the parameters for GA have been selected and user selects the 'Apply GA' Apply GA button then the screen below will appear showing the values of optimized stimulation slurry and change in skin due to this stimulation. The picture below shows the GA optimization done on well \# 12-345-67890.

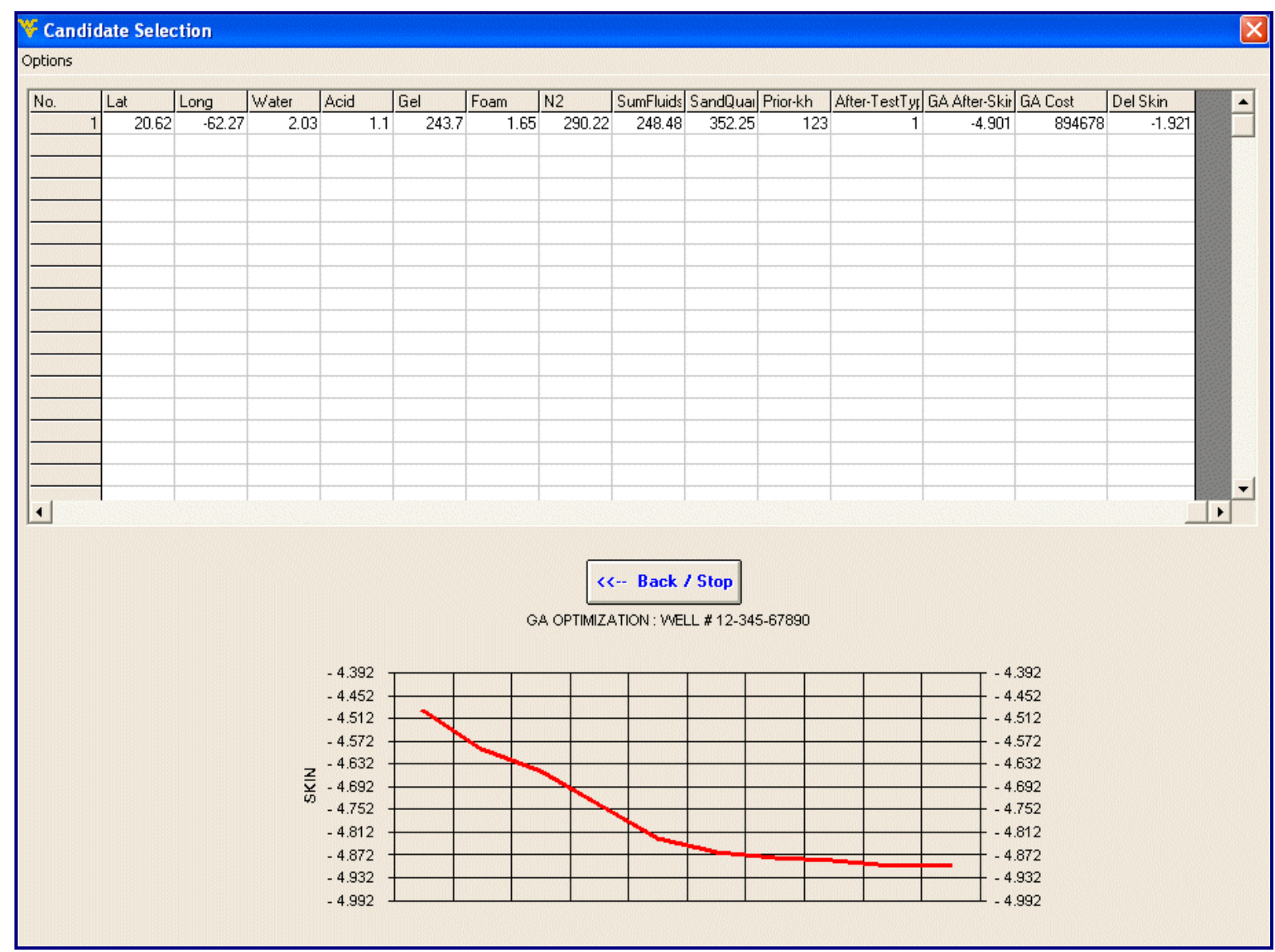


If the optimization is applied to all the wells then we can rank the wells according to the change in skin by selecting 'Rank the wells' from Options menu bar on the top left corner of the form as shown in snapshot below.

\begin{tabular}{|c|c|c|c|c|c|c|c|c|c|c|c|c|c|c|c|c|}
\hline \multicolumn{16}{|c|}{ W Candidate Selection } & $x$ \\
\hline \multicolumn{17}{|c|}{ Options } \\
\hline \multicolumn{2}{|c|}{ Rank the Wells } & & & & & & & & & & & & & & & \\
\hline \multirow{2}{*}{\multicolumn{2}{|c|}{ Export result to Excel }} & 8 & Water & Acid & Gel & Foam & N2 & SumFluids & SandQual & Prior-kh & After-Test Ty & GA After-Skir & GA Cost & Del Skin & & \\
\hline & & & 6.75 & 11.34 & 121.85 & 1.63 & 252.77 & 141.57 & 469.67 & 123 & 1 & -5.024 & 458092 & $\quad-2.044$ & & \\
\hline 군 & .71 & $=26$ & 0.68 & 10.52 & 161.08 & 1.7 & 162.04 & 173.97 & 5107.63 & 395 & 1 & -4.959 & 595277 & -1.1013 & & \\
\hline 3 & 68 & .32 & 3.38 & 6.17 & 153.75 & 1.66 & 272.94 & 164.96 & 6340.51 & 378 & 1 & -5.048 & 575179 & -1.3871 & & \\
\hline 4 & .71 & .22 & 4.05 & 11.21 & 103.03 & 0.03 & 46.09 & 118.32 & 23835.62 & 100 & 1 & -4.457 & 389857 & -1.7965 & & \\
\hline 5 & .71 & .25 & 10.8 & 5.71 & 78.45 & 1.7 & 205.96 & 96.66 & 3287.67 & 523.3 & 1 & -4.882 & 301995 & -1.2657 & & \\
\hline 6 & .64 & .31 & 0 & 9.67 & 124.47 & 1.7 & 315.43 & 135.84 & 880.63 & 362 & 1 & .5 .048 & 470491 & -0.9724 & & \\
\hline 7 & 0.7 & 2.3 & 12.15 & 6.46 & 234.81 & 1.63 & 137.55 & 255.06 & 117.42 & 210 & 1 & -5.04 & 855608 & -1.4872 & & \\
\hline 8 & .75 & .27 & 2.7 & 8.14 & 102.5 & 1.67 & 163.48 & 115.02 & 7866.93 & 557 & 1 & -4.797 & 387383 & -0.5144 & & \\
\hline 9 & .73 & .31 & 272.08 & 11.89 & 434.59 & 0.03 & 356.48 & 718.6 & 28649.71 & 1374 & 1 & .5 .782 & 1598780 & -0.859 & & \\
\hline 10 & .73 & .33 & 2.7 & 11.35 & 132.83 & 1.69 & 227.57 & 148.58 & 1115.46 & 288 & 1 & -5.042 & 496186 & -1.0263 & & \\
\hline 11 & .68 & .34 & 10.8 & 2.45 & 189.32 & 1.7 & 247.01 & 204.27 & 2407.05 & 793 & 1 & -5.05 & 699456 & -0.7801 & & \\
\hline 12 & .67 & .34 & 5.4 & 2.57 & 211.28 & 1.7 & 195.16 & 220.95 & 1819.96 & 134 & 1 & -5.049 & 774901 & -1.5019 & & \\
\hline 13 & .68 & .34 & 11.48 & 3.78 & 218.08 & 1.7 & 41.05 & 235.04 & 5107.63 & 120 & 1 & -5.049 & 793018 & -1.654 & & \\
\hline 14 & .72 & .31 & 8.1 & 7.01 & 211.28 & 1.69 & 109.46 & 228.07 & 2172.21 & 141 & 1 & .5 .039 & 770906 & -1.0117 & & \\
\hline 15 & .73 & .32 & 103.97 & 11.88 & 446.62 & 0.4 & 364.4 & 562.87 & 29647.75 & 1210 & 1 & -5.699 & 1637575 & -2.6374 & & \\
\hline 16 & .72 & .33 & 8.78 & 9.56 & 144.34 & 1.64 & 177.88 & 164.32 & 5988.26 & 233 & 1 & -5.043 & 536900 & -1.4835 & & \\
\hline 17 & .73 & 31 & 2.7 & 7.75 & 182.52 & 1.67 & 223.25 & 194.63 & 1467.71 & 401 & 1 & -5.026 & 673442 & -1.1274 & & \\
\hline 18 & $\ldots$ & 31 & $18 \cap 2 \mathrm{~F}$ & 1133 & $\triangle 4871$ & ก52 & $3 \mathrm{~F}>\mathrm{9F}$ & f. $4 \cap 83$ & $29 \cap F \cap \cap 57$ & 1770 & 1 & .5877 & 1FAF 975 & $.18 \cap 87$ & & 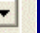 \\
\hline 1 & & & & & & & & & & & & & & & - & \\
\hline
\end{tabular}

The wells are ranked according to change in skin as shown in the figure below. These ranked wells and the optimized stimulation data now can be exported to excel by selecting 'Export to Excel' in the Option menu of Candidate Selection module.

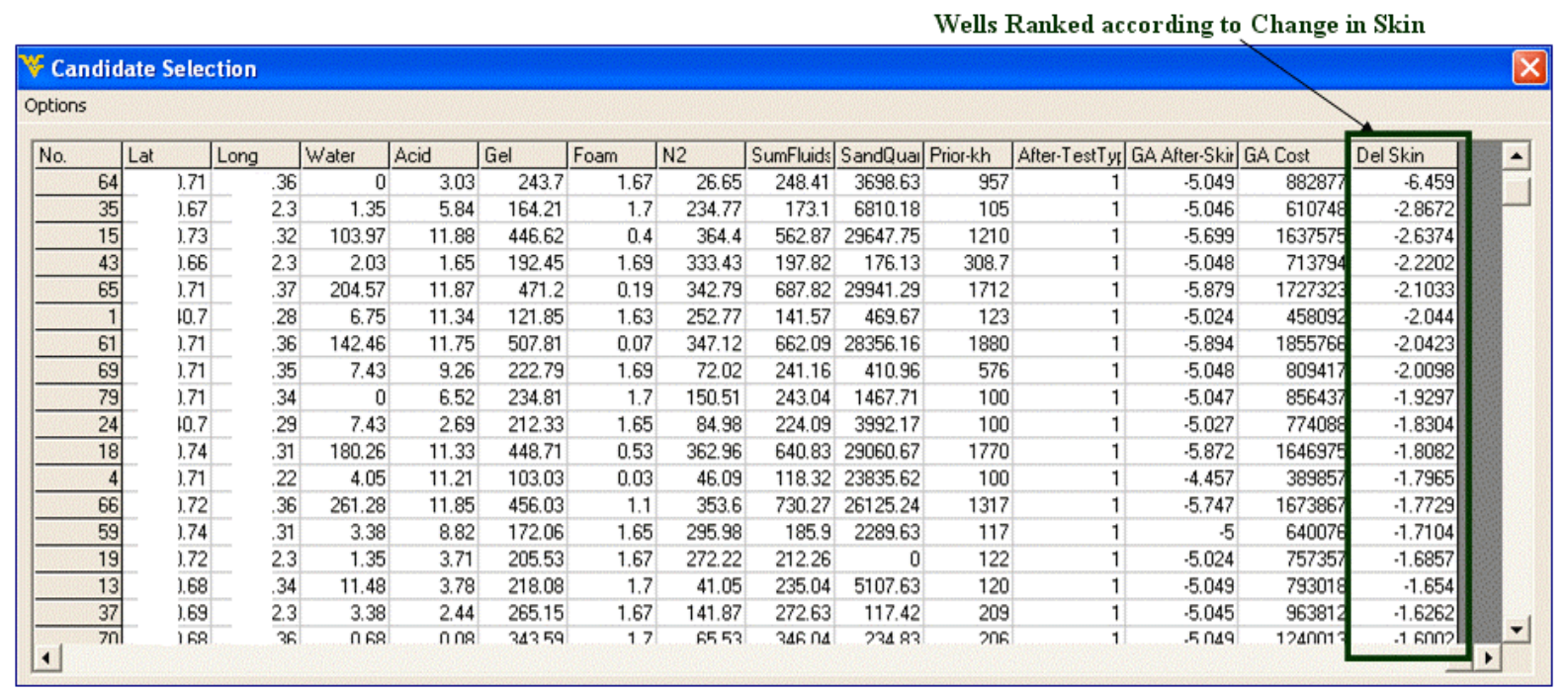

